Portland State University

PDXScholar

\title{
Teaching and Learning for Intercultural Sensitivity: A Cross-Cultural Examination of American Domestic Students and Japanese Exchange Students
}

Yoko Hwang Sakurauchi

Portland State University

Follow this and additional works at: https://pdxscholar.library.pdx.edu/open_access_etds

Part of the Educational Methods Commons, International and Intercultural Communication Commons, and the Other Teacher Education and Professional Development Commons Let us know how access to this document benefits you.

\section{Recommended Citation}

Sakurauchi, Yoko Hwang, "Teaching and Learning for Intercultural Sensitivity: A Cross-Cultural Examination of American Domestic Students and Japanese Exchange Students" (2014). Dissertations and Theses. Paper 1643.

https://doi.org/10.15760/etd.1642

This Dissertation is brought to you for free and open access. It has been accepted for inclusion in Dissertations and Theses by an authorized administrator of PDXScholar. Please contact us if we can make this document more accessible: pdxscholar@pdx.edu. 
Teaching and Learning for Intercultural Sensitivity: A Cross-Cultural Examination of American Domestic Students and Japanese Exchange Students

by

Yoko Hwang Sakurauchi

A dissertation submitted in partial fulfillment of the requirements for the degree of

Doctor of Education

in

Educational Leadership: Postsecondary Education

\author{
Dissertation Committee: \\ Becky Boesch, Chair \\ Samuel D. Henry \\ Andrew Job \\ Martha Hickey
}

Portland State University

2014 
(C) 2013 Yoko Hwang Sakurauchi 


\begin{abstract}
Global student mobility has become a dynamic force in American higher education. Integrating international students into diverse campus environments provides domestic as well as foreign students with enriched learning opportunities. However, a diverse campus climate itself will not make college students interculturally competent. Intentional curricular design is critical for overcoming issues such as resistance and reinforcement of stereotypes, but the research literature is extremely limited on effective pedagogical strategies for cultivating college students' intercultural sensitivity.

This paper explicates a research study to investigate college students' development of intercultural sensitivity through an intentional course design utilizing Kolb's (1984) learning styles cycle and Hammer's (2009) Intercultural Development Continuum (IDC). Quantitative and qualitative data were collected to explore domestic and international students' intercultural learning experiences and to potentially identify pedagogical approaches that facilitate students' intercultural competence. These findings show that the four pedagogical strategies associated with Kolb's learning cycle were effective and crucial when designing an intercultural course in order to develop college students' intercultural competence. This study also revealed a gap in intercultural development through the intentional intercultural course between American students and Japanese exchange students due to their vastly different intercultural experiences.
\end{abstract}


Dedication

This work is dedicated to my husband Jeff and to my sons Kenji and Tyler. 


\section{Acknowledgements}

I would like to thank all the people who believed in me. In particular, I could not have been able to do this without the love, encouragement and support of my family. I want to offer deepest gratitude to my husband Jeff for supporting me in many ways. He always accommodated me so that I could do my work, and never complained about more burdens of house chores and childcare. There were countless times when he took our sons somewhere to play while I was writing in weekends. I also want to thank my fouryear-old twin sons Kenji and Tyler for being good and healthy. I did not have to worry about them and was able to concentrate on this project when I was working on it. I would like to thank my parents in Japan. They have always believed in me and been proud of me. Their encouragement has kept me going toward the goal. I believe that my father, a retired high school principal, has been a role model for me to be a great educator. I also want to thank my brothers in Japan for supporting me, even though we do not see each other very often.

I want to thank Becky Boesch for enthusiastically agreeing to become my advisor in the middle of writing my proposal. Her encouragement, feedback, and support were invaluable. She always created a relaxing atmosphere when we were talking about intense research topics so that I was able to breathe and think straight. I really enjoyed discussing and exploring my research topics with her. I am also proud of myself being her very first doctoral advisee who finished her work. I also want to thank Christine Cress, who was my original advisor, for guiding me to this professional and academic 
path and teaching me to believe in my ability to pursue my studies. I would like to thank my other committee members, Samuel Henry, Andrew Job, and Martha Hickey, for listening, helping me talk through things, believing in my abilities, and supporting me constantly.

I would like to thank the participants in my study for their willingness to commit their time and sharing their personal stories openly and honestly. Thank you for entrusting me to convey your experiences, thoughts, and beliefs. I also thank my teaching assistant Ruri Yoshii for playing a role in recruiting the research participants in the class. She is also a good friend of mine, who was kind enough to take care of my sons while I was meeting with my advisor. I thank the bicultural speaker Chie Furukawa for willingly coming to my class and sharing her stories.

I would like to acknowledge Martha Hickey at the Office of International Studies and Sally Mudiamu at the PSU-Waseda Transnational Program for offering the course and allowing me to collect the research data in the course. Moreover, I thank these two offices greatly for funding for the entire cost of the assessments that I conducted in my research. I could not have done my research without their support.

I remain grateful to Michell Hammer for introducing The Intercultural Development Inventory (IDI) to me and teaching me the theoretical frameworks and how to administrate it. I also thank Debra Freathy for arranging for me to take the IDI administrator qualifying seminar as an intern with only a short notice and to implement the inventories in a timely manner. 
I would like to thank Suwako Watanabe for generously offering to arrange the tea ceremony at Kashintei the Tea House at Portland Japanese Garden for the field trip in my course. I thank her for taking her time to put on the beautiful kimono, come and explain the philosophy and all the procedures of tea ceremony to my class. This learning experience became a crucial component of my study. I want to thank Patricia Wetzel for originally giving me an opportunity to create and teach this course six years ago when my research interest started to grow. I thank her for her constant support since then.

I am indebted to numerous other professors and community members at Portland State University, who helped me tremendously. I thank Kim Brown and Chris Cartwright for giving me great ideas about my research and helping me break through the researcher's wall. I would like to thank Cassie McVeety, Pat Squire, Mary Coniglio, and the other members from PSU Alumni Association for giving me a graduate assistantship to support me to pursue my doctoral program and for their constant encouragement. I thank my colleagues from the Graduate School of Education: Kathie Godfrey for sharing her research ideas, Paulina Zapeda for offering childcare and encouraging me, and cohort 2005 members: Zafreen Jaffery and Aylin Bunk for being long-term writing partners, Amy Juve for coming all the way to my house to encourage me with a lot of tips when I was having a hard time keeping up my work, and Deb Nelli for being my inspiration. I thank Akiko Ota, who is my long-term friend, former colleague, former roommate, and has just earned her Ed.D. for admiring and encouraging me. I thank Personal Professor Daveena Tauber for assisting me to write the dissertation proposal and a professional editor Kristin Carlsen for proofreading my entire dissertation. 
I thank my friends Satomi Hayashi, Naoko Mccullah, Tomoko Cervantes, and Akiko Weierman for kindly and generously providing me with childcare when I had to work on this project. I owe thanks to my long-term friend Yoshiko Tamura, who has known me since middle school in Matsue, Japan, and recently moved to Portland for career change, for believing in me and encouraging me tremendously. I want to thank my long-term friends Lisa McGarvey and Susan Higashi for cheering for me since I started the doctoral program. 
Table of Contents

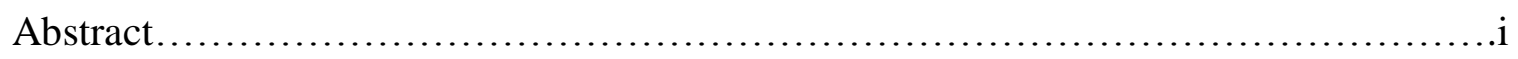

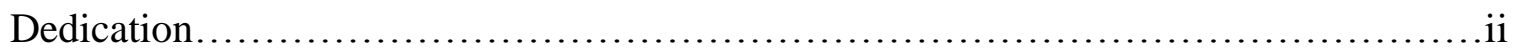

Acknowledgements.........................................................ii

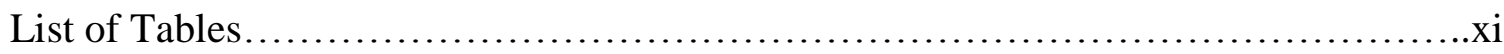

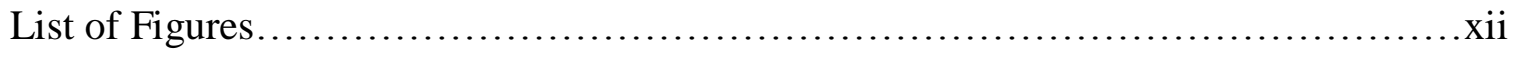

Chapter 1: INTRODUCTION.............................................

Diversity Initiatives and Internationalization in American Higher Education......1

Anatomy of Internationalization.................................. 3

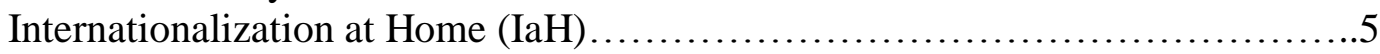

Teaching and Learning in IaH....................................6

Distinction Between Internationalization and Intercultural Education......7

Previous Studies and Research Gaps......................................8

Chapter 2: LITERATURE REVIEW ............................................ 11

The Four Pedagogical Strategies for Intercultural Learning ....................11

Kolb's Experiential Learning Theory .............................. 12

Previous Research With Kolb's Learning Cycle........................15

The Four Pedagogical Strategies for Intercultural Courses...............16

Conceptual Framework....................................................19

Allport's Intergroup Contact Theory...............................19

Smith's Core of Scholarship........................................21

Intercultural course content: a two-layer approach..............22

Process-oriented and student-centered teaching................25

Scholarly inquiry for intercultural teaching and learning..........28

Intercultural Competence as an Outcome of Intercultural Learning ..............29

Pyramid and Process Models of Intercultural Competence................30

Developmental Model of Intercultural Sensitivity.....................35

Social constructivism....................................36

Transformation from ethnocentrism to ethnorelativism...........38

The stages of the Developmental Model of Intercultural

Sensitivity.............................................41

Cultural Identity Development / Cultural Self-Awareness...............48

Assessment Methods of Intercultural Competence...........................52

Intercultural Development Inventory...........................53

Administrating the IDI...................................54

Intercultural development continuum and cultural disengagement

in the IDI............................................... 56 


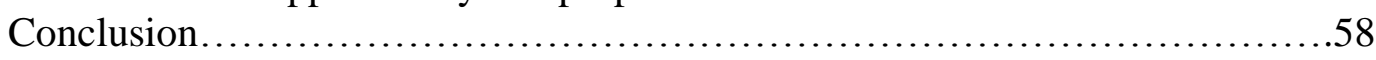

Applicability and purposes of the IDI........................57

Chapter 3: METHODOLOGY ................................................61

Research Purpose and Research Questions...............................61

Mixed Research Methods...............................................62

Positivism: Rationale for the Quantitative Method.....................63

Reliability and validity of the IDI..........................64

Constructivism: Rationale for the Qualitative Method..................65

Rationale for the Use of Mixed Methods.............................67

Research Design..................................................... 70

Research Site.................................................. 70

Positionality................................................... 71

Population of Research Participants................................. 72

Participant Recruitment.........................................73

Kolb's Four Pedagogical Strategies in Action...........................74

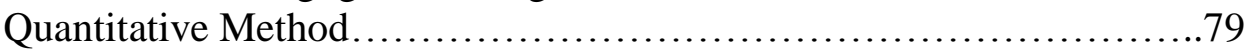

Data collection............................................ 79

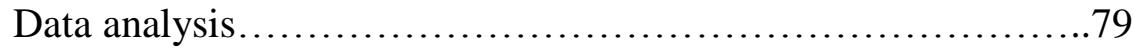

Qualitative Methods..............................................81

Sampling strategies.....................................81

The original plan of sampling .......................83

The actual sampling.................................84

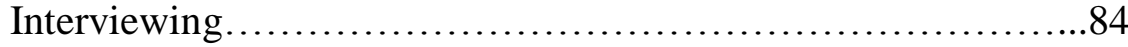

Data collection.......................................84

Interviewer and respondent relationship................86

Data analysis.....................................87

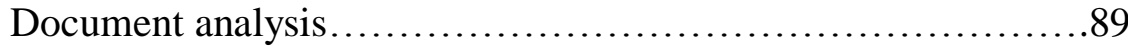

Data collection......................................89

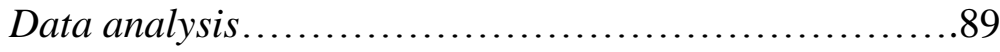

Validity and Reliability................................................ 91

Profiles of Research Participants.........................................93

Mark............................................................ 93

Cary.............................................................

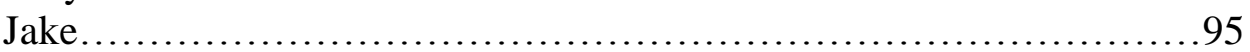

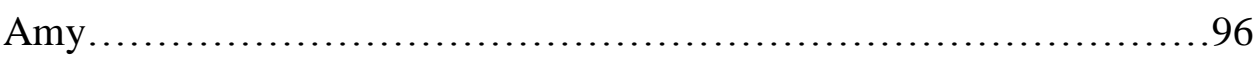

Nao...........................................................97

Masako............................................................98

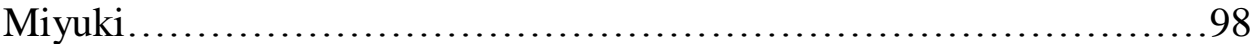

Aki........................................................ 99

Conclusion......................................................... 100

Chapter 4: FINDINGS ..................................................... 102

The Intercultural Development Inventory (IDI) Scores..................... 102 
The Findings From the Qualitative Data...................................104

The Most Effective Learning Dimensions: Japanese vs. Americans......106

Highlights and Achievements in the Course........................107

Understanding cultural basic assumptions.....................108

Developing cultural self-awareness........................110

Understanding through intergroup interaction..................111

Developing intercultural sensitivity........................113

Kolb's Learning Dimensions and Intercultural Sensitivity

Development.

Theory-based materials as Abstract Conceptualization

(AC) ...............................................

Cultural self-awareness...............................117

Cultural appreciation..................................119

Cultural inspiration..................................119

Tea ceremony as Concrete Experience (CE)..................120

Cultural self-awareness.............................121

Cultural appreciation................................124

Bicultural guest talk as Reflective Observation (RO)............129

Cultural appreciation................................130

Intergroup discussions as Active Experimentation (AE).........135

Cultural appreciation................................137

Cultural inspiration.................................146

Application to Real Life.......................................... 148

Cultural appreciation.....................................149

Cultural inspiration........................................152

Necessity of Intercultural Learning for This Globalized World..........153

Conclusion.

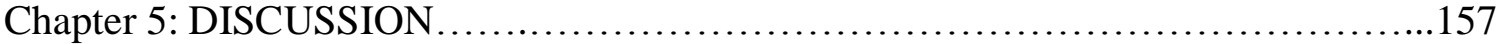

The Intercultural Development Inventory (IDI) Scores...................... 157

Anatomy of Intercultural Development: Japanese vs. American Participants...158

Japanese Participants: The Development of Cultural Self-Awareness...158

American Participants..........................................161

Cultural marginalization..................................163

Three Areas of Intercultural Development and Existing Models...............165

Three Areas of Intercultural Development and Deardorff's Pyramid

Model........................................................165

Three Areas of Intercultural Development and the Intercultural

Development Continuum........................................167

Kolb's Learning Dimensions and Intercultural Development..................167

Perceived vs. Preferred Learning Styles............................168

Kolb's Learning Dimensions and the Three Areas of Intercultural

Development................................................169

Effectiveness of Respective Learning Dimension....................171 
Theory-based materials as Abstract Conceptualization (AC).....172

Tea ceremony as Concrete Experience (CE).................173

Bicultural guest talk as Reflective Observation (RO)...........175

Intergroup discussions as Active Experimentation (AE).........176

Recommendations.................................................... 178

Theory-Based Materials as Abstract Conceptualization (AC)............179

Intercultural Experience as Concrete Experience (CE) .................180

Bicultural Guest Talk as Reflective Observation (RO)................180

Intergroup Interaction as Active Experimentation (AE)..................180

Benefit of Nonmainstream Instructors............................... 181

Benefit of the Culturally Hybrid Classroom............................181

Necessity of Intercultural Courses.................................. 182

Limitations of the Study............................................. 182

Implications of the Study........................................... 186

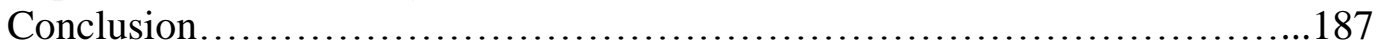

References............................................................ 189

Appendix A: Introductory Script............................................199

Appendix B: Informed Consent Letter.......................................... 200

Appendix C: Interview Protocol...........................................................................202

Appendix D: Interview Protocol in Japanese (日本語) ...........................205

Appendix E: Instruction of Reflection Papers.......................................................209 


\section{List of Tables}

1 Participants' IDI Scores, Stages, and Gaps Between Pre and Post Assessments.......................................................103

2 The Most Effective Learning Dimensions Perceived by the Participants and Participants' Preferences of Kolb's Learning Styles............................107

3 Three Areas of Intercultural Development by Kolb's Learning Dimensions.....116

4 The Three Areas of Intercultural Development in Detail by Kolb's Learning

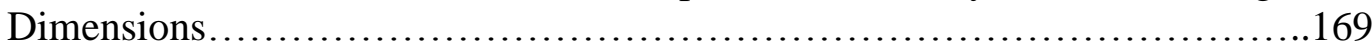

5 Two Patterns of Intercultural Competence by Kolb's Learning Dimensions.....171 
List of Figures

1 Kolb's Learning Cycle Applied to Pedagogical Strategies for Intercultural Learning .............................................................. 17

2 Cultural Iceberg Model Modified From Weaver's Iceberg Analogy of

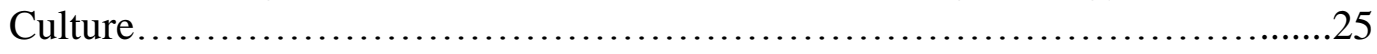

3 Deardorff's Pyramid Model of Intercultural Competence........................ 32

4 Deardorff's Process Model of Intercultural Competence........................34

5 Bennett's Developmental Model of Intercultural Sensitivity (DMIS)............39

6 Hammer's Intercultural Development Continuum (IDC) .....................54

7 Kolb's Teaching Strategies for Intercultural Learning....................... 77

8 Diagram of the Three Development Areas of Intercultural Competence With Kolb's Learning Dimensions Combined With Deardorff's Pyramid Model......166 


\section{Chapter 1}

\section{INTRODUCTION}

\section{Diversity Initiatives and Internationalization in American Higher Education}

As a result of global student/faculty mobility, American college campuses have become more diverse than ever, including racial diversity among domestic students/faculty as well as incoming international students/faculty. American higher education has invested money and staff time toward internationalization for the last several decades (Parsons, 2010; Smith, 1997). According to Knight and de Wit (as cited in Montgomery, 2009), the main educational goals of internationalization are "to encourage students to understand, appreciate and articulate the reality of interdependence among nations" in terms of environmental, economic, cultural and social dimensions, and "to prepare students to develop competences and tolerances that enable them to live and work in an intercultural context” (p. 256).

Internationalization movements in American higher education originated from domestic diversity movements as the world has continued to shrink. Universities have rethought their mission, tasks, and responsibilities, and begun to conclude that "educating all students for a diverse society and world is part of an emerging institutional missionone from which all students might benefit, and one for which having students from diverse backgrounds is a genuine asset" (Smith, p. 11). Milem, Chang, and Antonio (2005) insisted that "a first step in signaling an institution-wide commitment to diversity is for the top campus leadership to issue statements of support, purpose, and action" (p. 
23). Today, more and more universities and colleges in America include a diversity statement in their school mission. Good statements establish principles for diversity and education, and set goals for creating a welcoming and safe environment for intergroup interactions and for diversifying the curriculum, faculty, and student body (Milem et al.). For example, Portland State University (PSU) mentions diversity in its mission as "a climate of mutual respect" stating, "PSU values diversity and fosters a climate of mutual respect and reflection that supports different beliefs and points of view and the open exchange of ideas" (Portland State University, 2011). As another example, the diversity statement at Brandeis University articulates a stance toward diversity and internationalization that higher education should take, expressing that the university:

- Aims to engage members of our community as active citizens in a multicultural world.

- Seeks to build an academic community whose members have diverse cultures, backgrounds and life experiences.

- Believes that diverse backgrounds and ideas are crucial to academic excellence. (Brandeis University, 2011)

Many American higher education institutions also have built strategies and called for campus diversity plans that "aim to take into account the social chances and the needs of minorities to improve equality of chances and access as well as an inclusive climate without open or hidden discrimination" (Otten, 2003, p. 17). Smith (1997) argued that "many campuses have begun to conclude that educating all students for a diverse society and world is part of an emerging institutional mission—one from which all students 
might benefit, and one for which having students from diverse backgrounds is a genuine asset" (p. 11). Responding to this rapid and dynamic change of campus climate, campus diversity plans have needed to expand their focus from national to international diversity. In other words, the appreciation of domestic diversity has led to the appreciation of international diversity.

\section{Anatomy of Internationalization}

The three elements of internationalization directly affecting the student experience are (1) increasing participation in study abroad, (2) enrolling more international students (or increasing contact between domestic and international students), and (3) internationalizing the curriculum (Parsons, 2010). These three elements are relevant to the three groups of student mobility that Jon (2009) categorized as: "outgoing study abroad participants, incoming international students and domestic students who stay at home" (p. 440). Among the three categories of students, the number of outgoing study abroad participants and incoming international students are more highlighted than the majority of students, who stay and study on their home campus in terms of an internationalization achievement. The number of international students in U.S. higher education institutions increased from 547,867 in $2000-2001$ to 690,923 in the $2009-2010$ academic year, or by 26\% (Institute of International Education, 2010). This number indicates that $3.5 \%$ of the student population on American college campus is international students. The number of U.S. students studying abroad for academic credit in 2008-2009 was 260,327, which has tripled in the last two decades (Institute of International Education). 
Even though the number of study abroad students has increased, a vast majority of higher education students never leave their home country, choosing to study at a university in their own country (Wächter, 2003). The statistics shows that only $1.36 \%$ of U.S. college students studied abroad in 2008 (National Center for Education Statistics, 2010). A major issue is that studying abroad usually costs a considerable amount of money and not all students who wish to study abroad can afford to do so (Zlatic, 2009). Study abroad students often have to pay tuition to both their host and foreign schools in addition to room, board, airfare, and health insurance (Pappano, 2007). However, a much greater issue is that the majority of students at universities in their home country are not interested in internationalization or intercultural education; rather, domestic students tend to highly value vocational courses in order to obtain marketable skills (Dunstan, 2003).

Even though most domestic students do not recognize the value of internationalization, higher education institutions must be committed to this new direction of education because of the nature of the globalized living and working situations. Yet, the institutions and administrators in national educational systems are "constantly in a dilemma between maintaining cultural traditions and stability on the one hand, and on the other facing the necessity to adapt and change according to global cultural change" (Otten, 2000, p. 16). Dunstan (2003) also argued that "the tension between educating domestic students for national development and fulfilling the expectations of temporary students from overseas is problematic" (p. 66). With the rapid change toward globalization, American higher education institutions must realize the potential benefits of international education for all students, which will also promote 
national development. Teekens (2007) argued that "our 'national' universities face the impact of globalization and need to change their setting in order to refocus their view from a national perspective into a multi-perspective one" (p. 6). To do so, higher education institutions need to provide students who study at their home university a full opportunity for and access to international experience and learning on campus.

\section{Internationalization at Home (IaH)}

Internationalization movements have not only occurred nationwide, but have also spread worldwide. In 1999, Bengt Nilsson posited a new direction for internationalization in higher education, called "internationalization at home," in an article in the spring issue of Forum, the magazine of the European Association for International Education (EAIE) (Teekens, 2007; Wächter, 2003). Nilsson's concept of internationalization at home was articulated in the position paper written by the IaH initiative group (Crowther, Joris, Otten, Nilsson, Teekens, \& Wächter, 2000). Internationalization at home $(\mathrm{IaH})$ has been launched as an integrated process of institutional change and reform that emphasizes the importance of involving the whole student population beyond the issue of international mobility, including domestic students as a main focus (Jon, 2009; Mestenhauser, 2007; Wächter, 2003). IaH represents "a new phase in a process that moves beyond student mobility as the prime focus of international activity" (Teekens, 2007, p. 3). Internationalization is not for 'others,' who go overseas or come from other countries, but for everyone. A goal of IaH is to contribute to the benefit of all students from all backgrounds (Coleman, as cited in Otten, 2003; Leask, 2007). This viewpoint is deeply intertwined with that of campus 
diversity initiatives. As mentioned above, campus diversity initiatives have expanded their focus from national to international diversity. It is imperative for all stakeholders in higher education to realize the potential benefits of international education for all students. Specifically, it is critical to provide the substantial student population, those who stay and study on their home campus, a full opportunity for international experience and intercultural learning on campus.

\section{Teaching and Learning in IaH}

The practice of internationalization at home often takes place in the classroom. Dunstan (2003) stated that "in the school sector, the central business of teaching and learning activities, rather than large administrative operations or policy bodies, can certainly affect the progress of internationalisation at home" (p. 68). As a matter of fact, internationalizing the curriculum is the central practice of IaH (Jon, 2009; Paige, 2003; Parsons, 2010). More and more colleges and universities across the United States are internationalizing their curricula, because "college leaders increasingly recognize that knowledge about domestic and international diversity is essential for today's students" (Otten, 2003, p. 18). Many higher education institutions have discussed "the inclusion of diversity" and regarded "diversity as central to teaching and learning" (Smith, 1997, p. 11). After reviewing 300 diversity programs, Smith (1997) observed that "serious engagement of issues of diversity in the curriculum and in the classroom has a positive impact on attitudes toward racial issues, on opportunities to interact in deeper ways with those who are different, on cognitive development, and on overall satisfaction an involvement with the institution" (p. 139). Moreover, Smith argued that these benefits 
are particularly powerful for domestic students who have less opportunity for such engagement. One of the most remarkable benefits of diverse classrooms is that students are sources of knowledge themselves; that is, "they come and go with their own cultural baggage — and are one of the most important resources in conditions where students can learn from each other" (Teekens, 2007, p. 9).

Otten (2003) posited that a diverse campus climate itself will not simply make college students culturally responsible global citizens. The formal learning environment is needed in order to stimulate their cognitive, emotional, and behavioral development (Paige, 2003). More specifically, courses designed with effective pedagogical dimensions should be provided in order to develop college students' intercultural awareness and sensitivity.

\section{Distinction Between Internationalization and Intercultural Education}

Because the concepts of internationalization and intercultural education are not defined very well, they are often misunderstood. It is important to draw a distinction between internationalization or international education and intercultural education or intercultural learning, which are the two terminologies that will appear across this paper. The term "internationalization" describes the growth of relations among nations and among national cultures (Marginson, as cited in Otten, 2003). Internationalization relates to increasing intergroup contact as part of globalization. Internationalization is a phenomenon and environment that gives people an opportunity to interact with people from different cultural backgrounds (intercultural experience) and to cultivate their intercultural perspectives (intercultural learning). 
While internationalization on campus can occur in informal settings, intercultural education is a series of disciplines that students can learn through intercultural interactions or contexts in formal settings, such as academic courses, seminars, workshops, and so on. Otten (2003) emphasized the necessity of academic input for intercultural learning, arguing, "cultural diversity and internationalisation do not automatically lead to intercultural contacts and intercultural learning experiences" (p. 14). In other words, internationalization "seeks to introduce some kind of intercultural learning as a key element in the academic world" (Otten, p. 13). Thus, the term “internationalization" comprises a broader concept, including any international contexts and activities happening on and off campus of higher education institutions, whereas the concept of intercultural education more specifically encompasses academic components, such as taking intercultural or diversity-sensitive courses. Intercultural education for all college students is a key to accomplishing the university missions on internationalization.

\section{Previous Studies and Research Gaps}

There are several studies on internationalization at home. Jon (2009) conducted a case study to explore Korean college students' intercultural experiences at a summer international program in South Korea. The researcher demonstrated significant findings on the domestic Korean students' intercultural development, such as acknowledging stereotypes and biases toward certain cultures, becoming aware of different cultural norms, and recognizing their own culture. However, rather than having positive experiences, some of those students got frustrated about how to deal with the cultural differences and interact with the cultural encounters appropriately. Jon suggested the 
necessity of using academic intercultural concepts that would facilitate a deeper level of intercultural understanding between domestic and international students.

Another study shows positive effects on worldview and general international knowledge for students who reported greater international course content (Parsons, 2010). A research study on the impact of a diverse student population on mainstream students' learning experience shows that "a diversity-sensitive curriculum can lead to both academic achievement and growth of the students' personalities" (Otten, 2003, p. 19). Duster (1995) also reported that the intercultural course requirements led students to a greater appreciation of the complexity of cultural concepts across cultures. Several studies on the effects of cultural diversity courses show that these courses can enhance students' satisfaction with college, cognitive development, and intercultural understanding (Smith, 1997).

Even though several studies show positive effects of intercultural education, there is little consensus about what the intercultural or diversity-sensitive courses indicate. Intercultural or diversity-courses could indicate having courses with a mix of domestic and international students enrolled, diversity-sensitive issues discussed in class, specific cultural aspects introduced, or some intercultural theories taught. Few studies demonstrate an integrated and concrete design of intercultural teaching and learning. Therefore, more systematic pedagogical strategies are needed. This paper will identify effective pedagogical approaches for achieving the goal of internationalization, which is to cultivate students' intercultural sensitivity, and will present a research study to assess 
the outcome of intercultural learning and development on students by teaching a course using the effective pedagogical strategies.

This research study seeks to investigate the utilization of Kolb’s (1984) conceptual learning framework for increasing students' intercultural competence. The pedagogical strategies adapted from Kolb's four experiential learning models include (1) Abstract Conceptualization (AC), such as theory-based materials delivered by lectures and readings; (2) Concrete Experience (CE), such as an intercultural field trip or service learning; (3) Reflective Observation (RO), such as inviting bicultural guest speakers; and (4) Active Experimentation (AE), such as intergroup discussions. This paper explicates a research study that investigates college students' intercultural learning experience and developmental process through the course where the four pedagogical strategies are applied as interventions. The goal of this study is to promote intercultural education in American higher education with integrated and systematic pedagogical dimensions in order to prepare students to develop intercultural competences and tolerances that enable them to live and work in this multicultural world. 


\section{Chapter 2}

\section{LITERATURE REVIEW}

This literature review will discuss the primary texts and concepts related to this study. It begins by introducing Kolb's (1984) experiential learning theory that provides the essential and theoretical foundation of this study, followed by the four pedagogical strategies for intercultural learning. To substantiate the four pedagogical strategies, two important theories will be discussed as a conceptual framework: Allport's (1954) intergroup contact theory and Smith's (1997) core scholarship. Then, the literature review will discuss the definitions of intercultural competence as an outcome of intercultural learning, focusing on Deardorff's (2006) pyramid and process models, M. J. Bennett's (1986, 1993b) Developmental Model of Intercultural Sensitivity (DMIS), and cultural identity development. Finally, the literature review addresses appropriate assessment methods of intercultural competence as an outcome of international learning, including qualitative assessment methods and Hammer's (1998) Intercultural Development Inventory (IDI).

\section{The Four Pedagogical Strategies for Intercultural Learning}

Essentially, students learn differently; for example, some students learn better from experience, and others do better from observation. Mitsis and Foley (2009) claimed that "although good learning occurs when people move through all stages of learning, certain styles can become preferences for individuals or provide advantages in certain learning environments and contexts" (p. 243). This variety is significant across students 
from different cultural backgrounds. Students from all cultures may have learning style preferences; however, 'students' culturally anchored values and experiences may predict learning style preferences" (Mitsis \& Foley, 2009, p. 244). In other words, some cultures have a higher occurrence of one or two kinds of the learning styles than others because of their cultural and social values. Kolb (1984) explained that "this learning is a process; and thus, the course of individual development is shaped by the cultural system of social knowledge" (p. 133).

It is imperative for educators to realize this diversity of learning styles and use systematic and effective pedagogical strategies which respond to as many learning styles as possible. Mitsis and Foley (2009) insisted that "understanding student learning style preferences is one step toward having a deeper understanding of students. . . The effective understanding and management of students' learning experiences when they come from diverse cultural value backgrounds is important” (p. 241). Kolb's (1984) experiential learning theory deals with integration of theory and practice for diverse learning styles. When it comes to intercultural education, his theory fits the intercultural learning process well and can be adapted to be the foundation for systematic pedagogical strategies.

\section{Kolb's Experiential Learning Theory}

Experiential learning theory offers the foundation for adult learning theory that relates to lifelong learning with "the critical linkages among education, work, and personal development” (Kolb, 1984, p. 4). Aiming for students' personal development and career success, higher education institutions have adopted experiential learning into 
their curricula by offering "internships, field placements, work/study assignments, structured exercises and role plays, gaming simulations, and other forms of experiencebased education" (p. 4). Kolb (1984) argued that learning should be experiential in the sense that "the learner is directly in touch with the realities being studied. . . . It involves direct encounter with the phenomenon being studied rather than merely thinking about the encounter or only considering the possibility of doing something with it" (Keeton \& Tate, as cited in Kolb, p. 5). More specifically, the experiential learning model emphasizes the strong linkages between the classroom and the real world.

Experiential learning is also beneficial for nontraditional students-minorities, the poor, and mature adults, because it has become "the method of choice for learning and personal development" (Kolb, 1984, p. 4). The experiential learning model offers "educational methods that can translate the abstract ideas of academia into the concrete practical realities of these people's lives" (p. 6). Kolb insisted that although many nontraditional students may not be familiar with the classroom/textbook way of learning, the experiential learning model can offer them an opportunity to develop their own distinctive approach to learning and empower them to "capitalize on their practical strengths while testing the application of ideas discussed in the classroom" (p. 6).

Experiential learning theory shares its rationale with Piaget's cognitivedevelopment theory that describes how intelligence is shaped by experience: "Intelligence is not an innate internal characteristic of the individual but arises as a product of the interaction between the person and his or her environment" (Piaget as cited in Kolb, 1984, p. 12). Importantly, Piaget's epistemological approach — the relationship 
between the structure of knowledge and how it is learned-described the experiential learning process as "a dialectic between assimilating experience into concepts and accommodating concepts to experience" (p. 18). Kolb argued that "ideas are not fixed and immutable elements of thought but are formed and re-formed through experience" (p. 26). Jerome Bruner's quotation, "Knowing is a process, not a product" (as cited in Kolb, p. 27), means that learning is "a process whereby concepts are derived from and continuously modified by experience" (Kolb, p. 26).

Experiential learning theory originates from "a holistic integrative perspective on learning that combines experience, perception, cognition, and behavior" (Kolb, 1984, p. 21). In other words, learning involves "the integrated functioning of the total organismthinking, feeling, perceiving, and behaving" (p. 31). Kolb posits four different kinds of learning experiences in order to achieve new knowledge, skills, and attitudes: (1) Concrete Experience (CE), (2) Reflective Observation (RO), (3) Abstract Conceptualization (AC), and (4) Active Experimentation (AE). Concrete Experience emphasizes personal involvement with people in new experiences where learners are open-minded and willing to learn from feelings and people. Reflective Observation refers to learning by watching and listening and viewing things from a variety of perspectives to look for the meaning of what learners observe. The Abstract Conceptualization ability involves creating concepts that integrate learners' observations into logically sound theories. In the Active Experimentation stage, learners can "use these theories to make decisions and solve problems" (p. 30). In other words, they take 
action by experimenting with influencing or changing situations and see and learn from the results of the action.

\section{Previous Research With Kolb's Learning Cycle}

Kolb's (1984) experiential learning cycle has been applied to course designing of multiple subjects in higher education. Butler and Zander (2008) designed an international business course, focusing on teaching and learning through multicultural teams, with Kolb's learning cycle blended with their 4 Cs model (composition, communication, conflict, and creativity). Butler and Zander insisted that through working on projects with a multicultural team along with debriefing in class, students "can understand conceptually as well as personally experience" how to work in multicultural teams (p. 212). Hopkinson and Hogg (2004) adopted Kolb's experiential learning theory as an experiential pedagogic approach to a qualitative research course in the social sciences. Hopkinson and Hogg asserted that Kolb's experiential pedagogic approach effectively helps students "acquire practical skills for and applying critical thought to qualitative research" (p. 307).

Some research studies have focused on Kolb's (1984) experiential learning cycle and cultural differences. Joy and Kolb (2009) sought the role that culture plays in the way individuals learn, by examining whether individual culture dimensions influence in shaping the learning style preferences. They found that people in in-group collectivistic cultures, which are more likely to be Asian cultures than Western cultures, tend to have a preference for abstract learning styles and reflective learning styles (Joy \& Kolb).

Yamazaki and Kayes (2004) focused on Asian countries and compared three countries, 
Japan, China, and Malaysia, on the topic of human resource management. Yamazaki and Kayes investigated the learning style preferences of workers from the three countries as predictors of expatriate adaptation and job satisfaction. Their research shows that Japanese workers preferred experiencing and reflecting learning styles; Chinese workers preferred thinking and reflecting learning styles; and Malaysian workers preferred thinking and acting learning styles (Yamazaki \& Kayes). It is crucial for educators to understand that learning styles and cultural differences are intertwined and consider this fact in teaching.

\section{The Four Pedagogical Strategies for Intercultural Courses}

Kolb's (1984) experiential learning theory can be applied to intercultural teaching and learning. Fantini (2000) mentioned Kolb's experiential learning cycle as useful in designing intercultural programs and activities in order to foster intercultural competence development. It is beneficial to embrace all the learning cycles in designing intercultural courses in order to provide students with a variety of learning opportunities. As Figure 1 shows, the systematic and effective pedagogical strategies for intercultural learning include (1) theory-based materials delivered by lectures and readings that reflect Abstract Conceptualization (AC), (2) an intercultural field trip or service learning that reflects Concrete Experience (CE), (3) having bicultural guest speakers that reflect Reflective Observation (RO), and (4) intergroup discussions that reflect Active Experimentation (AE). These pedagogical strategies can be applied in designing various courses, such as area studies in international studies, intercultural communication studies, cultural learning in linguistics, or interdisciplinary studies. 


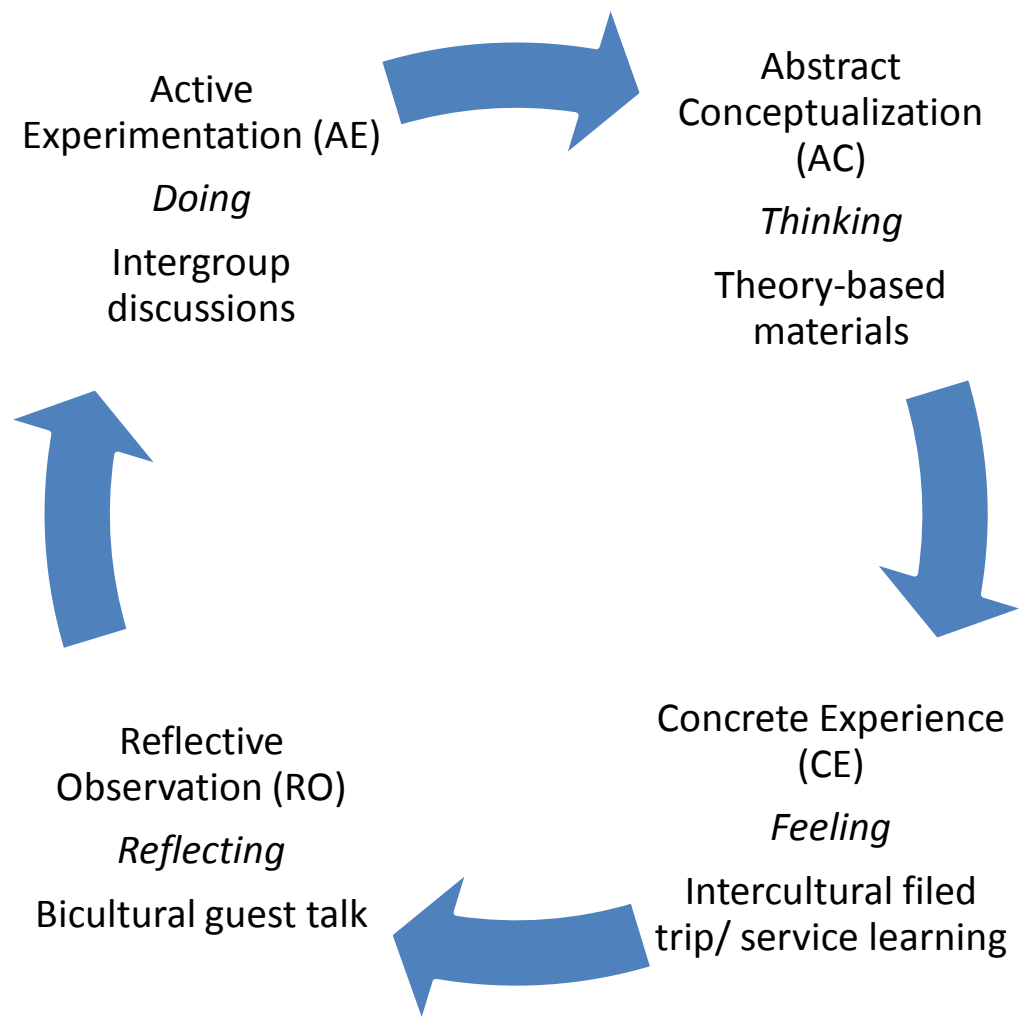

Figure 1. Kolb's Learning Cycle Applied to Pedagogical Strategies for Intercultural Learning

First, the course gives theory-based materials via lectures and readings. Learning theories and concepts through lectures and readings cultivates students' knowledge base and provides students with the opportunity for cognitive understanding, namely Abstract Conceptualization (AC). Second, the course can provide an intercultural field trip or service learning, where students can observe and experience an authentic cultural context. These intercultural experiences offer personal involvement with people in authentic cultural contexts where students are open-minded and willing to learn from feelings and people. Therefore, this pedagogical strategy reflects Kolb's Concrete Experience. 
Third, the course invites a guest speaker, who is a bicultural or multicultural person. A bicultural or multicultural speaker can share her or his personal stories of multicultural perspectives and experiences with the class. Storytelling is a powerful tool because it is someone's real voice, not something in lectures or readings (Merriam \& Caffarella, 1999). While watching and listening to the guest speaker, students have a chance to reflect on what they observe and to form their opinions and insights with a variety of perspectives. This process is considered Reflective Observation.

Lastly, the course should encourage students to participate in intergroup interactions, including in-class and outside-of-class intergroup discussions or team projects where students discuss assigned topics by exchanging different cultural values and norms. Students not only learn from lectures and readings or the experience and observation of a cultural event, but they also learn intercultural concepts through actual interactions with classmates from different cultural backgrounds. They can experiment to see if what they have learned works in the intercultural context. At the beginning, they may feel uncomfortable in communicating with the group members from different cultures. However, after trying out different intercultural communication skills that they have learned and gaining mutual understanding, they may start to feel more comfortable or connected with each other. This exercise represents Kolb's Active Experimentation; thus, students take action by experimenting with influencing or changing situations and see and learn from the results of their actions. 


\section{Conceptual Framework}

Two theoretical frameworks provide the basis for Kolb's four pedagogical strategies, Allport (1954) and Smith (1997). Allport's intergroup contact theory highlights the importance of intergroup discussions as Active Experimentation. Smith's (1997) core of scholarship demonstrates essential principles behind the four pedagogical strategies for intercultural learning.

\section{Allport's Intergroup Contact Theory}

Allport's (1954) intergroup contact theory can be applied to a crucial component of intercultural learning: intergroup interactions in the classroom. It could be detrimental rather than beneficial for domestic students to have international encounters without intercultural knowledge and skills from academic input. Otten (2003) warned that international encounters can "reinforce stereotypes and prejudices if the experiences of critical incidents in intercultural contexts are not evaluated on cognitive, affective, and behavioural levels" (p. 15). Researchers and scholars have studied intergroup relations and interactions for over 100 years. As early as the early 1900s, William Graham Summer theorized that intergroup hostility and conflict are natural and inevitable outcomes of intergroup contact (Pettigrew \& Tropp, 2005). Allport (1954) introduced the most influential statement of contact theory in The Nature of Prejudice. The theory posits that intergroup contact will reduce prejudice if the contact situation is associated with four positive features: (a) equal status between the groups, (b) common goals, (c) intergroup cooperation, and (d) the support of authorities, law, or custom. 
These four positive factors can be applied to the classroom situation, particularly for culturally blended classes, where domestic and international students interact. Domestic and international students have the same status in the sense that they are all students, sharing the common goals of learning the same subject and completing the course. A study shows that intergroup cooperation, such as working together and relying on each other to achieve shared goals, leads to effective intergroup contact. Pettigrew and Tropp (2005) underscored the idea that "attainment of common goals should be an interdependent effort based on cooperation rather than competition" (p. 265). Intergroup cooperation encourages the development of positive relations between the groups. In the classroom situation, domestic and international students can experience intergroup cooperation through group work and projects. Duster's study (1995) found positive interactions in cooperative learning activities such as group projects through which students can learn about each other's ways of thinking and problem-solving. Finally, "intergroup contact will also have more positive effects when it is backed by explicit support from authorities and social institutions" because "authority sanction establishes norms of acceptance and guidelines for how members of different groups should interact with each other" (Pettigrew \& Tropp, p. 265). In the classroom, a teacher plays the role of authority by creating guidelines and a safe learning environment for all students.

Considering Allport's intergroup contact theory, blended student groups create rich dynamics in the classroom where students can learn different viewpoints from each other. More specifically, a blended course with domestic and international students should reduce prejudice among students and promote positive intergroup attitudes and 
behaviors (Gaertner, Dovidio, \& Bachman, 1996). Kyabasi (as cited in Smith, 1997) hypothesizes that "the diverse nature of the student population may contribute to the students' experiences with cultural diversity and therefore their openness to the issue" (p. 33). Domestic students in particular can obtain great benefits from blended courses, because they are among the majority of the student body who has less opportunity to have contact with people from different cultural backgrounds than do international students (Smith, 1997).

Well-designed courses with systematic pedagogical strategies help students from different cultural backgrounds develop intercultural sensitivity, because the strategies cover multiple learning styles in order for students to have various learning opportunities. Allport's intergroup contact theory reinforces the strategy of Active Experimentation, including intergroup discussions. Students can apply intercultural concepts from theorybased materials, new perspectives from concrete experience, and reflective observation to actual conversations with their classmates from different cultural backgrounds, where students can enrich their intercultural knowledge and skills.

\section{Smith's Core of Scholarship}

Smith (1997) claims that the core of scholarship in higher education is "made up of: 1) the curriculum — what we teach; 2) pedagogy—how we teach it; and 3) scholarly inquiry-what we value" (p. 11). These are essential dimensions of teaching and learning for intercultural competence. The curriculum — what we teach—relates to offering courses addressing diversity issues and intercultural concepts. Pedagogy—how we teach — it refers to process-oriented and student-centered learning principles. 
Scholarly inquiry — what we value — relates to changing teachers' attitudes to appreciate diversity, more specifically a mindful and flexible attitude toward diversity.

\section{Intercultural course content: a two-layer approach.}

The first dimension of Smith's (1997) core of scholarship is the curriculumwhat we teach. Smith argues that "the inclusion of cultural diversity content and perspectives in coursework has positive effects on critical thinking skills and knowledge acquisition" (p. 36). Intercultural course content allows students to acquire intercultural awareness in an intercultural context (Dunstan, 2003).

Students may bring their own cultural perspectives to bear on the new culture if they do not learn how to realize and analyze their own cultural values, beliefs, and norms, as well as the others. Domestic students, particularly Anglo-Europeans who are part of the dominant or mainstream culture, are often not aware of how their culture has influenced their behavior and interactions (Okayama, Furuto, \& Edmondson, 2001). They may end up getting judgmental and oppositional toward foreign students and ruin potential trusting relationships with them. Instead of having this negative outcome, in intentionally designed courses students can learn skills to "suspend habitual judgments, pay attention to the difference, face it, and engage in dialogue leading to a better understanding of differences" (Okayama et al., p. 90). People's own cultural values and norms are embedded into their minds and it is natural that people take them for granted; therefore, it takes a great amount of time and effort to change people's ways of thinking (Paige, 1993). It is a complex process by which students gain new intercultural perspectives without losing what they have believed as their own cultural values and 
norms. Thus, contact with students from different cultural backgrounds is not enough if the social experience of international encounters is not transformed into a personally relevant learning experience (Paige, 1993). It is essential for students to learn intercultural content in the classroom, where there is an opportunity to reflect on individual and collective social experiences with people from different cultures beyond the contact with them (Brewer, 1996: Gaertner, Dovidio, \& Bachman, 1996).

M. J. Bennett (1998) addresses a two-layer approach to introducing intercultural course content: culture-general and culture-specific. This approach is effective for courses on any cultural topics. M. J. Bennett (1998) defines the culture-general level as "general cultural contrasts that are applicable in many cross-cultural situations" (p. 9). A culture-specific level of intercultural content explores "differences between two particular cultures. . . for their likely impact on communication between people of those cultures" (Bennett, 1998, p. 9). Weaver (1993) insists that "the sequence of topics is very important" (p. 160) — that it should move from the culture-general to the culturespecific_-because learners "are more likely to develop coping strategies and gain understanding rather than simply amassing questionable information” (pp. 160-161). Thus, it is important to introduce the culture-general knowledge before the culturespecific, because when learning different cultural perspectives, it is crucial to understand that there is no right or wrong way, but that they are just different. Students will have to learn not to judge others by their own perspectives and stereotypes, and to suspend their assumptions and analyze other cultures with intercultural awareness and sensitivity. 
The cultural iceberg model with basic assumptions is an example of culturegeneral course content. Edward T. Hall, an anthropologist, suggested that culture is like an iceberg; the tip (or external culture) is really the smallest part, and the largest part of culture is inside our minds (internal culture) at the unconscious level, which is beneath the water level of the conscious (Weaver, 1998). Hall as cited in Weaver regarded “internal culture or 'mind' as dominant over external culture" (p. 73). Weaver went on to say that "if we are to understand what motivates behavior, we must explore internal culture" (p. 73). In the process of analyzing cultures with this iceberg model, shown in Figure 2, students learn to understand not only the external culture above the water, which is what they see or hear, but also internal culture under the water. Internal culture consists of two layers: the upper layer is values, norms, and beliefs, and the bottom layer is basic assumptions, which people take for granted and do not usually think about. Basic assumptions can be described as dichotomous orientations, including collectivism and individualism, high-context and low-context communication patterns, vertical and horizontal relationships, masculine and neutral gender roles, process and product orientations, strong and weak uncertainty avoidance styles, and four other dichotomous orientations. Weaver (1993) argued that this model serves as a device for explaining a fairly complex concept and allows learners to focus on culture as a system, rather than trying to memorize lists of culture-specific behaviors. In other words, students can understand other cultures as well as their own culture not only at the surface level but also at a deeper level. 


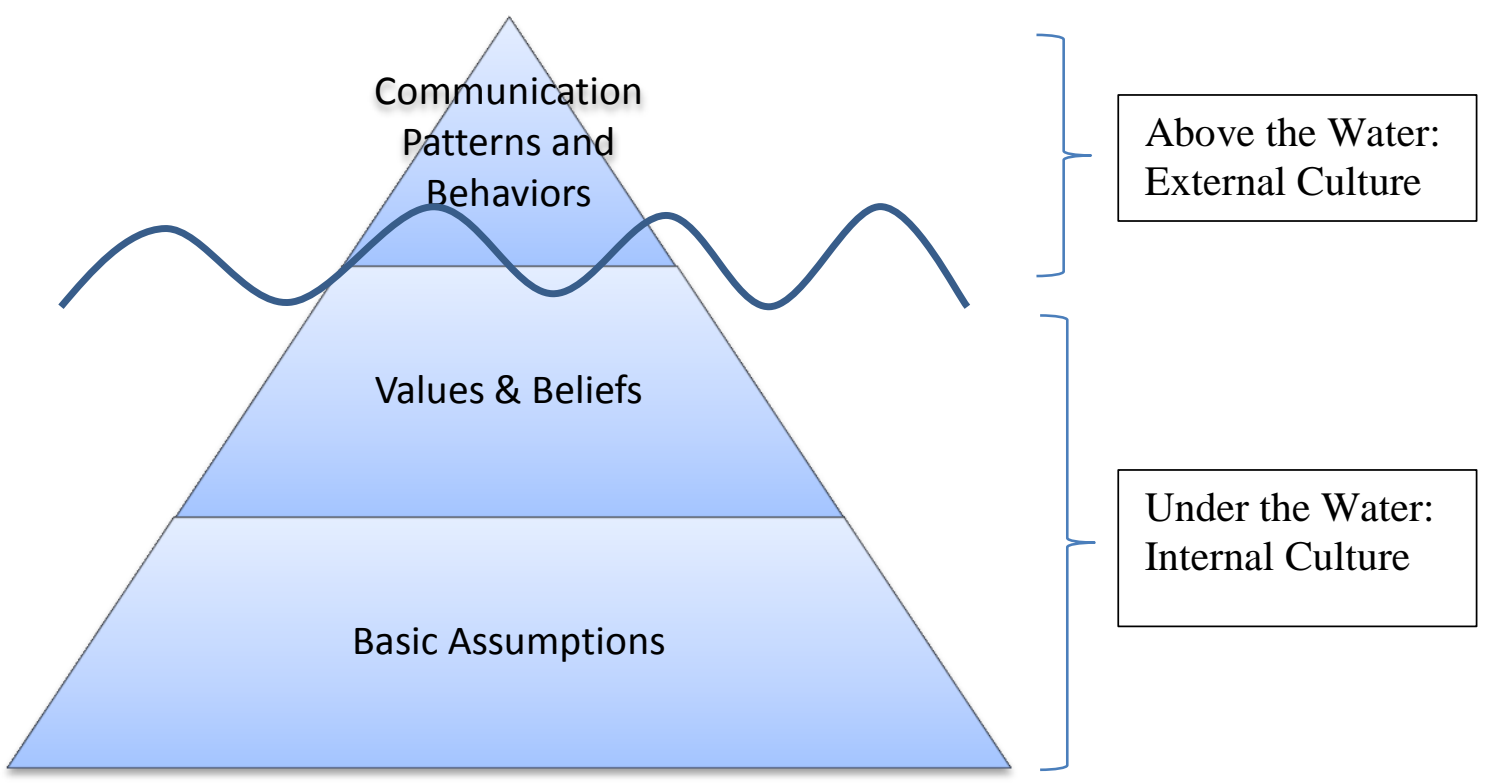

Figure 2. Cultural Iceberg Model Modified From Weaver's Iceberg Analogy of Culture

The first dimension of Smith's (1997) core scholarship, the curriculum — what we teach, reinforces one of Kolb's pedagogical strategies: Abstract Conceptualization (AC). Applying the two-layer approach of intercultural content—culture-general and culturespecific - to the theory-based materials stimulates students into cognitive development through understanding intercultural concepts from the two dimensions.

\section{Process-oriented and student-centered teaching.}

Smith's (1997) second core of scholarship is pedagogy; namely, how we teach it. In order to provide college students with intercultural learning experience in the classroom, transformation of learning principles from outcome-oriented to processoriented or from teacher-centered to student-centered is imperative. This is the case because the traditional educational contexts and procedures cannot foster the cognitive growth necessary for developing alternative perspectives. Otten (2003) argued that "a parochial learning environment creates a no-risk climate among teachers and students 
rather than openness, curiosity, and trust" (p. 15). Traditional college courses are regarded as outcome-oriented or teacher-centered learning. According to Freire (2000), the banking method of education is aimed at gaining factual information about the course contents. For a long time, many college courses have been outcome-oriented; namely, students are tested on what a teacher has taught and on the information in a textbook (Kramsch, 2003).

Recently, more courses have started to pay attention to process-oriented teaching by encouraging "creative self-expression, critical questioning, and interpretive inquisitiveness" in the classroom (Kramsch, 2003, p. 20). Clinchy (2000) argued that students need to "examine ideas closely, whether the ideas originate in a text, a classmate's comment, a teacher's lecture, or their own minds" (p. 30) rather than passively receiving knowledge from a teacher or a textbook or subjectively believing their own values. Paige (1993) emphasized the importance of "epistemological explorations regarding alternative ways of knowing and validating what we know, i.e., the meaning of truth and reality" (p. 3).

In intercultural education with process-oriented and student-centered teaching, students can actively ponder what they have taken for granted and what absolute truth means regarding their and others' cultural perspectives. Otten (2003) emphasized culturally sensitive teaching with "the variation of teaching methods and working formats and the integration of different types of course assignments" (p. 19) that allow students from different educational backgrounds to apply different skills of knowledge (re)production. Since most people expect a learning and teaching environment to be what 
they are used to from their own educational experience as a student, teaching should be sensitive to different cultural learning styles. More specifically, students from the mainstream culture may think that "course requirements are easier to achieve in a homogeneous group or alone, whereas a culturally mixed group has to struggle with foreign languages, different learning styles, and so on" (Otten, 2003, p. 21). Teachers should encourage students to practice intercultural group work, conflict resolution, and negotiating, bearing in mind that the objective of intercultural learning is "to expand people's knowledge about their own and other cultures, influence their attitudes concerning foreign culture, and develop their skills to interact effectively with people of other cultural backgrounds" (Otten, pp. 20-21). Paige (2003) encouraged teachers to "use international examples, readings, and resource persons in their classes" (p. 58). Multiple studies show some effective teaching strategies in cultural diversity courses: intense dialogue on diversity issues, informal peer interaction and peer-led discussions in class, required and supplemental readings, and personal involvement with peers and the instructor (Smith, 1997).

All these recommendations for intercultural teaching address the process-oriented and student-centered approach and can be applied to all of the four pedagogical strategies from Kolb's learning cycle. For example, after learning theories and concepts through lectures and readings, students will have plenty of opportunity to process the knowledge base with multiple learning activities such as a cultural field trip, a bicultural guest speaker, and intergroup discussions inside and outside of class. Students would be encouraged to actively and critically think, listen, and speak in the classroom. 
Additionally, students could be asked to write reflection papers on each learning activity so that they would have a chance to reflect on their insights in writing. Writing reflection papers requires "creative self-expression, critical questioning, and interpretive inquisitiveness" (Kramsch, 2003, p. 20). The different types of learning activities based on the four pedagogical strategies, followed by reflection papers can be firmly grounded in process-oriented and student-centered learning principles. Thus, Smith's second core of scholarship, pedagogy—how we teach, reinforces Kolb's four pedagogical strategies that facilitate systematic and effective intercultural teaching for educators.

\section{Scholarly inquiry for intercultural teaching and learning.}

The last core of scholarship that Smith (1997) posits is scholarly inquiry — what we value. Teachers' beliefs and values toward intercultural education directly impact intercultural teaching and learning in the classroom. In other words, it is essential for teachers to have a mindful and flexible attitude toward diversity and intercultural issues. Having faculty members who emphasize diversity or use materials on intercultural issues in courses has a positive correlation with students' openness to intercultural understanding and overall satisfaction with college (Astin, 1993). Teachers' mindful and flexible attitudes create a safe learning environment for all students by valuing diverse cultural perspectives. Teachers' beliefs and values toward intercultural education directly impact the other two dimensions of the cores of scholarship: (1) curriculum — what they teach, and (2) pedagogy-how they teach.

The number of international faculty members is increasing as a result of globalization. This phenomenon can promote internationalization in the postsecondary 
curriculum because of what international faculty value. International faculty include faculty members from nonmainstream cultural backgrounds and visiting international scholars. International faculty can have a positive impact on students' intercultural learning (Jon, 2009). Jon's study showed that domestic students enjoy nontraditional class atmospheres, perspectives, and thoughts from international faculty in class. International faculty bring and value different cultural perspectives and enrich students' learning experience.

Development of intercultural sensitivity is important for all faculty members, including domestic and international faculty, because "IaH can be enhanced by faculty who themselves have international experience" (Paige, 2003, p. 58). For example, faculty should be encouraged "to participate in international education by attending international conferences, teaching and conducting research abroad, working on research and writing projects with international colleagues, and consulting on international projects" (Paige, p. 58).

Smith's third core of scholarship, scholarly inquiry — what we value — plays a fundamental role in Kolb's pedagogical strategies for intercultural learning. Teachers' mindful and flexible attitudes toward intercultural issues and a diverse student population determines how systematically and effectively they design the courses with the four pedagogical strategies and facilitate the courses.

\section{Intercultural Competence as an Outcome of Intercultural Learning}

One meaningful outcome of intercultural learning is students' development of intercultural competence (Deardorff, 2006; Otten, 2003; Parsons, 2010). The study of the 
concepts of intercultural competence has been undertaken over the last 50 years, including "many attempts to create comprehensive definitions of these concepts and their components as well as means to measure them" (Parsons, 2010, p. 314). Deardorff (2006) enumerated nearly 50 articles that have given their own definitions of intercultural competence. By compiling those definitions, three core components are observed: knowledge, skills, and attitudes (Bennett, 1993; Deardorff, 2006; Mushi, 2004; Okayama, Furuto, \& Edmondson, 2001; Otten, 2003; Paige, 1993; Parsons, 2010; Sercu, 2004). Otten (2003) described the three components in his definition of intercultural competence as: “a long-term change of a person's knowledge (cognition), attitudes (emotions), and skills (behaviour) to enable positive and effective interaction with members of other cultures both abroad and at home" (p. 15). Additionally, the fourth component is personal attributes or personality traits/dispositions, such as "curiosity, general openness, and respect for other cultures" (Deardorff, 2006, p. 248) or "empathy, interest in cultures, flexibility, tolerance, initiative, sociability and positive self-image" (Sercu, 2004, p. 76). Personal attributes help the process of obtaining intercultural knowledge, attitudes, and skills through experiencing intercultural contexts or learning intercultural concepts (Mushi, 2004). It is important to note that "one component alone is not enough to ensure competence (i.e., knowledge by itself)" (Deardorff, 2006, p. 248). These components are intertwined, and each is significant in improving intercultural competence.

\section{Pyramid and Process Models of Intercultural Competence}

Deardorff's (2006) study with a panel of internationally known intercultural scholars and academic administrators was the first to document consensus on 
intercultural competence. As shown in Figure 3, Deardorff illustrated a pyramid model of intercultural competence by ordering components; the lower-level components enhance the upper levels. The model indicates the degrees of an individual's competence, which means that "the more components acquired and developed increases probability of greater degree of intercultural competence as an external outcome” (p. 255). In other words, the model moves from the individual level of attitudes and personal attributes to the comprehension of knowledge, to the internal outcome, and to the external outcome.

Deardorff (2006) asserted that although students can enter these frameworks of the pyramid model of intercultural competence at any particular point, "attitude is a fundamental starting point" (Byram, as cited in Deardorff, p. 255). Even though they learn the same theories and skills from the same textbooks, students grasp them differently because they have different attitudes to start with (Lynch \& Hanson, as cited in Deardorff). Okayama, Furuto, and Edmondson (2001) emphasized the foundational importance of attitude when attaining new knowledge and skills, because "awareness, the valuing of all cultures, and willingness to make changes are underlying attitudes that support everything that can be taught or learned" (p. 97). Thus, "the attitudes of openness, respect (valuing all cultures), and curiosity and discovery (tolerating ambiguity) are viewed as fundamental to intercultural competence" (Deardorff, p. 255). 


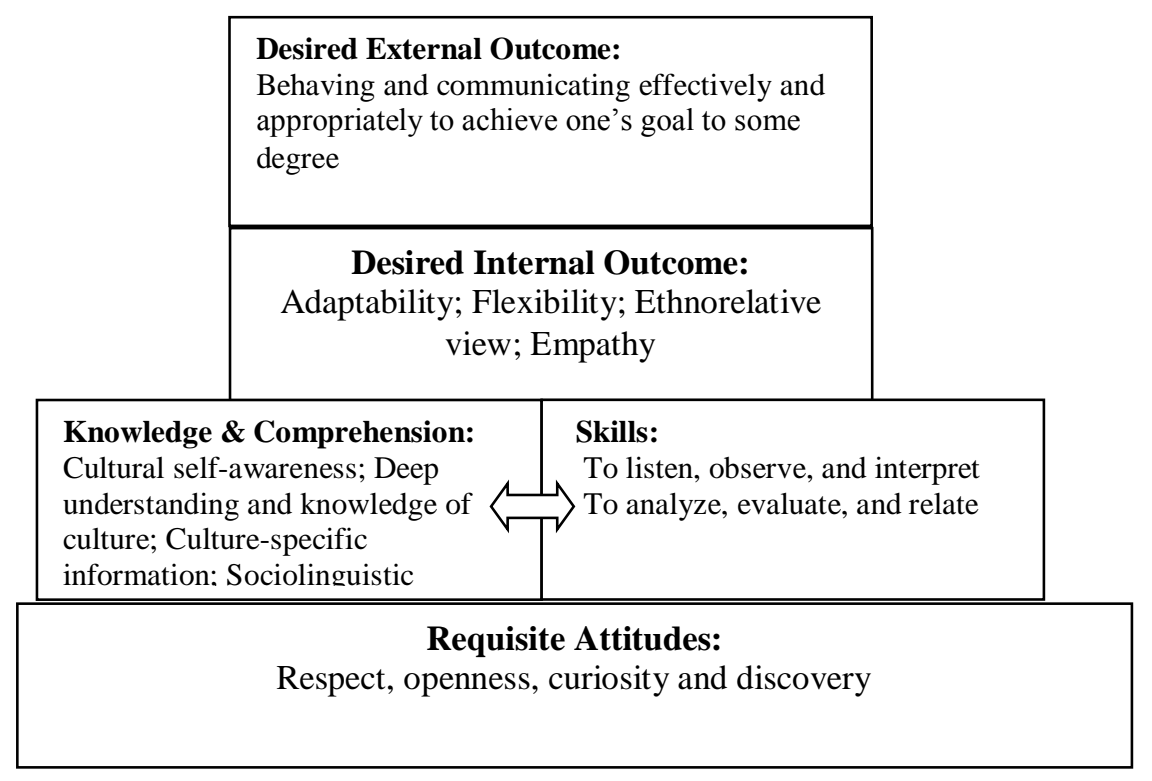

\section{Figure 3. Deardorff's Pyramid Model of Intercultural Competence}

The model underlines the importance of knowledge/comprehension and skills as well as the importance of attitude. Knowledge here means deep understanding of other cultures as well as one's own culture, including contexts, role, and impact of culture and others' worldviews. The term worldview refers to each person's "basic perceptions and understandings of the world" (Okayama et al., 2001, p. 91), which are usually formed out of personal experience through interactions with members of her/his own culture. Intercultural knowledge includes both culture-specific and culture-general. The culturespecific approach assesses differences between two particular cultures that impact communication among people of those cultures; while the culture-general approach describes "general cultural contrasts that are applicable in many cross-cultural situations" (Bennett, 1998, p. 9), such as the concept of high-context and low-context cultures or collectivistic and individualistic cultures. Through the process of gaining intercultural 
knowledge, students learn to listen, observe, and interpret intercultural contexts, and to analyze, evaluate the contexts, and relate them to their own cultural identity - in other words, they learn interconnectedness.

Deardorff (2006) stated that "a unique element of this pyramid model of intercultural competence is its emphasis on the internal as well as external outcomes of intercultural competence" (p. 255). Internal outcomes involve an internal shift in frame of reference, including adaptability to different communication styles and behaviors, adjustment to new cultural environments, flexibility of selecting and using appropriate communication styles and behaviors as well as cognitive flexibility, an ethnorelative view explained later, and empathy (Figure 3). Deardorff posited that the internal outcome should enhance the external outcome of intercultural competence, although it is not requisite. The external outcome is described as "behaving and communicating appropriately and effectively in intercultural situations" based on one's intercultural knowledge, skills, and attitudes (Deardorff, p. 255). Spitzberg (as cited in Deardorff) defined "effective" and "appropriate" in this way: "Appropriateness is the avoidance of violating valued rules and effectiveness is the achievement of valued objectives" (p. 256). Deardorff (2006) created a process model of intercultural competence, shown in Figure 4, which consists of the same elements as the pyramid model, in order to "depict the complexity of acquiring intercultural competence in outlining more of the movement and process orientation that occurs between the various elements" (p. 257). The process model shows that when the entire process-model cycle completes, it starts again from the attitude stage, moving to knowledge and comprehension, to internal outcome, and to 
external outcome. It is also possible to move from the stage of attitudes or knowledge/skills directly to the level of the external outcome, skipping the internal outcome level.
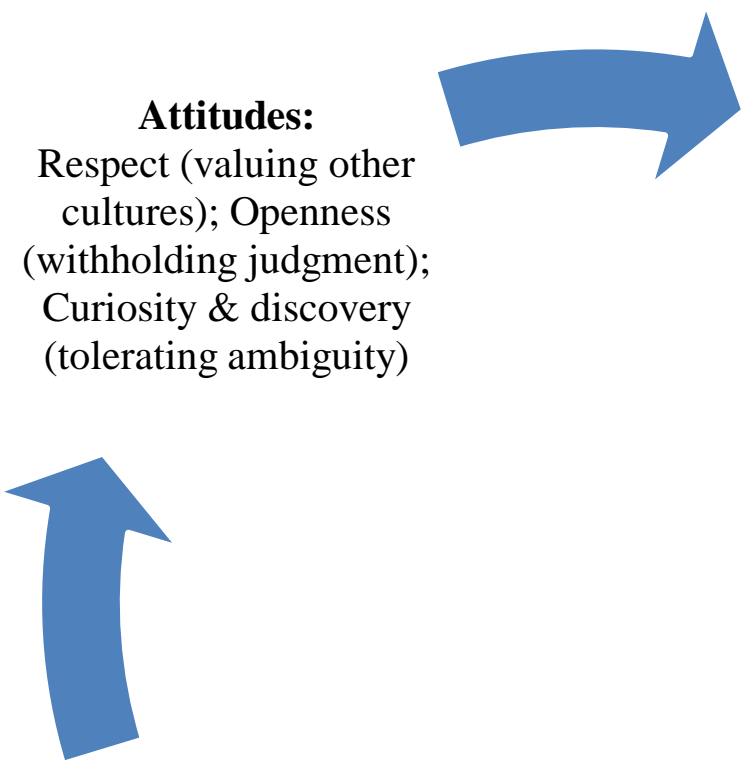

\section{Knowledge \& Comprehension:} Cultural self-awareness, deep cultural knowledge, sociolinguistic awareness

\section{Skills:}

To listen, observe \& evaluate; To analyze, interpret \& relate

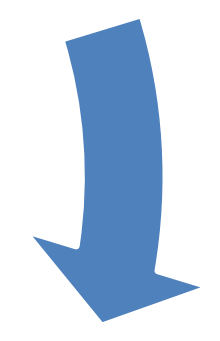

\section{External Outcome:}

Effective and appropriate communication \& behavior in an intercultural situation

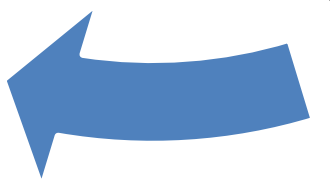

Internal Outcome:

Informed frame of reference shifts (adaptability, flexibility, ethnorelative view, empathy)

\section{Figure 4. Deardorff's Process Model of Intercultural Competence}

The pyramid and process models both encompass pivotal components of intercultural competence and explicitly demonstrate its developmental process, starting from students' attitudes to cognitive understanding at the personal (internal) level to the interpersonal (external) level, which indicates the communicative and behavioral aspects, such as intercultural interactions. It is important to note that this process model 
demonstrates "the ongoing process of intercultural competence development, which means it is a continual process of improvement, and as such, one may never achieve ultimate intercultural competence" (Deardorff, 2006, p. 257).

There is another developmental model of intercultural competence: M. J. Bennett's (1986, 1993b) Developmental Model of Intercultural Sensitivity (DMIS), which is fully discussed in the following section. Deardorff's and Bennett's models have different approaches, though both of them systematically describe individuals' growth in terms of intercultural competence. Deardorff focuses on the essential elements for one's development in intercultural competence, such as attitudes, knowledge, and skills, and explicates how they are interconnected. The DMIS focuses on one's experience of cultural difference in delineating the development stages of intercultural sensitivity and competence.

\section{Developmental Model of Intercultural Sensitivity}

M. J. Bennett's (1986, 1993b) Developmental Model of Intercultural Sensitivity (DMIS) elucidates the comprehensive process of intercultural sensitivity and competence development by stages. Intercultural sensitivity indicates "the ability to discriminate and experience relevant cultural differences" and the willingness to modify one's behavior as an indication of respect for the people of other cultures; intercultural competence means "the ability to think and act in interculturally appropriate ways" (Hammer, Bennett, \& Wiseman, 2003, p. 422). Hammer et al. argued that "greater intercultural sensitivity is associated with greater potential for exercising intercultural competence" (p. 422). 
The DMIS was developed with a grounded theory approach, which entails "using theoretical concepts to explain a pattern that emerges from systematic observations" (Bennett, 2004, p. 73). The pattern, which indicates the orientations of cultural difference, was induced from M. J. Bennett's intensive observation of empirical data over 20 years, examining how people encounter cultural differences and change their perspectives and behaviors as their intercultural experience becomes more sophisticated (Bennett, 2004; Greenholtz, 2000). Social constructivism and transformational learning will be discussed below as the two main theoretical concepts in the DMIS.

\section{Social constructivism.}

Social constructivists believe that people gain new knowledge and restructure preexisting knowledge by interpreting and generalizing their experiences through interactions and dialogue in social contexts (Fenwick, 2000; Taylor, Marienau, \& Fiddler, 2000). M. J. Bennett (2004) stated that "the most basic theoretical concept in the DMIS is that experience (including cross-cultural experience) is constructed" (p. 73). In other words, people do not perceive events directly; rather, their experiences or events are built up through templates, or sets of categories, with which they organize their perception of phenomena (Bennett, 2004). This assumption is based on the constructivist viewpoint, which involves the cognitive structure of people's interpretation of cultural difference. Hammer et al. (2003) also explained that "experience does not occur simply by being in vicinity of events when they occur" (p. 423); rather, experience is a function of how one interprets the events of cultural difference. M. J. Bennett (2004) provided a striking example to describe this concept: 
For instance, an American person who happens to be in the vicinity of a Japanese event may not have anything like a Japanese experience of that event, if he or she does not have any Japanese categories with which to construct that experience. Instead, he or she will have an ethnocentric experience, meaning that one's own culture is the only basis for perceiving events. (p. 73)

Greenholtz (2000) adopted George Kelly's personal construct theory to explain this concept of the DMIS, stating that "it is not what happens that makes a man experienced; it is the successive construing and reconstruing of what happens, as it happens, that enriches the experience of life" (Kelly, as cited in Greenholtz, p. 412). In other words, a more perceptual and conceptual construction during the event of cultural difference results in gaining richer experience (Hammer et al., 2003).

M. J. Bennett (2004) applied the constructivist idea of cognitive complexity to this assumption of the DMIS, which posits that more cognitively complex individuals, meaning those more sensitive to cultural difference, are able to organize their perceptions of events and experience into more differentiated categories. In other words, more interculturally sensitive people have a more expanded set of categories for noting differences among culture. For example, "sophisticated sojourners can observe subtle differences in nonverbal behavior or communication style, while a naïve traveler may only notice differences in the money, the food, or the toilets" (M. J. Bennett, 2004, p. 74). Therefore, "as categories for cultural difference become more complex and sophisticated, perception becomes more interculturally sensitive" (p. 74). 
The cognitive complexity of intercultural sensitivity is integrally related to the improvement of intercultural competence. Hammer et al. (2003) asserted that "as one's experience of cultural difference becomes more complex and sophisticated, one's potential competence in intercultural relations increases” (p. 423). According to M. J. Bennett (2004), studies in communicative constructivism have shown that one's quality of cognitive complexity, namely one's intercultural sensitivity, is associated with more sophisticated interpersonal communication skills. In other words, the keys to successful intercultural communication are abilities "to see a culturally different person as equally complex to one's self" and "to take a culturally different perspective" (p. 74). Therefore, "greater intercultural sensitivity creates the potential for increased intercultural competence" (p. 74).

\section{Transformation from ethnocentrism to ethnorelativism.}

M. J. Bennett (2004) stated that "as people became more interculturally competent it seemed that there was a major change in the quality of their experience" (p. 62), which he calls the movement from ethnocentrism to ethnorelativism. The DMIS delineates "the successive stages of cultural understanding through which one must progress, each associated with particular attitudes and behaviours" (Greenholtz, 2000, p.

413). The developmental model posits "a continuum of increasing sophistication in dealing with cultural difference, moving from ethnocentrism through stages of greater recognition and acceptance of difference, here termed as ethnorelativism" (Bennett, 1993b, p. 22). 
Ethnocentrism is defined as "assuming that the worldview of one's own culture is central to all reality" (Bennett, 1993b, p. 30). In other words, in the ethnocentric stages "the beliefs and behaviors that people receive in their primary socialization are unquestioned; they are experienced as 'just the way things are"' (Bennett, 2004, p. 62). On the other hand, in the ethnorelative stages, people realize that "one's own culture is
Denial
Defense /
Reverse
Minimizati
on
Acceptance
Adaptation
Integration

\section{ETHNOCENTRISM}

ETHNORELATIVISM

\section{Figure 5. Bennett's Developmental Model of Intercultural Sensitivity (DMIS)}

merely a representation of one of many equally valid worldviews" (Greenholtz, 2000, p.

413). Ethnorelativism is based on the assumption that "cultures can only be understood relative to one another and that particular behavior can only be understood within a cultural context" (Bennett, 1993b, p. 46). In the ethnorelative stages, people can suspend their ethnocentric stereotypes and judgments toward intercultural situations, be more open to other perspectives, and take culturally based actions in the specific cultural contexts (Bennett, 1993b).

On the continuum shown in Figure 5, the most ethnocentric experience is named the Denial of cultural difference, followed by Polarization, including Defense and Reversal. The Minimization of cultural difference is placed in the middle of the continuum, which is a transition state from more ethnocentric to more ethnorelative 
stages, leading to the Acceptance of cultural difference. At the heart of ethnorelativism is Adaptation to cultural difference, followed by the Integration of cultural difference into identity. Regarding the transformation from ethnocentrism to ethnorelativism, M. J. Bennett articulated that the more ethnocentric orientations can be regarded as ways of avoiding cultural difference, either by denying its existence, by raising defenses against it, or by minimizing its importance. The more ethnorelative worldviews can be interpreted as ways of seeking cultural difference, either by accepting its importance, by adapting perspectives to take it into account, or by integrating the whole concept into a definition of identity.

M. J. Bennett (1993b) insisted that ethnocentrism is an innate reaction of human beings when we encounter cultural contexts different from our own. He asserted that intercultural learning is a practice that changes a learner's natural behavior. Through this practice, learners gradually transition from ethnocentrism to ethnorelativism. A goal of intercultural learning is to cultivate students' developmental process of transformation from ethnocentrism to ethnorelativism. Transformational learning is "about changedramatic, fundamental change in the way we see ourselves and the world in which we live" (Merriam \& Caffarella, 1999, p. 318). It focuses on the cognitive process of learning: "the mental construction of experience, inner meaning, and reflection" (p. 318). Hence, the process of transformational learning explicates the developmental model of intercultural sensitivity. 


\section{The stages of the Developmental Model of Intercultural Sensitivity.}

M. J. Bennett (2004) defined the Denial of cultural difference as "the default condition of a typical, monocultural primary socialization" (p. 63). This is the state in which one's own culture is experienced as the only real one; therefore, "the reality of other cultures is either not perceived at all or is denied by the erection of psychological or physical barriers to contact" (Greenholtz, 2000, p. 413). Thus, people with a Denial worldview tend to be disinterested in cultural diversity and avoid recognizing or confronting cultural difference (Bennett, 2004). Dominant culture members are more likely to go through the Denial stage because they generally have less chance to confront cultural difference than nondominant culture members. In contrast, nondominant culture members are less likely to maintain a Denial worldview because they are constantly reminded of their difference in daily life where the social system and media convey an unstated message for them to fit in the mainstream culture (Bennett, 1993b; Hammer, 2009).

The best developmental strategy at the Denial stage of cultural difference is to begin to confront and notice cultural differences (Bennett, 1993b; Hammer, 2009). M. J. Bennett (1993b) underscored the importance of having skilled facilitators to go along with the movement toward more cultural sensitivity. He insisted that unfacilitated intercultural interactions tend to be more entertaining or destructive than developmental, because "the first reaction to encountering difference is likely to be increased tension" (p. 34), which is associated with the next developmental stage-Defense. 
After cultural difference is recognized, there is a developmental shift from the Denial orientation to the Defense orientation in intercultural sensitivity. However, since cultural difference is received as a threat, people in this stage are apt to defend themselves from the threat and preserve the absoluteness of their own worldview (Bennett, 1993b). As a result, their own culture is experienced as "the only viable onethe most 'evolved' form of civilization, or at least the only good way to live" (Bennett, 2004, p. 65). The world is organized into "us and them," where "one's own culture is superior and other cultures are inferior" (Bennett, 2004. p. 65). In other words, people at the Defense stage tend to denigrate other cultures with negative stereotyping and emphasize the positive characteristics of their own cultural group.

Reversal is a variation of Defense, which refers to a state involving the denigration of one's own culture and the superiority of a different culture. People in Reversal do not perceive other cultures as a threat; rather they generally have positive evaluations toward other cultures. Reversal is common among long-term sojourners, such as Peace Corps Volunteers, missionaries, corporate expatriates, and exchange students (Bennett, 2004). It seems to be a more interculturally enlightened position than Defense, because "it provides a positive experience of a different culture along with seemingly analytical criticisms of one's own culture" (Bennett, 2004, p. 66). However, "it is actually only changing the center of ethnocentrism" (Bennett, 1993b, p. 40), because "the positive experience of the other culture is at an unsophisticated stereotypical level, and the criticism of one's own culture is usually an internationalization of others' negative stereotypes" (Bennett, 2004, p. 66). 
M. J. Bennett (1993b) suggested that developmental movement out of the Defense/Reversal stage is facilitated by stressing the commonality of cultures, which is associated with Minimization, "a necessary stage of development that must precede a subsequent emphasis of difference” (p. 41). Hammer (2009) underscored the key resolution "to recognize the stereotypic nature of one's perceptions and experience of the other culture and to actively identify commonalities between one's own views, needs, and goals and that of the other" (p. 208).

Minimization of cultural difference is the state where "elements of one's own cultural worldview are experienced as universal" (Bennett, 2004, p. 66). At the Minimization stage, cultural difference is apparently acknowledged and not negatively evaluated; however, it is trivialized and considered as unimportant compared to the far more powerful directions of cultural similarity (Bennett, 1993b). Minimization lies alongside the assumption of universalism that there is a single truth that after all everyone is the same so that one needs to only be one's self to ensure successful interaction with all people (Bennett, 1993b). M. J. Bennett (2004) argued that these "universal absolutes" mask a deep level of cultural differences. This stage is regarded as ethnocentric, because the assumption is derived from one's own worldview, which means that people in this stage consider one's own cultural beliefs as central to an assumed universal reality. In other words, the experience of Minimization is that all people are essentially similar in ways that can be explained by one's won cultural beliefs (Bennett, 2004).

When one attempts Minimization behaviors in a number of intercultural situations, s/he learns that expectations of successful interaction based on the commonality are not 
met. This learning experience with proper instructions can lead to the next big step to the ethnorelative stages. M. J. Bennett (1993b) emphasized that this transition means a major conceptual shift from reliance on absolute truth to an acknowledgment of non-absolute relativity, starting from cultural self-awareness, the recognition of one's own culture. Lack of awareness of one's own culture underlies the assumption of cultural similarity at the Minimization stage. More specifically, cultural self-awareness is the ability to perceive one's beliefs, values, and behaviors in the particular context where s/he is socialized (Bennett, 2004). Cultural self-awareness can occur with proper instructions by skilled facilitators, in activities such as discussion, exercises, simulations, and reflective writing of personal experience (Bennett, 1993b). Cultural self-awareness will be discussed in more detail in the next section: cultural identity development.

Unlike the ethnocentric stages, where difference is experienced as threatening, the ethnorelative experience of difference is nonthreatening and rather enjoyable and appreciative (Bennett, 1993b). People with Acceptance respect both behavioral and value differences across cultures. At the Acceptance stage, cultural difference is acknowledged and respected as a necessary and preferable human condition; in other words, "other cultures are accepted as complex and valid alternative representations of reality" (Greenholtz, 2000, p. 413). In addition, from the viewpoint of cultural selfawareness or self-reflexiveness, one's own cultural perspectives and behaviors are experienced as one of a number of different, but equally complex worldviews (Bennett, 2004; Hammer, 2009). 
People with Acceptance are usually curious and interested in cultural difference; however, it should be noted that the fact that an individual is knowledgeable about a specific culture may or may not be associated with the ethnorelative experience of Acceptance (Bennett, 2004). It is more important in this stage to be able to experience cultural worldviews that rest on those specific cultural patterns of beliefs and behaviors.

M. J. Bennett (2004) argued that Acceptance does not mean agreement. More specifically, intercultural sensitivity and competence is not accompanied with liking other cultures or agreeing with their values or customs. The major issue of resolution for the Acceptance orientation is value or ethical relativity (Bennett, 2004; Hammer, 2009). In order to accept the relativity of values in cultural context and to gain the ability to experience the world filled with different values, one needs to figure out how to maintain ethical commitment, which means to take the perspective of another culture without losing one's own perspective (Bennett, 2004). Therefore, the crucial task for further development, Hammer (2009) insisted, is:

Deepening one's perceptions of other cultures, demonstrating a willingness to understand different (and even abhorrent) cultural practices from that other cultural perspective, and an increased capability to weigh one's own cultural values alongside the values from the other cultural perspective in such as way as to make ethical judgments in which cultural differences are fully taken into consideration. (p. 209)

The Adaptation stage allows one to become sufficiently comfortable with cultural differences and to shift in and out of alternative viewpoints (Greenholtz, 2000). Hammer 
(2009) defined Adaptation to cultural difference as the capability to shift perspective to another culture, to bridge between different cultural systems, and to change behavior in culturally appropriate and authentic ways according to cultural context. Thus, the shift of perspective does not occur only cognitively, but also operates on affect and behavior (Bennett, 2004). M. J. Bennett pointed out that adaptation is not assimilation. While assimilation refers to giving up one's own identity, adaptation involves the extension of one's repertoire of beliefs and behavior, which is not a substitution of one worldview for another.

The major issue to be resolved at Adaptation is authenticity: how an individual can sufficiently shift her/his perspective and adapt behavior to a culturally different context in ways that allow her/him to approximate the cultural experience of the cultural other, and still be oneself (Bennett, 2004; Hammer, 2009). M. J. Bennett (2004) suggested that one needs to expand the repertoire of perception and behavior. M. J. Bennett (1993b) mentioned an additive process where the fact "that one might temporarily behave or value in a way appropriate to a different culture does not threaten the integrity or existence of one's own cultural identity. Rather, the new ways of being are added to one's repertoire of cultural alternatives" (p. 52).

The resolution of authenticity at Adaptation may promote a person to the last stage of development-Integration. However, M. J. Bennett (2004) emphasized that "movement to the last stage does not represent a significant improvement in intercultural competence. Rather, it describes a fundamental shift in one's definition of cultural identity" (p. 72). The Integration orientation is conceptually separated from the 
intercultural development continuum; it is more concerned with the construction of an intercultural identity (Hammer, 2009).

The Integration stage indicates that one's experience of self expands to include the worldviews of other cultures. People at Integration are dealing with issues of cultural marginality where "they construe their identities at the margins of two or more cultures and center to none" (Bennett, 2004, p. 72). M. J. Bennett (1993b) posited two forms: encapsulated marginality and constructive marginality. The encapsulated form is defined as "the separation from culture is experienced as alienation" (Bennett, 2004, p. 72) or the state where "one's sense of self is stuck between cultures in a dysfunctional way" (J. M. Bennett \& Bennett, 2004, p. 157). The constructive form is defined as "movements in and out of cultures [that] are a necessary and positive part of one's identity" (Bennett, 2004, p. 72). Integration is not necessarily better than Adaptation in terms of intercultural competence, because cultural marginality, especially the encapsulated form, "may arise from any number of other experiences-experiences that are not grounded in the developmental state of adaptation" (Hammer, 2009, p. 210). Many nondominant culture members or long-term sojourners are dealing with encapsulated marginality with a feeling of being caught between their own minority ethnic group and the majority ethnic group (Bennett, 2004). The issue of resolution for encapsulated marginality is to "reestablish identity in a way that encompasses (one's) broadened experience (J. M. Bennett \& Bennett, 2004, p. 157). In this sense, constructive marginality is the resolution of the identity issue of Integration, in which 
"people are able to experience themselves as multicultural beings who are constantly choosing the most appropriate cultural context for their behavior" (Bennett, 2004, p. 72).

In sum, the Developmental Model of Intercultural Sensitivity is an integrated developmental scale, which was designed with solid conceptual frameworks, such as social constructivism and transformational learning. The goal of the DMIS is to develop an intercultural worldview, which refers to "the ability to create an alternative experience that more or less matches that of people in another culture" (Bennett, 2004, p. 74). Individuals within monocultural socialization usually possess their own cultural worldview, with which they are unable to experience the difference between their own perception and that of people from different cultures. The DMIS describes how people gain an intercultural worldview, through encountering cultural difference along with appropriate instructions. Each orientation of the DMIS is indicative of a particular worldview structure toward cultural difference, and transformation through the orientations is assumed to be unidirectional with only occasional retreats: "People do not generally regress from more complex to less complex experiences of cultural difference" (Bennett, p. 75). Finally, M. J. Bennett emphasized the underlying assumption that greater intercultural sensitivity generates the potential for more intercultural competence. Thus, the DMIS can be a robust model of intercultural competence that could indicate the outcome of intercultural learning for college students.

\section{Cultural Identity Development / Cultural Self-Awareness}

Cultural identity development proceeds along with intercultural sensitivity development. In other words, cultural identity development is a substantial factor in 
intercultural sensitivity development. M. J. Bennett (1993b, 2004) regarded cultural selfawareness, the recognition of one's own culture, as the first step of the transformation from the ethnocentric to the ethnorelative stages of cultural sensitivity. More specifically, cultural self-awareness is addressed as a resolution in Minimization by deepening understanding of one's own culture so that the individual will "increase understanding of culture-general and specific frameworks for making sense (and more fully attending to) culture differences" (Hammer, 2009, pp. 208-209).

Agar (1994) claimed that "culture is not what some group has: it's what happens to you when you encounter differences" (p. 22). While gaining knowledge of others' cultural perspectives, students synchronously reflect on their own beliefs and values in order to analyze their own cultural identity. In other words, the process of intercultural learning stimulates students to face their own identity, asking, "Who am I in the multicultural world?" Campbell (2000) defined the development of individual cultural identity as "the process of acceptance of the cultural norms, beliefs, attitudes and values of one cultural group rather than another" (p. 31). The development of cultural identity, self-awareness of one's own culture, or knowledge of self, is a substantial element of intercultural competence (Byram, 1997; Deardorff, 2006; Okayama et al., 2001).

Discovering one's own cultural identity is crucial for understanding others.

Okayama et al. (2001) asserted that an attitude of appreciation for and sensitivity toward other cultures develops as students gain deeper awareness of and value their own cultural identity. Cultural identity development is defined by Chavez and Guido-DiBrito (1999) as "an individual's movement toward a highly conscious identification with their own 
cultural values, behaviors, beliefs, and traditions" (p. 39). Until they encounter culturally unfamiliar contexts and realize the existence of different cultural perspectives, people may never have a chance to ponder their own cultural values and beliefs. Discovery of one's own cultural identity is an important process in intercultural education. The process of cultural identity development is a kind of transformational learning, in the way that one will transform the way of framing personal identity.

The process of cultural identity development starts from one's experience of identity encounters (Knefelkamp, 2006). Identity encounters are defined as events that raise one's awareness of her/his own identity (Knefelkamp, 2006). People may experience identity encounters in an informal setting, such as when they are traveling abroad and exposing themselves to culturally unfamiliar situations. Identity encounters may also occur in a formal setting, such as taking courses with intercultural content, where students learn new cultural perspectives through lectures, discussions, reflections, and interactions with a teacher and classmates from different cultural backgrounds. Learning diverse cultural values and norms may become a trigger for learners to wonder what their own cultural identity is, where they belong, or who they are.

Identity encounters can be shocking events and can be dangerous, because people going through an identity encounter might be judgmental, having thoughts such as "my culture is superior or inferior to the counterpart," which can be described as the Defense stage in the DMIS. Therefore, as the second step, people need to process their experiences and feelings and to scrutinize their own cultural values, beliefs, and norms, just like analyzing other cultural perspectives. An informal setting will not allow people 
to process what is happening during an identity encounter incident as well. Yet, academic inputs, such as diversity-sensitive courses with intercultural content facilitated by a skilled instructor can provide an opportunity to do so (Bennett, 1993b).

The next phase after analyzing one's own cultural identity is to appreciate and respect oneself as a global citizen in the multicultural world. Until an individual accepts her or his whole self and develops a cultural identity, s/he will not be able to fully acquire intercultural knowledge and skills to analyze other cultural perceptions (Bennett, 1993b). This advanced phase is concomitant with constructive cultural marginality in the Integration stage of the DMIS. M. J. Bennett (2004) claimed that it is exhilarating and fulfilling for people with constructive marginality to shift cultural perspectives and take the role of cultural bridge-builders in intercultural situations. They can do this without losing themselves, because they self-reflexively define their identities from a position of perspective shifting and bridge building.

From the stance of adult learning theories, it is imperative for young adults, such as college students, to have an opportunity to explore their cultural identity in a formal setting, because they are in the stage of developing their identity and cultivating their values, norms, and beliefs. Adult learners who have not exposed themselves to various intercultural contexts or have not improved their cultural competence may resist changing their perspectives. In the process of discovering one's own culture and that of others, learners naturally get emotional, confused, or resistant to some degree (Tatum, 1992). Therefore, the theoretical and structural instruction of intercultural concepts will help college students to process their "negotiation of their own and other cultures" (Chavez \& 
Guido-DiBrito, 1999, p. 41). Intercultural learning courses should provide college students with a great opportunity to develop a secure and positive sense of their cultural identity as a member of a social group, with an acceptance of other groups (Phinney, 1996).

\section{Assessment Methods of Intercultural Competence}

It is important and possible to assess students' intercultural competence; however, few universities have addressed "the development of interculturally competent students as an anticipated outcome of internationalization" or "designated methods for documenting and measuring intercultural competence" (Deardorff, 2006, p. 241). This is because it is difficult to achieve a consensus on definitions and to identify the specific components of intercultural competence due to this complex concept.

Deardorff's (2006) study showed that $38 \%$ of the postsecondary institutions she investigated had assessed students' intercultural competence. Interestingly, there is consistency among the methods these institutions used; the most popular method was student interviews, followed by student papers and presentations, student portfolios and narrative diaries, observation of students by others/the host culture, professor evaluations (in courses), and pretests and posttests. More importantly, these institutions used a variety of methods to assess students' intercultural competence, with an average of five different assessment methods used per institution. Indeed, Deardorff concluded that it is crucial to "use multiple assessment methods and not just one method, such as an inventory" (p. 257). 
Recommended methods to assess intercultural competence are "primarily qualitative in nature, including the use of interviews, observation, and case studies, as well as the possible use of standardized competency instruments" (Deardorff, 2006, p. 258). In her study, administrators of the institutions and intercultural scholars agreed that it was best to use a mix of qualitative and quantitative measures to assess intercultural competence.

As a quantitative measure of intercultural competence, the next section will introduce Hammer's Intercultural Development Inventory (IDI), which is adapted from the Developmental Model of Intercultural Sensitivity.

\section{Intercultural Development Inventory}

The Intercultural Development Inventory (IDI) v.3, invented by Mitchell R. Hammer, is an empirical and theory-based measure of an individual's or group's intercultural competence as adapted from Milton Bennett's Developmental Model of Intercultural Sensitivity (DMIS) (Hammer, 1999, 2007). It is a statistically reliable tool that operates and quantifies the orientations toward cultural differences (Greenholtz, 2000). Hammer (1999) posited that "the IDI is a self-assessment inventory that focuses on how individuals construe their social world in terms of dealing with cultural differences between themselves and people from other social/cultural groups" (p. 70). In other words, the inventory provides feedback to respondents regarding their general orientations or viewpoints toward cultural differences, namely their intercultural sensitivity (Hammer, 1999). Restating a definition of the term, intercultural sensitivity refers to an individual's interest in other cultures, sensitivity in noticing cultural 
differences, and willingness to modify her/his behavior as an indicator of respect for people of other cultures (Bhawuk \& Brislin, as cited in Hammer, 1999).

The IDI is cross-culturally valid because it was developed within the intercultural context, not any specific cultural context (Hammer, 1999). Thus, the instrument is appropriate for a wide variety of people from any culture. The IDI has been translated into 12 languages and has been administrated by over 1,200 qualified IDI administrators in over 30 countries (Hammer, 2009).

\section{Administrating the IDI.}

The current version (v.3) consists of a 50-item, online (or paper-and-pencil) questionnaire, with selected demographics, along with four open-ended "contexting" questions, which can be completed in about 20 to 30 minutes (Hammer, 2009). The open-ended questions "help further capture the experience around cultural differences of the respondent" (Hammer, p. 205).

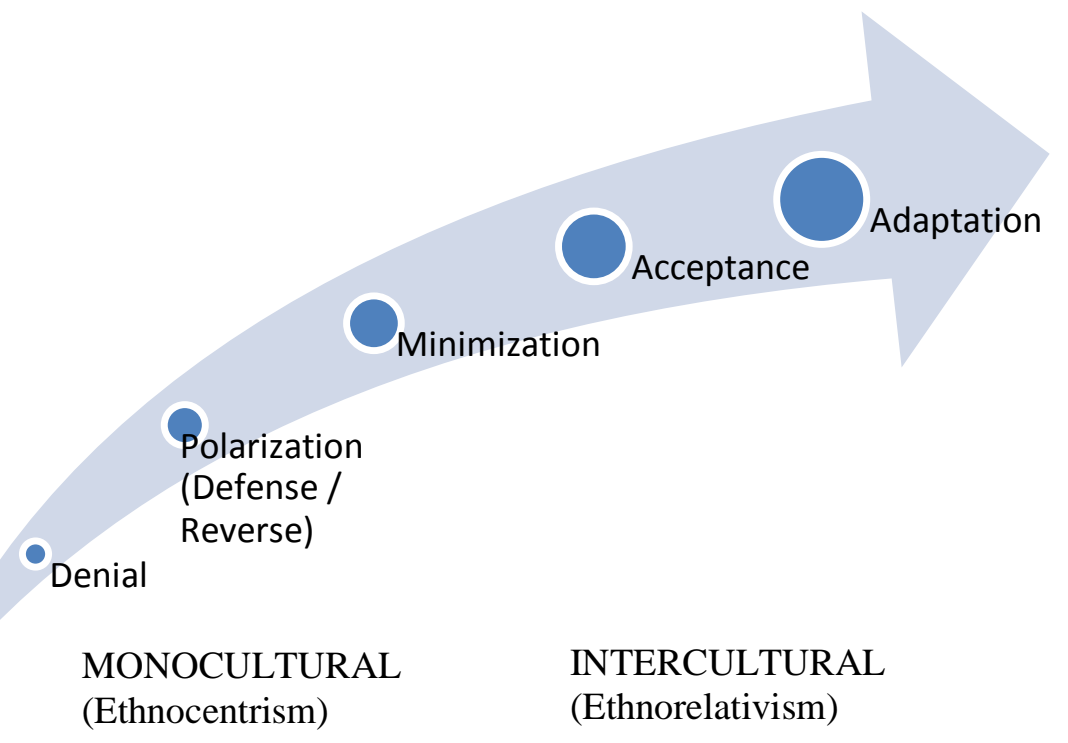

Figure 6. Hammer's Intercultural Development Continuum (IDC) 
In the process of data analysis, "the IDI analytic structure generates an individual (or group) graphic profile of the respondent's overall position on the intercultural development continuum" (Hammer, 2009, p. 205). The intercultural development continuum (IDC), shown in Figure 6, modified from the DMIS, includes denial, polarization (defense/reversal), minimization, acceptance, and adaptation, ranging from a more monocultural perspective to a more intercultural mindset. In parallel with the concept of the Developmental Model of Intercultural Sensitivity, an intercultural mindset indicates the capability of transforming cultural perspective and of adapting behavior to cultural contexts, while a more monocultural mindset indicates perceiving cultural differences from one's own cultural perspective.

According to Hammer (2009), “the IDI assesses a respondent's or group's primary orientation toward cultural differences... along this developmental continuum" (p. 206). In addition, “the IDI profile indicates key developmental, or 'leading,' issues that directly face the respondent that...can result in further progressions along the continuum" (Hammer, p. 206). The IDI profile also “identifies 'trailing' issues that are currently holding back the respondent or group from moving further along the developmental continuum" (p. 206), namely those that refer to unresolved aspects linked with an earlier orientation. Thus, not only does the IDI profile identify an individual's or group's primary orientation, but also it "reflects the individual's experience of cultural differences in terms of the degree to which the respondent has resolved issues associated with earlier (and less complex) perspectives toward cultural differences" (p. 206). It also indicates 
the challenges that the individual confronts "in further developing a deeper set of perceptions and consequently a more complex experience of cultural diversity" (p. 206).

Intercultural development continuum and cultural disengagement in the IDI.

It should be noted that the core orientations toward cultural differences in the intercultural development continuum of the Intercultural Development Inventory does not synchronize with the orientations in the Developmental Model of Intercultural Sensitivity. Hammer (1999) mentioned that some of the terminology and descriptions of the orientations in the DMIS "have been slightly revised in order to establish a more descriptively accurate portrayal of the meaning of some of the orientations" (p. 63). This redefinition happened because in the process of designing and formulating the IDI, the orientations toward cultural differences were carefully tested by several raters who were intercultural specialists, and were modified to make the inventory more valid and reliable (Hammer, Bennett, \& Wiseman, 2003). Validity and reliability testing will be discussed in detail later.

The IDI's intercultural development continuum identifies five core orientations of cultural differences, moving from "the more monocultural orientations of Denial and Polarization (Defense/Reversal) through a more transitional mindset of Minimization to the more intercultural or global mindsets of Acceptance and Adaptation" (Hammer, 2009, pp. 206-207). Although Minimization is categorized as the last stage in ethnocentrism in the DMIS, it is recognized as a transitional stage between ethnocentric and ethnorelative orientations in the IDI. 
Integration, the last stage of the DMIS, is not included in the IDI's development continuum, because it is related to the construction of an intercultural identity and considered a separate and distinct dimension from the other stages. This separate dimension, assessed by the IDI, is called Cultural Disengagement, which refers to the degree to which individuals or groups experience a sense of being disconnected or alienated from their own cultural community (Hammer, 2009). The concepts of Cultural Disengagement and encapsulated marginality in Integration overlap; however, Hammer (2009) asserted that they are different in that Cultural Disengagement simply measures a sense of alienation or feeling disconnected from one's own cultural group identity, which "does not imply that the individual's identity is somehow between two different cultures in a dysfunctional way" (p. 216). The IDI assesses Cultural Disengagement is an independent dimension of one's experiences around cultural identification, but is not developmentally a core orientation that goes along the intercultural development continuum described in Figure 6 (Hammer, 2009).

\section{Applicability and purposes of the IDI.}

Allowing users to objectively assess intercultural competence of either individuals or groups, the IDI has been identified as a crucial predictor of success in intercultural endeavors in expanded areas around the world (Greenholtz, 2000). This inventory is widely and successfully used in corporate, academic, and other settings to support individual coaching, action planning, and team development (Hammer, 1999).

Hammer (1999) suggested four purposes for using the IDI, which include (1) to “increase respondents' understanding of the developmental stages of intercultural 
sensitivity" (p. 62); (2) to improve respondents' intercultural skills and to assist them in making a decision to work or live in a culturally diverse setting; (3) to evaluate the effectiveness of various training, counseling, and education programs; and (4) to identify cross-cultural training needs of targeted individuals and groups within the context of culturally diverse settings. Because the IDI is a feedback instrument, the first two purposes focus on respondents' intercultural development by giving them their resulting profile and feedback. The latter two purposes target groups or organizations for program evaluation and improvement.

This study will employ the IDI for the purpose of evaluating the effectiveness of an intentional course of intercultural learning. The IDI is a suitable instrument for the purpose of this study, which is to investigate and understand college students' intercultural sensitivity development through a course designed with the four pedagogical strategies.

\section{Conclusion}

This chapter discussed the primary texts and concepts related to this study. First, it introduced Kolb's (1984) experiential learning theory that provides the essential and theoretical foundation of this study, followed by the four pedagogical strategies for intercultural learning. To substantiate the four pedagogical strategies, two important theories were discussed as conceptual framework. Allport's (1954) intergroup contact theory emphasizes the importance of intergroup interactions in the academic setting. This conceptual framework reinforces the strategy of Active Experimentation, including intergroup discussions inside and outside the class. Smith's (1997) core of scholarship, 
including curriculum, pedagogy, and scholarly inquiry, is a vital conceptual framework for Kolb's pedagogical strategies for intercultural learning.

The literature review discussed intercultural competence as an outcome of intercultural learning. Deardorff (2006) developed the pyramid and process models of intercultural competence after compiling a large number of multiple definitions and examining them with a panel of experts. M. J. Bennett $(1986,1993 b)$ also regarded intercultural competence as a developmental process, yet observed it from one's experience of cultural difference. M. J. Bennett established the Developmental Model of Intercultural Sensitivity (DMIS), which is an empirically and theoretically grounded model of intercultural sensitivity and competence. M. J. Bennett applied social constructivism and transformational learning to his model. Cultural identity development or cultural self-awareness is a requisite in developing intercultural sensitivity and competence, because discovering one's own cultural perspectives and cultural identity is crucial to understanding those of others.

Finally, the literature review addressed appropriate assessment methods of intercultural competence as an outcome of international learning, including qualitative assessment methods and Hammer's (1998) Intercultural Development Inventory (IDI). The IDI is an empirical and theory-based measure of an individual's or group's intercultural competence as adapted from M. J. Bennett's Developmental Model of Intercultural Sensitivity (DMIS) (Hammer, 1999; Hammer, 2007). It is a statistically reliable tool that operates and quantifies the orientations toward cultural differences. 
The purpose of this research study is to investigate how students learn and develop their intercultural understanding through a course designed with Kolb's four pedagogical strategies. As this chapter has discussed, it is important to assess students' intercultural competence as an anticipated outcome of intercultural learning if appropriate research design and strategies are used with solid conceptual framework. The extended goal of this study is to promote intercultural education in American higher education using integrated and systematic pedagogical dimensions. This study employed mixed research methods, by conducting Hammer's (1998) Intercultural Development Inventory (IDI) and qualitative assessment methods, including document analysis of students' papers and individual student interviews. The research methods and strategies will be discussed in detail in the next chapter. 


\section{Chapter 3 \\ METHODOLOGY}

This chapter discusses the methodology of my research study with an intercultural course, called Japan and U.S. Cultures in Contact, which employed Kolb's four pedagogical strategies for intercultural learning. Uniquely, the course consisted of onehalf domestic American students and one-half Japanese exchange students. This research study examined both domestic students' and Japanese students' intercultural learning experience and developmental process through the course. This study adopted explanatory mixed methods, by conducting Hammer's (1998) Intercultural Development Inventory (IDI) and using qualitative assessment methods, including document analysis and individual interviews. This chapter discusses the methodology of this research study. This includes the research purpose and research questions, followed by the rationale for mixed research methods, and the research design with the strategies for collecting and analyzing the data that described the quantitative and qualitative methods separately. The validity and reliability of the study will be also discussed, followed by the profiles of research participants.

\section{Research Purpose and Research Questions}

This research study investigated domestic students' and Japanese exchange students' intercultural learning experience and developmental process in an intercultural course designed with the four pedagogical strategies linked to Kolb's learning cycle: (1) theory-based materials delivered by lectures and readings (Abstract Conceptualization), 
(2) an intercultural field trip (Concrete Experience), (3) bicultural guest talk (Reflective Observation), and (4) intergroup discussions (Active Experimentation). This study addresses one main research question (RQ) and two subquestions shown below: RQ: Is there a connection between an intentional intercultural course using Kolb's learning cycle and student intercultural sensitivity development?

(a) How are these connections or patterns the same or different for American students and Japanese exchange students?

(b) How are the aspects of the intentional course design more or less effective for developing students' intercultural sensitivity?

These questions were answered by employing explanatory mixed methods, which "consists of first collecting quantitative data and then collecting qualitative data to help explain or elaborate on the quantitative results" (Creswell, 2005, p. 515). The next section will thoroughly discuss positivism and constructivism as the rationale for the research methods.

\section{Mixed Research Methods}

A mix of quantitative and qualitative research methods is defined as "a procedure for collecting, analyzing, and 'mixing' both quantitative and qualitative data in a single study to understand a research problem" (Creswell, 2005, p. 510). Both quantitative and qualitative data can provide a better understanding of a research problem than either type by itself (Creswell). I believe using mixed methods can maximize research outcomes, not by eliminating the possibility of multiple perspectives of the problems and issues, but by adopting two paradigms: positivism that quantitative method represents, and 
constructivism that qualitative method represents. The following sections will discuss the rationale for each paradigm and mixed methods design.

\section{Positivism: Rationale for the Quantitative Method}

When a positivistic paradigm is viewed epistemologically, the meaning of truth and reality lies under the research result of "cause-and-effect or stimulus-response relationships" (Creswell, 2005, p. 40). In other words, positivists regard the world as knowable and rational (Kempner, 1992). The ontological assumptions, which refer to the nature and sources of reality, are based on "the procedures of comparing groups or relating factors about individuals or groups in experiments, correlational studies, and surveys" (Creswell, p. 41). These procedures are deductive and theory-based.

For this research study I conducted pre- and posttesting to explore whether there was a positive relationship between the input of college students' intercultural learning in the intentional course using Kolb's four pedagogical strategies and the output/outcome of it by examining the difference in their levels of intercultural sensitivity and competence before and after taking the course. The Intercultural Development Inventory (IDI) was employed as an assessment tool. If the intentional intercultural course stimulated students enough to grasp multiple cultural values and beliefs and transform their own perspectives, it means that they increased intercultural sensitivity after taking the course. Therefore, it was hoped that there would be a positive relationship between these two variables: (a) taking a course designed with the systematic pedagogical strategies for intercultural learning, which is linked to Kolb's learning cycle and (b) the degree of the students' intercultural sensitivity development. 


\section{Reliability and validity of the IDI.}

Reliability and validity are critical issues with instruments of this nature. The development of the IDI has addressed these issues with great effort. Regarding content validity, the items on the inventory were generated from statements made during in-depth interviews with people from a variety of cultures (Hammer, 1999). The interviews were thoroughly transcribed, and statements related to intercultural sensitivity were selected and rated by raters who were familiar with the intercultural development continuum (Greenholtz, 2000). Inter-rater reliabilities were calculated, and the result showed high inter-rater reliability, which confirmed great content validity (Hammer, 1999). The instrument is also cross-culturally valid, because the items were generated within an intercultural context rather than in a specific cultural context and were based on interviews with people from a wide variety of cultural backgrounds. Further, the items of the instrument were refined by intercultural communication experts, who are intimately familiar with the DMIS.

Construct validity posits that "scores resulting from a measure of a construct should relate in a theoretically meaningful manner to other variables with which the construct is supposed to be connected" (Emmert \& Barker, as cited in Greenholtz, 2000, p. 414). In order to test the construct validity of the IDI, two theoretically related measures, the World-Mindedness scale and the Social Anxiety scale, were administered along with the IDI to a sample of over 300 respondents. Overall results from extensive statistical analyses demonstrate that the IDI is a robust, highly reliable, valid, crosscultural measure of the core orientations of the intercultural development continuum and 
Cultural Disengagement, and that the assessment is generalizable not only across ethnic cultural groups but also across gender, educational level, and age differences (Hammer, 1999, 2009).

The IDI is a statistically reliable measure that operates and quantifies intercultural sensitivity. Yet instead of using the inventory alone, in order to expand the research outcomes, this study included qualitative methods as well.

\section{Constructivism: Rationale for the Qualitative Method}

Qualitative research is inductive; it is open-ended and exploratory (Bogdan \& Biklen, 2007). Qualitative inquiry follows theoretical assumptions "that meaning and process are crucial in understanding human behavior, that descriptive data are what is important to collect, and that analysis is best done inductively" (Bogdan \& Biklen, p. 55). Qualitative research is defined as "a type of educational research in which the researcher relies on the views of participants, asks broad, general questions, collects data consisting largely of words or text from participants, describes and analyzes these words for themes, and conducts the inquiry in a subjective, biased manner" (Creswell, 2005, p. 39). The qualitative method reflects the constructivist paradigm.

Epistemologically, the constructivist paradigm views the contextually grounded meaning of human action as the nature of knowledge (Mishler, 1986). In other words, the nature and sources of knowledge and knowing are meaning-making in each context where individuals are situated. More specifically, the constructivist perspective emphasizes the setting or context (e.g., a classroom) in which the participants express their views on and personal meanings about educational issues (Creswell). Unlike the 
positivist paradigm, the constructivist researcher seeks neither cause-and-effect facts nor correlation of variables. Therefore, the conclusions of qualitative research methods are not conclusive, but "suggestive, incomplete, and inconclusive" (Creswell, p. 402). An ontological query, such as how we know the contextually grounded meaning of human action, indicates that the constructivist approach focuses on the meanings attributed to participants, more specifically looking at their views, values, beliefs, feelings, assumptions, and ideologies (Creswell, 2005). In other words, in the qualitative inquiry, participants can express their contextual understandings of their problems in their own words, which can be their way of constructing meaning (Mishler, 1986).

Applying the constructivist paradigm to this research study, qualitative methods, including document analysis of students' writing materials and individual student interviews, provided better understanding of how each pedagogical strategy impacts the students' learning experience and the process of increasing intercultural sensitivity across different student groups. It is also important to consider cultural and social implications, since these factors deeply affect students' transformational processes in intercultural learning (Deardorff, 2006). Qualitative inquiry can view students' developmental processes as a combination of their learning experience in the classroom and their personal life experience. Since the meaning of truth and reality is contextual, constructivists observe each student making meaning differently, even though students are taking the same intercultural course. 


\section{Rationale for the Use of Mixed Methods}

Employing the two different paradigms gives dichotomous perspectives in the research practice. The positivist paradigm would focus on the researcher's view and seek primarily the relationship between the systematic input of intercultural learning in the course and the output/outcome of it; while the constructivist paradigm would focus on the participants' views and emphasize the individual contextual meaning of reality. Combining the two different worldviews creates a more complete worldview. Creswell (2005) argued that "mixed methods research has its own philosophical worldview" (p. 512). More specifically, from the pragmatists' point of view, mixed methods researchers "believe philosophically in 'what works' for a particular research problem under study and that you should use all methods when understanding a research problem" (Tashakkori \& Teddlie, as cited in Creswell, p. 512). Mixed methods research is "a very powerful mix" (Miles \& Huberman, as cited in Creswell, 2005, p. 510) in the way that the data from assessing both outcomes of a study (i.e., quantitative) as well as the process (i.e., qualitative) can "provide 'a complex' picture of a social phenomenon" (Greene \& Caracelli, as cited Creswell, p. 510). As Deardorff (2006) suggested, in order to maximize research outcomes, it is best to combine the two paradigms and use a mix of quantitative and qualitative methods to investigate student intercultural sensitivity development through the intentional intercultural course using Kolb's learning cycle.

There are a few types of mixed methods designs, depending on priority, sequence, and procedures of the data collection and analysis (Creswell, 2005). In this research study I employed the explanatory mixed methods design, which "consists of first 
collecting quantitative data and then collecting qualitative data to help explain or elaborate on the quantitative results" (Creswell, p. 515). The rationale for this approach, according to Creswell, is that "the quantitative data and results provide a general picture of the research problem; more analysis, specifically through qualitative data collection, is needed to refine, extend, or explain the general picture" (p. 515).

In this study, the Intercultural Development Inventory (IDI) was conducted as a primary instrument of the quantitative research. The inventory assessed students' intercultural sensitivity and competence before and after taking the intercultural course. The results revealed the relationship between the input and the output/outcome of American students and Japanese exchange students' intercultural sensitivity development by taking the intentional course designed with Kolb's four pedagogical strategies. As discussed in Chapter 2, the IDI is an empirically and theoretically grounded measure of an individual's or group's intercultural sensitivity and competence as conceptualized by the intercultural development continuum (IDC) (Hammer, 2007, 2009). It is a statistically reliable and cross-culturally valid tool that operates and quantifies the orientations toward cultural differences (Greenholtz, 2000).

While the inventory holistically assessed students' intercultural development through the systematically designed course, this research study also investigated how each of the four pedagogical strategies affected the students' transformational process. Moreover, students' learning experiences are contextual and always intertwined with their personal life experience. A follow-up qualitative inquiry added more detailed and specific information including the components of participants' cultural and social 
implications to the numeric data, namely the assessment results. Therefore, in this research study I used a mixed methods explanatory design that primarily collected quantitative data, and then refined the findings through an in-depth qualitative exploration.

The qualitative methods consisted of document analysis of students' reflection papers for the course and individual student interviews. Because the reflection papers are descriptive indicators of the students' learning outcomes, they demonstrated what and how students learned from each learning element based on the four pedagogical strategies for intercultural learning. The qualitative evidence, written documents, proved an individual student's learning experience and developmental process as well as the cultural and social implications for her/him. Interviewing as a qualitative method was used "to gather descriptive data in the subjects' own words so that the researcher can develop insights on how subjects interpret some piece of the world" (Bogdan \& Biklen, 2007, p. 103). I conducted individual interviews in addition to the inventory and document analysis, because "multiple sources lead to a fuller understanding of the phenomena you [are] studying" (Bogdan \& Biklen, pp. 115-116). In the interviews, I gained information about whether and how each element of the pedagogical strategies impacted students' intercultural learning experience and developmental process. Hence, the mixed methods explanatory design maximized research outcomes and achieved the best understanding of the research problem. 


\section{Research Design}

\section{Research Site}

This research study was implemented at Portland State University (PSU), a metropolitan university in the center of Portland, Oregon. PSU articulates its great effort toward a diversity-sensitive campus in the university mission statement, stating "PSU values diversity and fosters a climate of mutual respect and reflection that supports different beliefs and points of view and the open exchange of ideas" (Portland State University, 2011). Therefore, it was an appropriate research site for examining how students engaged in intercultural learning and developed their intercultural sensitivity and competence through a course organized by Kolb's four pedagogical strategies.

The data was collected in the course offered in the spring of 2012. This was a 300-level 4-credit course in International Studies, titled Japan and U.S. Cultures in Contact, scheduled from the end of March to the beginning of June in 2012. The class met twice a week, two hours each time, for 10 weeks. This course offered a comparative approach to principles of interaction in Japanese and American cultural contexts as well as to intercultural communication theories in general.

I chose this course because it consisted of one-half domestic American students and one-half Japanese exchange students who were new to American culture, society, and its educational system. These two groups of students had different cultural and social backgrounds. This unique learning environment automatically encouraged both of the student groups to interact with each other; therefore, it was a great research venue for investigating whether and how the systematic and effective pedagogical strategies 
worked for each student group's intercultural learning experience and developmental process. This case was also unique because I taught this course and therefore could implement the four pedagogical strategies for intercultural learning.

\section{Positionality}

It is important in this study that $\mathrm{I}$, the teacher and researcher, had a mindful and flexible attitude toward diversity because of my cultural and professional background. I am from nonmainstream culture so I was able to present nonmainstream cultural perspectives. My academic background is intercultural communication so I am greatly aware of and sensitive to cultural diversity and intercultural issues. Process-oriented and student-centered learning disciplines were reflected in the expectations of participation in the syllabus: "active participation in the class; respect for the thoughts, ideas, and contributions of others; .... Different learning styles are acknowledged; therefore, active participation does not only mean active speaking, but also active listening and thinking" (Sakurauchi, 2011, p. 2). As this statement of expectation articulates, this course encouraged the students' active participation including active speaking, listening, and thinking, which indicates process-oriented and student-centered learning. I also had students complete Kolb's learning style inventory in the first week of the course and explained it in class so that students recognized their own learning style preferences and maximized their learning experience through the course. The research purpose in doing this was to add information and enrich the qualitative data. More specifically, I examined how the participants' own learning style preferences interacted with various aspects of the course design. 


\section{Population of Research Participants}

The class population consisted of 16 American students and 12 exchange students from Waseda University in Japan. The exchange students consisted of 11 Japanese students and one Korean student. The American students were majoring in various fields of studies and were specifically interested in Japanese culture or other cultures. Many of the domestic students had diverse cultural backgrounds and had already had a variety of intercultural experiences, including studying or traveling abroad and hosting international students. The Japanese exchange students were new to American culture, society, and its higher education system, taking this course in their very first term of the exchange program. Most of them had never been outside Japan. This unique student dynamic was created by the co-curriculum between the department of International Studies and the PSU-Waseda Transnational Program.

Because domestic American students and Japanese exchange students had quite different cultural and social backgrounds and different intercultural experiences, it was worth investigating whether there were any significant differences or similarities in terms of their intercultural learning experience and developmental process. The two student groups experienced significantly different learning contexts: American students were learning within their own cultural environment, while Japanese students were learning in a new and unfamiliar cultural environment. It is notable that this significant difference may have impacted the research findings. For example, there were possibilities that American students might not have developed as much intercultural sensitivity because they were still within their own cultural environment or because they were already highly 
interculturally sensitive because of their past international experiences. The other case would have been that American students might have greatly developed their intercultural sensitivity because there was significant room to develop through the intentional course design or the exposure to the intercultural classroom environment. On the other hand, Japanese students might significantly have developed their intercultural sensitivity because they lived in a foreign country or because of the classroom experience. The other case would have been that Japanese students might not have developed as much intercultural sensitivity because they were suffering from culture shock, meaning the experience of being in a foreign country made them retreat emotionally. Careful analysis of the descriptive data from documents and interviews revealed these possible different factors which could have caused a difference in their development of intercultural sensitivity.

\section{Participant Recruitment}

First, I applied to and received approval from the Human Subject Review Committee at PSU. Because I was also the teacher of the students/subjects in this research study, it was optimal for someone else to do the recruitment and the consent process. This way, it was unlikely that students would have felt coerced into participating. Therefore, the teaching assistant of this course did the recruitment and the consent process on the first day of the class in the instructor/researcher's absence so as not to influence the students. The teaching assistant offered the opportunity to participate in the research study to all 28 enrolled students, including domestic and Japanese exchange students. As Appendix A: Introductory Script shows, the teaching assistant 
explained the research purpose and assured the students that it was truly voluntary, that participants' confidentiality would be strongly protected, that participation would not affect their grades, and that the data would be analyzed after grades had been assigned. The students were assured that pseudonyms would be used for any publications and presentations of this research study. Voluntary participants signed and submitted the consent form to the teaching assistant. The Japanese-translated consent forms were provided to the Japanese exchange students for maximum understanding. There was no restriction on gender, ethnic background, or health status. Since this was an upper-level college course, all the students were college students over 18 years old. I received 23 consent forms.

\section{Kolb's Four Pedagogical Strategies in Action}

I designed the course with the systematic and effective pedagogical strategies for intercultural learning based on Kolb’s (1984) learning cycle (Figure 7), including (1) theory-based material in lectures and readings (Abstract Conceptualization), (2) the tea ceremony experience at the Japanese Garden (Concrete Experience), (3) bicultural guest talk (Reflective Observation), and (4) intergroup discussions (Active Experimentation). Kolb's (1984) experiential learning theory posits that learning involves the integrated functioning of the total organism including experience (feeling), perception, cognition (thinking), and behavior. Mitsis and Foley (2009) claimed that "although good learning occurs when people move through all stages of learning, certain styles can become preferences for individuals or provide advantages in certain learning environments and contexts" (p. 243). Mitsis and Foley went on to say that students' culturally anchored 
values and experiences shape their learning style preferences. Fantini (2000) insisted that Kolb's experiential learning cycle was useful in designing intercultural programs and activities in order to develop intercultural sensitivity. This is the case because intentional intercultural courses designed with Kolb's pedagogical strategies provide students with a variety of learning opportunities and enlighten them about cultural differences.

First, in terms of the theory-based material delivered through lectures and readings as Abstract Conceptualization (AC), this course included lectures and assigned readings on the topics along with each lesson. I adopted M. J. Bennett's (1998) two-layer approach to intercultural content: culture-general and culture-specific. Before presenting the culture-specific topics, the course introduced general intercultural communication theories. The cultural iceberg model with basic assumptions, explained in Chapter 2, was introduced as a core theory. For example, Edward T. Hall's (1998) definition of highcontext and low-context communication patterns and the concept of individualism and collectivism are contrasts of basic assumptions that each culture has a tendency of either one of the contrasts in the continuum. One way that may have helped students understand the concept was to show the continuum on which different countries are placed and to explain that European countries are positioned somewhere on the lowcontext side and Asian countries are positioned more on the high-context side of the high/low-context continuum (Weaver, 1998). The culture-general layer of intercultural content also included the concept of the developmental stages of cultural sensitivity and awareness (Bennett, 1998). For example, this course introduced M. J. Bennett's (1986, 1993b) Developmental Model of Intercultural Sensitivity (DMIS) and Ting-Toomey and 
Chung's (2005) staircase model of intercultural communication competence. The point of learning the developmental models is that an individual's intercultural competence level is so relative, subjective, and fluid that it does not have to follow a certain developmental model, and it is important to realize that people are at different levels of cultural sensitivity and awareness and shift where they are over time, depending on their intercultural experience and knowledge.

Gaining general but fundamental intercultural knowledge before learning about specific cultures, students became better observers of their own cultural perspectives as well as others' and became able to suspend their judgments when examining new cultural values and norms. Learning the culture-general concepts first helped students compare and contrast two cultures. For example, American culture values individualism and Americans tend to use a low-context communication style, while Japanese culture values collectivism and Japanese people have a tendency to use a high-context communication style (Weaver, 1998). The culture-specific level includes two phases: cross-cultural and intercultural aspects. The cross-cultural aspect compares the two cultures and scrutinizes how Americans communicate differently from the Japanese. The intercultural aspect investigates intercultural communication 


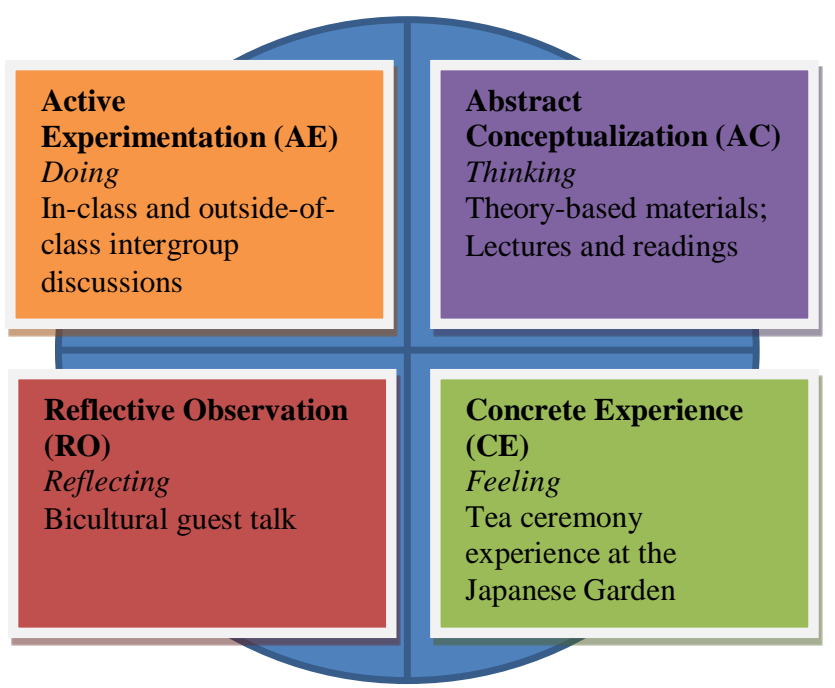

\section{Figure 7. Kolb's Teaching Strategies for Intercultural Learning}

between people from the two different cultures, namely how Americans and Japanese interact with each other.

Regarding the second strategy, Concrete Experience (CE), this course provided a field trip to the Portland Japanese Garden, where students observed and experienced a Japanese tea ceremony. This intercultural experience was a powerful learning device, because students were able to get involved with the cultural context and feel the authentic atmosphere where they were open-minded and willing to learn from feelings and people in this context.

Thirdly, for the strategy of Reflective Observation (RO), the course originally planned to invite two bicultural guest speakers, one Japanese and the other American. Unfortunately, the American speaker could not make it due to a time conflict. The Japanese speaker is originally from Japan and has lived in the United States for three years. Her pseudonymous name is Chai. She shared her experience working in Japan and in America. Storytelling is a powerful tool because it is someone's real voice, not 
something in lectures or readings (Merriam \& Caffarella, 1999). While watching and listening to the guest speaker, students had chance to reflect on what they observed and to form opinions and insights from their own thoughts and feelings.

Lastly, fulfilling the fourth strategy of intercultural learning, Active Experimentation (AE), the course required in-class and outside-of-class intergroup discussions. The in-class discussion opportunity was provided during and after lectures, where students were able to share their experiences, opinions, and perspectives. I was aware of cultural differences in class participation-namely that American students would be more comfortable to speak up in class than Japanese students. I tried to make the class a safe environment as much as possible so that the Japanese students felt comfortable to speak up.

For the project of outside-of-class culture-exchange group discussions, students were divided into small groups of three to five, with a mix of students from the two different cultural backgrounds. Each group met four times during the term, and discussed assigned topics by exchanging different cultural values and norms. Through the actual interaction with the classmates from different cultural backgrounds, students were able to experiment with what they learned from lectures, readings, the guest speaker, and the field trip. At the beginning, they might have felt uncomfortable communicating with the group members from a different culture due to different cultural values, norms, and communication patterns. After trying out a variety of intercultural communication skills that they had learned, they gained mutual understanding and felt more comfortable with and connected to each other. 


\section{Quantitative Method}

\section{Data collection.}

In the quantitative strategy, the Intercultural Development Inventory (IDI) was employed as an instrument. The inventory was conducted twice, once in the first week and once at the end of the course, as a pre- and posttest at an interval of 10 weeks. The current version (v.3) in both English and Japanese was available online. The website of the IDI and the assigned access codes for the IDI for the pre- and posttest were given to each participant so that s/he could go online and take the IDI individually outside class. I e-mailed each of the 23 consented participants with an individual password in order for them to go online and access to the IDI. The participants were asked to finish the inventories by the end of the first week of the class for the pre-testing and during the week after the class was over for the posttesting. As is explained in detail in the previous chapter, the IDI consists of a 50-item questionnaire with selected demographics, along with four open-ended contexting questions, all of which can be completed in about 20 to 30 minutes (Hammer, 2009). The open-ended questions helped capture the experience around cultural differences of the participants.

\section{Data analysis.}

The IDI profiles are saved online. I am a qualified administrator of the IDI, and had access with a password to all the group and individual profiles. No one else could access the data so that the participants' privacy was protected. As is written clearly on the consent from, I did not access the profiles until the final grades were submitted due to ethical issues. After the final grades were submitted, the individual profile results were 
analyzed. Each profile showed the developmental orientation by a score ranging from 55 to 145 . A higher score means the test taker is more interculturally sensitive.

First, in order to seek the answer to the first research question, "Is there a connection between an intentional intercultural course using Kolb's learning cycle and student intercultural sensitivity development?" the profiles were analyzed as a group. Comparing the profile results of the pre- and posttesting, I examined whether all the participants as a whole increased intercultural sensitivity and competence through the intentional intercultural course using Kolb's learning cycle. If the score increased, it would indicate that there seems to be a positive connection between the intentional intercultural course using Kolb's learning cycle and student intercultural sensitivity development.

Second, I compared the profiles of domestic American students and Japanese exchange students in order to seek the answer to the second research question: "How are these connections or patterns the same or different for American students and Japanese exchange students?" In order to examine and compare the two groups, I manually divided the individual profiles into two groups: American students and Japanese students. And then, I investigated if the IDI scores increased or not between the pre- and posttesting by group. If the results showed an increase, it would indicates that there seems to be a connection between the intentional intercultural course using Kolb's learning cycle and student intercultural sensitivity development. By comparing the two groups, if one group showed the increase to a higher degree than the other group, it would indicate that the former group seems to have a stronger connection between the 
intentional intercultural course using Kolb's learning cycle and student intercultural sensitivity development.

\section{Qualitative Methods}

The objective of using qualitative research methods was to reveal descriptions of participants' experiences, the underlying factors that explain what had been experienced. While the quantitative data sought the connection between the intentional course designed with Kolb's learning cycle and student intercultural sensitivity development, the qualitative research data uncovered how each aspect of the pedagogical strategies affected the students' intercultural sensitivity development. The qualitative data analysis answered the second subquestion: "How are the aspects of the intentional course design more or less effective for developing students' intercultural sensitivity?" Two qualitative methods, document analysis and interviewing, deeply examined each aspect of Kolb's pedagogical strategies to grasp how each aspect interacted with students' intercultural sensitivity.

After the course was over and grades were posted, I selected eight participants with the purposeful sampling strategies discussed below for the qualitative research methods. I conducted the eight interviews within one and a half months after the course was over when the participants' memories were still fresh. Document analysis of the same eight participants' reflection papers was conducted as well.

\section{Sampling strategies.}

I used purposeful sampling for the qualitative methods in order to select information-rich cases for insights and in-depth understanding about the research 
problem (Patton, 2002). Creswell (2005) defined qualitative purposeful sampling as "select[ing] people or sites who can best help us understand our phenomenon to develop a detailed understanding that might provide 'useful' information" (p. 203). Patton insisted that "purposeful sampling focuses on selecting information-rich cases whose study will illuminate the questions under study" (p. 230). More specifically, I used criterion sampling and theory-based sampling.

The logic of criterion sampling is "to review and study all cases that meet some predetermined criterion of importance" (Patton, 2002, p. 238). Merriam (1998) stated that "the criteria you establish for purposeful sampling directly reflect the purpose of the study and guide in the identification of information-rich cases"; therefore, "you say why the criteria are important" (pp. 61-62). To establish the criteria, I chose four participants from each group of students: the domestic American student group and the Japanese exchange student group. It is reasonable and beneficial to select an equal number of sampling from each group in such a unique case that consists of a class of one-half domestic students and one-half exchange students.

The other reason for the criteria is explained by the theory-based sampling strategy. Patton (2002) defined the theory-based sampling strategy as sampling "incidents, slices of life, time periods, or people on the basis of their potential manifestation or representation of important theoretical constructs" (p. 238). The IDI is designed based on the intercultural developmental theory that people develop intercultural sensitivity at the same time as their intercultural learning experience (Bennett, 1986). By collecting descriptive data from domestic and exchange students 
who enhanced their intercultural sensitivity to high and low degrees, I scrutinized their learning experience regarding each element of Kolb's pedagogical strategies and how each element impacted each student's intercultural sensitivity. Therefore, the qualitative research methods with the theory-based sampling strategy revealed what factors affected or did not affect the developmental process of students' intercultural sensitivity.

The sample size of eight participants selected by the criterion sampling and the theory-based sampling is rational, because "unlike survey research . . . in this type of research the crucial factor is not the number of respondents but the potential of each person to contribute to the development of insight and understanding of the phenomenon" (Merriam, 1998, p. 83).

\section{The original plan of sampling.}

The original plan was that by examining the IDI profiles, from each group I would select two students who most increased their assessment scores bytaking this course and the other two students who least increased their scores. In this case, I would have been able to examine similarities between the two participants with similar IDI scores in each group. After the final grades were submitted, I would have selected the eight respondents based on the sampling strategies discussed above. I would have contacted them via e-mail and asked for their availability for the interview. During the participant recruiting process, the participants were informed that some of them would be asked for an interview after their grades were submitted. It was also noted that participation was voluntary. If a respondent was unavailable, the next person fitting the 
criteria would have been selected. Thus, the sample selection would have continued until the number of participants became four from each group.

\section{The actual sampling.}

There were only nine students who completed both the pre- and postassessments online, the Intercultural Development Inventory (IDI), consisting of five domestic students and four Japanese exchange students. After the final grades were submitted, the researcher asked these nine students for an individual interview. Four domestic students and four Japanese students responded to accept the request.

\section{Interviewing.}

\section{Data collection.}

Once the eight participants were determined, I arranged the time and place with each respondent. The interviews took place at the group study room at the PSU library, which was quiet enough to audio record the interviews. I made sure it was a comfortable atmosphere for the respondent. I provided each participant with refreshments, such as a canned juice and snacks. I asked the respondents if they minded being audio recorded. Each interview took between 30 minutes and one hour.

For this research study I conducted a semistructured interview, in which "either all of the questions are more flexibly worded, or the interview is a mix of more and less structured questions" (Merriam, 1998, p. 74). As Appendix C shows, the interview consisted of four sections: participants' backgrounds, overall learning experience of the course, Kolb's four pedagogical strategies, and the course's influence on the participants' lives. The questions were carefully worded in order to elicit participants' perspectives on 
the topic. However, due to the semistructured interviews, I did not have to strictly follow the list in order, but used it as a guideline. This format allowed me to respond to the situations, fresh insights, and new ideas on the topic (Merriam). In fact, although it was not included in the original interview questions, later in the interview sessions I found it meaningful to ask the participants which learning dimension was the most effective in terms of developing intercultural sensitivity. This question was especially relevant in order to investigate the effectiveness of each learning dimension and to compare the American and Japanese participants regarding how differently they would have perceived it through their learning experience.

Probes, which are "questions or comments that follow up something already asked," were also used in order to gain more information by asking for more details, for clarification, or for examples (Merriam, p. 80). Some examples of probes used are "What do you mean?" "I'm not sure that I am following you," "Would you explain that?" "Give me an example," "Tell me about it," and "Take me through the experience." (Bogdan \& Biklen, 2007, p. 104).

The interviews with the four Japanese exchange students were conducted in the Japanese language, because I am also a Japanese native and it was more natural to speak our mother tongue with each other. It created a natural flow of conversation and an atmosphere of ease where the respondents could feel free to talk about their perspectives on the topic. Especially in this case, as the Japanese respondents had recently come to America and were able to articulate their feelings and perspectives in Japanese much 
better and more easily than in English as their second language. The list of interview questions in a Japanese translation is shown in Appendix D.

\section{Interviewer and respondent relationship.}

Bogdan and Biklen (2007) pointed out that "good interviews are those in which the subjects are at ease and talk freely about their points of view" and "produce rich data filled with words that reveal the respondents' perspectives" (p. 104). Yet it should be noted that "the interviewer-respondent interaction is a complex phenomenon" (Merriam, 1998, p. 87). Especially in this research study, the researcher-respondent relationship could also have been the teacher-student relationship. It was an ethical issue that I as the researcher could have held considerable power and control as a teacher, meaning "there is a danger of abuse" (Merriam, p. 213). Although the interviews took place after respondents' grades were submitted, they were likely to see me, the interviewer, as their teacher. There was a risk that the interview data might have become biased due to this factor. In order to reduce the risk of this problem, at the beginning of the interview, I assured to the respondents that grades were already submitted and this interview had nothing to do with their academic performance in the course, but that I was interested in the respondents' insights and perspectives regarding their intercultural learning experience as a researcher, not as a teacher. I also assured the respondents that their confidentiality would be strongly protected.

I also needed to keep this issue in mind all the time during the interviews, making sure that I shifted in roles from a teacher to a researcher. As Merriam (1998) mentioned, "being respectful, nonjudgmental, and nonthreatening" (p. 85) is key. Bogdan and Biklen 
(2007) advised giving the respondents your full attention and treating them "as the experts of what you are interested in finding out-how they think" (p. 106).

\section{Data analysis.}

"Interviewers have to be detectives, fitting bits and pieces of conversation, personal histories, and experiences together in order to develop an understanding of the informant's perspective” (Bogdan \& Biklen, 2007, p. 112). Merriam (1998) recommended postinterview notes in which researchers write their reflections immediately after the interview, including "insights suggested by the interview, descriptive notes on the behavior, verbal and nonverbal, of the informant, parenthetical thoughts of the researcher, and so on" (p. 88). I wrote postinterview notes because they allowed me to "monitor the process of data collection as well as begin to analyze the information itself" (Merriam, 1998, p. 88).

I transcribed all eight interviews by myself. Unlike hiring someone to transcribe the audio data, by transcribing them by myself, I was able to get familiar with my data and add nonverbal cues to the verbal transcription. However, transcribing eight hourlong interviews was an arduous task. I adopted a strategy that Bogdan and Biklen (2007) recommended, which is "to transcribe the first interviews more or less completely. . . and then narrow what you transcribe in later interviews" (pp. 132-133). As the study went on, I had a better idea about my focus so that I left out some materials that did not address my concerns. The postinterview notes and transcriptions were stored in a locked safe place only I could access so that the participant confidentiality was safeguarded. 
Once the transcripts were ready, I analyzed the text data by the coding process. The rationale of coding for this research analysis is discussed in the next section of the document analysis. I implemented three coding processes. At the first coding, in reading through the transcriptions and dividing the interview transcripts into segments, I sought descriptions that indicated intercultural awareness or sensitivity and cultural identity development. I then typed up the descriptions with direct quotes by participants. For example, if a participant described her/his intercultural sensitivity most frequently when s/he was talking about the intergroup discussions, it indicated that the aspect of Actual Experimentation in Kolb's learning cycle seemed to have made the most impact on this participant's intercultural sensitivity. At this point, I translated the Japanese transcriptions into English.

In the second coding process, by reading through the descriptions, I found patterns or categories that illuminated participants' intercultural sensitivity. Then I restructured the patterns by Kolb's four learning dimensions. For example, if the dimension of Abstract Conceptualization had more patterns with richer descriptions about intercultural sensitivity by more participants than the other dimensions, it indicated that the aspect of Abstract Conceptualization in Kolb's learning cycle seemed to have made more impact on students' intercultural sensitivity.

In the third coding process, by reading the patterns more thoroughly I came up with five common areas of intercultural sensitivity development across the four dimensions. Eventually, the five areas were narrowed down to three main areas that 
illuminate participants' intercultural sensitivity stages through learning with the four learning dimensions.

\section{Document analysis.}

\section{Data collection.}

Although the selected eight participants' reflection papers were to be analyzed, all the 23 consented participants were informed that their writing materials for the course requirements would be arbitrarily analyzed, meaning that they would not know whose and which writing materials would be chosen for the research data. The writing requirements included four reflection papers (of one to two pages) and a final paper as well as a daily report at the end of every class. In this way, the participants worked on all the writing requirements with the equal amount of effort, even though only the four reflection papers were chosen for the research data. The reflection papers were about the four key elements of the course content: (1) readings, (2) the experience of the tea ceremony, (3) the bicultural guest talk, and (4) the culture-exchange group discussions, all of which were designed with the four pedagogical strategies. I made photocopies of the reflection papers of all the 23 participants before returning the papers to them and kept the copies as the research data in a safe place only I can access.

\section{Data analysis.}

I read through the eight participants' reflection papers before the interviews so that I was able to use some information during the interview sessions. For example, one participant wrote about different concepts of patience across the two cultures, and I asked 
him to explain his perspective on it in the interview. More thorough analysis of the reflection papers was done after the interviews.

Qualitative data analysis is a process of developing a coding system by combining, reducing, and interpreting the data in order to make sense out of it (Bogdan \& Biklen, 2007; Merriam, 1998). The purpose of this research study was to test on the effectiveness of Kolb's four pedagogical strategies for college students' intercultural sensitivity development. This study applied phenomenological analysis as a conceptual framework that drives the qualitative data analysis. The aim of the phenomenological analysis was to capture "the essence or basic structure of a phenomenon" (Merriam, p. 158). The phenomenon in this research study was the students' intercultural sensitivity development. A technique of phenomenological analysis is trying to see the phenomenon from multiple angles or perspectives. Through coding the descriptions of each aspect of Kolb's learning cycle that the participants experienced, I sought "the underlying and precipitating factors that account for what is being experienced" (Merriam, p. 159) —in other words, the student's intercultural sensitivity development.

Creswell (2005) defined coding as "the process of segmenting and labeling text to form descriptions and broad themes in the data" (p. 237). The coding process started with reading through the text data, which in this case were the reflection papers of participants, and making sense out of them, namely grasping the subjects' ways of thinking (Bogdan \& Biklen, 2007; Creswell, 2005). While reading through the data, I searched for repeating words, phrases, regularities, and patterns as well as topics the data covered. Creswell described this process as dividing the text into segments of 
information. The next step was to "write down words and phrases to represent these topics and patterns," which became coding categories (Bogdan \& Biklen, p. 173), or to "label the segments with codes" (Creswell, p. 273). The subsequent step was to scrutinize codes for overlap and redundancy, and categorize codes into broad themes (Creswell). Creswell pointed out that "this is an inductive process of narrowing data into a few themes" (p. 273).

In dividing the text into segments, I sought descriptions that indicated intercultural sensitivity and cultural identity development. At the point of coding the reflection papers, there were already three patterns that had emerged from the interview data, and I placed the segments into these three patterns.

\section{Validity and Reliability}

It is important to ensure validity and reliability in order for the research study to produce trustworthy and meaningful findings. Internal validity, according to Merriam (1998), has to do with the meaning of reality and, more specifically, "the question of how research findings match reality" (p. 201). Notable perspectives on assessing validity are that "(1) (research) 'data do not speak for themselves: there is always an interpreter, or a translator' (p. 149); (2) that 'one cannot observe or measure a phenomenon/event without changing it ...'; and (3) that numbers, equations, and words 'are all abstract, symbolic representations of reality, but not reality itself' (p. 150)" (Ratcliffe, 1983, as cited in Merriam, 1998, p. 201-202). From this viewpoint, reality, especially for qualitative research, is assumed to be "holistic, multidimensional, and ever-changing; it is not a single fixed, objective phenomenon waiting to be discovered, observed, and measured" 
(Merriam, p. 202). Reliability in the traditional sense refers to "the extent to which research findings can be replicated" (Merriam, p. 205). This research study, which involved qualitative inquiries, paid more attention to the collected data and the results being consistent and dependable rather than being concerned about whether "outsiders get the same results" (Merriam, p. 206). I used three strategies to enhance internal validity and reliability: triangulation, peer examination/audit trail, and the researcher's position.

Merriam (1998) defined triangulation as "using multiple investigators, multiple sources of data, or multiple methods to confirm the emerging findings" (p. 204); "especially in terms of using multiple methods of data collection and analysis, triangulation strengthens reliability as well as internal validity" (p. 207). This study conducted an inventory, document analysis, and interviews in order to establish internal validity and reliability.

A peer examination or audit trail refers to asking colleagues to examine the findings of a study by following the trail of the researcher as s/he describes in detail "how data were collected, how categories were derived, and how decisions were made through the inquiry" (Merriam, 1998, p. 207). I went through this process with my committee members. The researcher's position refers to "clarifying the researcher's assumptions, worldview, and theoretical orientation at the outset of the study" (p. 205), including "his or her position vis-à-vis the group being studied, the basis for selecting informants and a description of them, and the social context from which data were collected" (LeCompte 
\& Preissle, as cited in Merriam, 1998, pp. 206-207). I have clarified all these points in this paper.

\section{Profiles of Research Participants}

This section describes each participant with her/his brief cultural background and intercultural experience based on the IDI contextualizing questions and the interviews. In the interest of securing the participants' confidentiality, pseudonyms are used in this paper.

Mark

The first American participant was Mark. He is half Hispanic, one quarter German, and the other quarter French Canadian. Despite his mixed ethnic background, he does not think that it has affected his identity, stating, "because both of my parents are fairly Americanized, ... I don't really identify particularly strongly with any of them." He mentioned that only his mother was somewhat in touch with her German heritage, celebrating German holidays and serving German meals. Because of that, he feels a little more oriented toward being German. He could even speak German when he was little.

Mark shows great interest in Japanese language and culture. He learned Japanese in high school and went to Japan for two weeks through the Japanese exchange program at his high school. He stayed with a host family in the first week and traveled around the country in the second week. He said he loved Japan and wanted to study the language by himself and to go back to Japan to teach English for a couple of years.

Mark's other ambition is to go to a medical school and become a doctor. He is currently taking science classes as prerequisites to get into medical school. He has also 
done some shadowing practice in the medical field. He seems to see the world based on his vision of being in the medical field.

\section{Cary}

The second domestic participant was Cary. She is majoring in International Studies. She is second generation Asian (Thai) American. She was born in California and moved to Portland when she was 16. She considers her dominant culture to be American, though she also has a strong feeling of her heritage culture, saying that she is thoroughly immersed in Thai culture at home. She has been to Thailand several times to visit her grandparents, aunts and uncles. She mentioned that she observed a lot of cultural differences and identified more with American culture there.

Due to her family background and spending her childhood in a culturally diverse community in Los Angeles, Cary seems to have been greatly aware of diversity and cultural differences. She explained how different California and Oregon are; Portland is much less diverse than Los Angeles; more specifically, the majority of people are Caucasian in Portland. She claimed that she has been asked if she could speak English in Portland because she is Asian.

Regarding further intercultural experience, Cary is studying Chinese, has traveled abroad, and her family has hosted a few international students. She not only has an intercultural background but also seems to be willing to be in contact with different cultures. 


\section{Jake}

The third domestic participant was Jake. He is first generation Cambodian American. Since he was born and raised in America, he considers American culture to be his dominant culture, but his entire family is Cambodian, so that is where his heritage and background originate.

Jake has never been back to his roots, to Cambodia, even though his extended family still lives there and his mother sometimes goes to visit them. He said he considered his extended family in Cambodia strangers rather than his family because they had never had been around him and so he doesn't know them. He thinks there is no reason to go to Cambodia despite his mother's will. However, it was interesting for him to say, "I might go to Cambodia to visit her family, I might not do it for myself, but I might do it for her." This is a collectivistic viewpoint. It seems that he has grown up in the mixed background of the mainstream and the heritage culture with his immediate family.

We're more influenced in the American way, but you know there are things we still do, like family is the most important thing and always put family above all else. They still stress the importance of education, well they leave it up to us to decide what we want to do in our future, and they just stand back and kind of just support us and all that.

Jake calls this situation "integrated culture." With people in his grandparents' generation, he becomes more Cambodian, regarding how he speaks and how he behaves.

Around the grandparent generation, we tend to become more Cambodian, try to be more respectful, because they are the only ones that aren't really integrated because they can't speak English or any of that. So all the parent generation kind of act as mediators and we kind of try to show respect and not offend them anyway, so we're kind of more Cambodian, acting more Cambodian toward the older generations. 
Although Jake has never left America, he grew up with a Cambodian family, which is an intercultural environment, and he seems to be aware of and sensitive to different cultures.

I've never left the country, so my prior experience is limited, but see it as kind of American born with a Cambodian family, as say it's kind of a cultural experience. Because I can see both views, the American view and the Cambodian view, I can adjust to either one.

Jake stated that even before taking the course he has always listened more than talked when interacting with people from different cultures, because he does not want to offend them.

I've always done that, especially when I'm dealing with people who are foreigners, or who aren't used to this country or haven't been here long. If I have ever encountered anyone like that, I tend to be careful with my words or actions.

\section{Amy}

The fourth American participant was Amy, who was born and raised in the Pacific Northwest, which is her main cultural influence, she said. She is a quarter Mexican and she said she would consider this a part of her heritage. She feels this way even more after she traveled through Mexico when she was in the $10^{\text {th }}$ grade and visited the village where her extended families live. Traveling to Mexico also opened her eyes to the international world and inspired her to want to go to other foreign countries.

Amy recalled that the trip to Mexico was "a cool experience." Her Mexican family members all have darker skin and she does not look like them because she is tall and her complexion is light. So she stood out when she visited them in Mexico, but it was great that they accepted and welcomed her as a part of their family. Since this trip, 
she has intended to do as much international traveling and have as many intercultural experiences as possible. Thus, the positive experience of her trip to Mexico became her great motivation for more intercultural experience in the future.

For a person who has really never gone anywhere, it's a matter of opening your eyes. Experiencing something that you've never had before, like being in another place, is so different from your day-to-day life. You may feel sort of displaced because everything is foreign, but it's recognizable, like it's different. It's a strange feeling. Even though I think that's naturally uncomfortable because it takes us out of our comfort zone, it's ultimately a positive and valuable thing.

Amy belonged to an intercultural club in high school, where she planned and organized the annual intercultural night. At the event, they had different types of food and people came to dance and do other activities. She said she enjoyed planning and organizing these events and learning about different cultures.

\section{Nao}

The first Japanese participant was Nao. She was born and raised in Tokyo. She has played soccer since she was in grade school, and according to her the soccer culture had a strong impact on forming her identity. For example, she learned how to do team play, which relates to how to communicate with other people. She likes to travel abroad. Since she was little she has traveled to nearly 10 countries mostly with her family and sometimes with her friends. She has wanted to study abroad since she was in middle school, and her dream came true this time, thanks to moral and financial support from her parents. Nao made an interesting comment on the difference between her previous experience of traveling abroad and her current experience of studying abroad.

I've realized that Japan is not normal since I came to the U.S. When I traveled abroad, I glanced at the foreign countries and observed the cultural differences by 
the Japanese standard. I thought the foreign cultures were strange, but now I think Japanese culture can be strange.

This is a good example of the transformation from an ethnocentric to an ethnorelative viewpoint. More specifically, she used to use the Japanese standard and now has an ethnorelative standard, viewing Japanese culture as one of many cultures in the world.

\section{Masako}

The second Japanese participant was Masako. She was born and raised in the countryside near Tokyo. She described herself as typically Japanese. She and her family went to New York City as her first trip abroad when she was in high school. They visited her older brother, who was studying at college there. She recalled that she had had culture-shock about how culturally and ethnically diverse it was. As another previous intercultural experience, she went to Vancouver, Canada, for a three-week summer program through her university. She stayed with a host family. She enjoyed her stay in Vancouver so much that Canada became and has remained her favorite country ever since. She remarked that unlike her experience in New York, she felt comfortable and included in the diverse community in Vancouver.

Masako majors in Intercultural Communication at Waseda University. She has wanted to study abroad and was excited to finally come to the States. Her older brother seems to have given Masako intercultural inspiration, as he went to New York City as a one-year exchange student when he was in college and now is a graduate student in India.

\section{Miyuki}

The other Japanese participant was Miyuki. She is half Chinese and was born and raised near Tokyo. She identifies mostly as Japanese and only about $10 \%$ with her 
Chinese heritage, even though she went to China to see her grandparents once every couple of years in her childhood. She went to high school at the Canadian international school in Dalian, China, for three years. She learned English and Chinese there. She recalls that though it sounds strange she observed Chinese culture as similar to Japanese culture when she was in China. She experienced great culture-shock when she encountered the Chinese peoples' anti-Japanese behaviors toward the historical event, called the Nanking Massacre in 1937. On the same day of the event every year, Chinese students take a class about this incident and watch brutal films. One year Miyuki was there, the Japanese flag was torn at her school. Other than that, she enjoyed her study abroad experience in China. She made a lot of Korean friends there and got interested in the language and culture. Then she took a Korean language course at Waseda University.
Aki
The fourth Japanese participant was Aki. She was born and raised in the countryside near Tokyo. Because both of her parents and her maternal grandparents were teachers, she feels that she was raised strictly. Her family is international and has hosted some international students from New Zealand and Italy. She traveled to Thailand and Singapore with her family when she was in grade school. Yet her most memorable intercultural experience was her direct interaction with her English teacher from a foreign country when she was in grade school. Aki remembers that the teacher talked to her very gently, even though she could not understand what she said. This good first impression of foreigners greatly interested her in foreign countries. 
When she was in junior high school, she went to a small town in Italy with a youth group from her hometown and stayed with a host family for a few weeks. She was surprised at the different life style where people including children in the town go out and gather to have fun late at night. She mentioned, "Everybody was still up at midnight; it would never happen in my hometown. I was told to go to bed by 10 p.m. So I enjoyed their lifestyle so much there."

She likes traveling abroad and has been to multiple countries since she entered the college. Aki has played soccer since she was in grade school and now is majoring in Sports Science at college. She wants to have a profession in this field in the future.

\section{Conclusion}

This chapter discussed the methodology of the research study with the intercultural course, which employed Kolb's four pedagogical strategies for the development of intercultural competence. The purpose of this study is to investigate the effectiveness of Kolb's learning dimensions as an intercultural course design for students' intercultural sensitivity development and to understand students' learning experience through this intentionally designed course across different cultural groups. The course uniquely consisted of one-half domestic American students and one-half Japanese exchange students. This research study examined both domestic students' and Japanese students' intercultural learning experiences and developmental processes through the course. This study adopted explanatory mixed methods, by conducting Hammer's (1998) Intercultural Development Inventory (IDI) and using qualitative assessment methods, including individual interviews and document analysis. In the mixed methods 
explanatory design, quantitative data was collected primarily, and then the findings were refined through in-depth qualitative exploration. The qualitative data added in detail individual participants' learning experiences and developmental processes as well as their cultural and social backgrounds. Therefore, the triangulated data maximized research outcomes and achieved the best understanding of the research problem. 


\section{Chapter 4}

\section{FINDINGS}

This chapter will discuss the findings of the study of teaching and learning for intercultural sensitivity by examining the students' learning experience in an intentional intercultural course designed with the four pedagogical strategies associated with Kolb's learning cycle. The eight participants' triangulated data, namely the IDI scores, interviews, and reflection papers, were analyzed for this research study. The Intercultural Development Inventory (IDI) scores of eight participants, including four Americans and four Japanese, were analyzed by the pre- and postassessments in order to reveal the relationship between the input and the output/outcome of the participants' development of intercultural sensitivity by taking the intentional course designed with Kolb's four pedagogical strategies. These participants' reflection papers and interviews were then analyzed in order to provide better understanding of how each pedagogical strategy impacted the participants' learning experience and the process of increasing intercultural sensitivity across the different participant groups, namely American and Japanese. The participants' learning experience is contextual and always intertwined with their personal life experience. The follow-up qualitative inquiry, which included the document analysis and the interviews, added more detailed and specific information to assessment scores.

\section{The Intercultural Development Inventory (IDI) Scores}

Comparing the pre- and postassessments, as Table 1 shows, overall all eight participants reached the stage of Minimization or higher at the posttest, whereas at the 
pretest some participants were in the Polarization stage reflecting an "us and them" judgmental viewpoint toward cultural differences. Minimization is a transitional orientation toward cultural differences and commonalities (Hammer, 2011), which is laid out twice as wide as the other stages in the developmental continuum; in other words, Minimization is from 85 to 115,30 points wide, whereas the other stages are each 15 points wide. Therefore, this reflects that it takes longer to get through this stage. Minimization is the essential phase which people go through during their intercultural experiences. Because the transformation of their world view from ethnocentric to ethnorelative is happening at this stage, the process takes a long time.

Table 1. Participants' IDI Scores, Stages, and Gaps Between Pre and Post Assessments

\begin{tabular}{|l|l|l|l|l|l|}
\hline & $\begin{array}{l}\text { Pretest } \\
\text { Scores }\end{array}$ & Pretest Stages & $\begin{array}{l}\text { Posttest } \\
\text { Scores }\end{array}$ & Posttest Stages & $\begin{array}{l}\text { Gaps } \\
\text { between } \\
\text { Pre \& Post }\end{array}$ \\
\hline Aki (J) & 72.04 & $\begin{array}{l}\text { Polarization } \\
\text { (Reversal) }\end{array}$ & 107.66 & Minimization & $\mathbf{+ 3 5 . 6 2}$ \\
\hline Nao (J) & 95.03 & Minimization & 114.09 & $\begin{array}{l}\text { The cusp of } \\
\text { Acceptance }\end{array}$ & $\mathbf{+ 1 9 . 0 6}$ \\
\hline Miyuki (J) & 80.83 & $\begin{array}{l}\text { Polarization } \\
\text { (Reversal) }\end{array}$ & 92.10 & Minimization & $\mathbf{+ 1 1 . 2 7}$ \\
\hline Mark (A) & 74.43 & $\begin{array}{l}\text { Polarization } \\
\text { (Defense) }\end{array}$ & 85.42 & Minimization & $\mathbf{+ 1 0 . 9 9}$ \\
\hline Amy (A) & 109.48 & $\begin{array}{l}\text { The cusp of } \\
\text { Acceptance }\end{array}$ & 117.86 & Acceptance & $\mathbf{+ 8 . 3 8}$ \\
\hline Masako (J) & 82.95 & $\begin{array}{l}\text { The cusp of } \\
\text { Minimization }\end{array}$ & 87.05 & Minimization & $\mathbf{+ 4 . 1}$ \\
\hline Jake (A) & 87.19 & Minimization & 91.15 & Minimization & $\mathbf{+ 3 . 9 6}$ \\
\hline Cary (A) & 98.94 & Minimization & 94.51 & Minimization & $\mathbf{- 4 . 4 3}$ \\
\hline
\end{tabular}

$*(\mathrm{~J})=$ Japanese participants; $(\mathrm{A})=$ American participants.

**The order of the participants is by the score gaps between Pre and Post from the greatest to the least.

Examining the scores across the pre- and posttests by individuals, seven participants out of eight got higher scores in the posttest, and six of these participants 
moved their developmental stages up to more advanced stages. In order to protect the participants' identities, pseudonyms are used. Aki increased her scores the most of all the participants, by 35.62 points, shifting from the Polarization (Reversal) stage to the Minimization stage, which is close to the Acceptance stage. The second most improved was Nao with an increase of 19.06 points, shifting from Minimization to the cusp of Acceptance. The third was Miyuki with an increase of 11.27 points, shifting from Polarization (Reversal) to Minimization. The fourth was Mark with a 10.99 point increase, shifting from Polarization (Defense) to Minimization. The fifth was Amy with an 8.38 point increase, shifting from the cusp of Acceptance to Acceptance. Masako increased her score by 4.1 points, shifting from the cusp of Minimization to Minimization, followed by Jake with a 3.96 point increase within the Minimization stage. Cary is the only one who lowered her score, with her score decreasing by 4.43 points. Three out of the four Japanese participants improved their intercultural sensitivity more than the American participants, and these three increased their scores remarkably.

\section{The Findings From the Qualitative Data}

The analysis of the interview data and the reflection papers yielded rich information about how each participant perceived the four learning dimensions in the intercultural course as it contributed to their development of intercultural sensitivity and competence. I excerpted the meaningful topics related to my research questions, seeking primarily (1) the connection between the four dimensions of Kolb's learning cycle and student intercultural sensitivity development, (2) the similarities and differences of these connections or patterns for American students and Japanese exchange students, and (3) 
the perceived effectiveness of each pedagogical dimension for developing students' intercultural sensitivity.

This section will report the interview data, starting with the most effective learning dimensions, highlights and achievements in the course, Kolb's four learning dimensions, and lastly, application to real life as the outcomes of the intentionally designed intercultural course. Kolb's four learning dimensions for this course consisted of (1) theory-based materials as Abstract Conceptualization (AC), (2) tea ceremony as Concrete Experience (CE), (3) bicultural guest talk as Reflective Observation (RO), and (4) intergroup discussions as Active Experimentation (AE). The report of each interview section includes several significant patterns that emerged. It should be noted that I translated the quotations of the Japanese participants from Japanese to English and that pseudonyms are used for the guest speaker as well as the participants. The detailed interview questions are listed in Appendices C and D.

The findings from the reflection papers further added to Kolb's four learning dimensions. The instructions for the reflection paper assignments are shown in Appendix E. The reflection papers amplify the interview findings, because the reflection papers offer a different medium that allows for deeper reflection. While you can get anecdotes about participants' learning experience from the interviews, you can perhaps grasp more fully what they learned cognitively from the reflection papers, because when they wrote the papers, they had to think and systematically put their thoughts and opinions together. Another reason why the reflection papers can enrich the findings is because some 
participants may be better at journaling or more comfortable writing out their feelings and opinions than talking.

\section{The Most Effective Learning Dimensions: Japanese vs. Americans}

The answers to the interview question "Which dimension do you think was most helpful for your intercultural learning?" indicate the most effective learning dimension(s) they perceived. Some participants immediately affirmed one dimension, while the others had a hard time deciding on one and ended up choosing all the dimensions.

When Masako was asked which learning dimension made the most impact on her intercultural learning, she mentioned the tea ceremony experience first. She commented that it was beneficial for her to discover her own culture and her cultural identity. Yet, she added that she enjoyed learning through the group discussions and was inspired by the guest talk and learned a lot from the lectures and class discussions. Thus, Masako equally but differently learned from all the four dimensions.

Amy is the only American participant who claimed that all four dimensions equally helped her learn about intercultural sensitivity. This could be connected to the fact that she is the only one who reached the Acceptance stage. She said:

I think I would say that's hard. I think that it's divided to work all together, and then they are all linked and one sort of naturally guides in together or you become more proficient in one and all of them, so it's hard to choose one.

As Table 2 shows, it is notable that Japanese and American participants perceived the most effective learning dimensions quite differently. The Japanese perceived theories that they learned through the readings and lectures and the tea ceremony experience as the two most effective learning dimensions, while the Americans perceived the 
intergroup discussions as the most effective. Table 2 also shows that the participants' perceptions of the most effective learning dimensions differ from their results of Kolb's learning style preferences. Thus, the findings show little connection between perceived learning styles and preferred learning styles.

Table 2. The Most Effective Learning Dimensions Perceived by the Participants and Participants' Preferences of Kolb's Learning Styles

\begin{tabular}{|c|c|c|c|}
\hline & & $\begin{array}{l}\text { The Most Effective Learning } \\
\text { Dimensions (Perceived) }\end{array}$ & $\begin{array}{l}\text { Kolb's Learning Style Preferences } \\
\text { (Assessment Results) }\end{array}$ \\
\hline \multirow{4}{*}{ 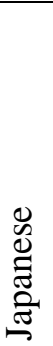 } & Aki & Theories (AC) & $\mathrm{AE}=38 ; \mathbf{A C}=\mathbf{3 1} ; \mathrm{RO}=29 ; \mathrm{CE}=22$ \\
\hline & Nao & Tea Ceremony (CE) & $\mathrm{AC}=39 ; \mathbf{C E}=\mathbf{3 4} ; \mathrm{RO}=25 ; \mathrm{AE}=22$ \\
\hline & Miyuki & Theories (AC) & $\mathrm{RO}=39 ; \mathbf{A C}=\mathbf{3 2} ; \mathrm{AE}=32 ; \mathrm{CE}=17$ \\
\hline & Masako & Tea Ceremony (CE) & $\mathrm{RO}=47 ; \mathbf{C E}=\mathbf{2 8} ; \mathrm{AC}=25 ; \mathrm{AE}=20$ \\
\hline \multirow{4}{*}{ 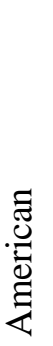 } & Mark & Intergroup Discussions (AE) & $\mathrm{AC}=43 ; \mathbf{A E}=\mathbf{4 0} ; \mathrm{RO}=23 ; \mathrm{CE}=14$ \\
\hline & Amy & All & $\mathrm{AE}=36 ; \mathrm{RO}=33 ; \mathrm{AC}=31 ; \mathrm{CE}=21$ \\
\hline & Jake & Intergroup Discussions (AE) & $\mathrm{RO}=46 ; \mathrm{AC}=29 ; \mathbf{A E}=\mathbf{2 2} ; \mathrm{CE}=19$ \\
\hline & Cary & Intergroup Discussions (AE) & $\mathrm{RO}=37 ; \mathbf{A E}=\mathbf{3 6} ; \mathrm{CE}=27 ; \mathrm{AC}=20$ \\
\hline
\end{tabular}

*AC=Abstract Conceptualization; $\mathrm{CE}=$ Concrete Experience; $\mathrm{RO}=$ Reflective Observation; $\mathrm{AE}=$ Active Experimentation

**The order of Kolb's learning style preferences listed for each participant is according to the scores, arranged from the greatest to the least.

***The bold preference for each participant reflects the most effective learning dimension $\mathrm{s} / \mathrm{he}$ perceived.

\section{Highlights and Achievements in the Course}

First, as to the overall learning experience of the course, I asked participants about (1) the highlight of their learning experience in this course, (2) the significant achievements of taking this course, and (3) how this course helped them improve their intercultural sensitivity. The highlight of the course reflected each participant's 
perceived learning dimensions that s/he thought most effective. Moreover, several patterns emerged. Some are similar and others are different across Japanese and American participants. This section will discuss the main patterns that emerged after compiling the answers to these three questions.

\section{Understanding cultural basic assumptions.}

As is explained in Chapter 2, the cultural iceberg analysis with 10 dichotomous orientations of basic assumptions is the core theory and method for the practical cultural analysis that students have the chance to learn and practice throughout the course. It clearly has a strong impact on participants' learning experience. Half of the participants, including two Japanese (Miyuki and Aki) and two Americans (Amy and Cary) actually mentioned this particular theory and method in helping them uncover cultural assumptions.

The highlight of Miyuki's learning experience in the course was an a-ha moment of a deeper understanding of the other culture as well as her own culture by learning how to analyze cultures with the iceberg model. Before taking this course, she was naïve about American culture. She said:

Right after I came to America, I couldn't understand Americans at all, such as why they say so directly what they think. For example, when I asked an American friend if I can invite our mutual friend to her party, the American friend said, "I don't like her, so don't invite her." I was kind of shocked and worried if all Americans are mean.

After she learned the cultural concept of basic assumptions, she started to understand why Americans' behaviors and communication patterns are so different from hers. She said:

At the beginning of this course, we learned about Basic Assumptions. When I looked at the list of the basic assumptions, listening to the explanation with some 
examples, I got it. I mean all the mystery was solved, like it's not that they are mean, and I don't have to worry about it. I still remember the moment when I got it.

Similar to Miyuki's experience, by learning the cultural iceberg analysis, Aki came to think deeply about the cultural differences, such as Americans' behavior or communication styles, without judging it as positive or negative. She stated, "I didn't like the direct speaking style of Americans before. But now I can understand that it is a part of the culture and I'm okay with it."

In terms of improving intercultural sensitivity, Amy said it was beneficial to learn about the basic assumptions in the cultural iceberg model.

The iceberg thing is a cool way to look at it [another culture], so not just having an experience or saying you got the basic assumptions of the culture, but putting them together and seeing how it's seen from the base to the roof all the way up the behavior and the surface sort of thing, just being able to see the step-by-step process was helpful and then I think it's the way that I would be inclined to think of culture in the future.

According to Cary, the significant achievement of taking this course was in getting to know her bicultural background more deeply. First, she talked about her continuing struggle, growing up in a bicultural environment.

I think I grew a lot as a person. I got to know myself. One of the things I struggle with in my own daily life is my parents because they're from a different culture and they have different expectations, but they are raising me in American culture. When I was growing up, there were two cultures; basically, when at home we had Thai culture and American culture outside, which are so different. My parents want me to basically study hard and get good grades and all that, just like study, study, study, school work, and academics. In American culture, you can have balance, like academics and maybe sports or something else.

After learning the cultural iceberg analysis and basic assumptions in this course, Cary understands what is going on in both cultures. 
Now I understand why my parents do that and different things that they do in both cultures. When we did the cultural iceberg analysis chart with the cultural basic assumptions, values, and beliefs, that helped me understand this is why they do it. I really liked that because I'm a very visual learner and I like to look at pictures and graphs and things like that. So that really helped me put it all together, yeah.

\section{Developing cultural self-awareness.}

Cultural self-awareness, or self-discovery of one's own culture, was one of the overall objectives in this intercultural course. All four Japanese and one American (Cary, mentioned above) talked about their growing cultural self-awareness as the highlight of their learning experience.

The highlight of Nao's learning experience in the course was discovery of her own culture by comparison to the other culture. She realized that the ordinary things for her were not ordinary in the other culture. For example, she learned from her classmates' presentations that such small things as vending machines or the coming-of-age ceremony in Japan were unique for Japan.

I learned about my own culture through this class. I thought I knew it, but I realized that I didn't truly know it until I compared it to the other culture. Before taking this class, I saw things by the Japanese standard or my standard based on the Japanese background. But now I learned that people have different standards and perspectives based on individual and cultural backgrounds.

Miyuki also realized things about her own culture by learning cultural differences

between the two cultures.

I see the differences of Japanese and American behaviors. Now I can understand there are reasons behind all of them and I can explain even why I do things in certain ways as well as why Americans do such things. I used to see my culture from inside when I was in Japan, but I came to be able to see it from the outside, like more objectively. 
Nao and Miyuki became able to see their own culture more objectively rather than subjectively, which is a great shift of worldview from ethnocentric to ethnorelative.

After learning about cultural differences, Aki started to think about her own cultural identity.

Comparing the two cultures, I've realized how Japanese I am. Actually I don't know if I should categorize myself as "Japanese." I never thought like this when I was in Japan. I thought I was an ordinary person, who likes what other people like and does what other people do. But leaving my own country, I discovered my identity, like who I am.

Cary reported that the highlight of her learning experience in this course was to have the Japanese students in class. She found it interesting to see how the Japanese students perceived American culture. She mentioned that she had learned about her culture, which is American culture in this case, by learning the perspectives of the Japanese students through intergroup discussions. Thus, Cary developed her cultural self-awareness through intergroup interaction.

\section{Understanding through intergroup interaction.}

Interestingly, while all four Japanese participants mentioned cultural selfawareness as the highlight, all four American participants mentioned intergroup interaction as the highlight.

Mark mentioned that the highlight of his learning experience in this course was the hands-on learning, such as interacting with the Japanese exchange students and trying to apply what he learned in the course to facilitate the interaction with them. More specifically, he stated that he learned different communication styles, such as high and 
low contexts, which he could keep in mind when he would communicate with people from other cultures.

Amy mentioned that the highlight of her learning experience in the course was the intergroup interaction with Japanese students. She repeated positive words about the experience, such as "cool" twice, "enjoy" or "enjoyable" three times, "a great deal" twice, and "useful" and "effective" once. She generally enjoys learning about different cultures and comparing cultures, because doing so is useful and effective, and she said this course helped her to do so. She said, "I feel like I learned a great deal, and it was cool to see the things that we learned about in the course reflected in interactions that we had because so many of the things were so true."

Jake mentioned that he liked the culturally mixed students in class and enjoyed learning different perspectives from each other.

The best learning experience was actually interacting with the Waseda students because I've had some Japanese exchange students in the class before here at PSU ... but not to the extent of this class, over half was Japanese. ... The more foreign students there are, the more different perspectives there are, so you can get not only the majority of the different culture, but you can also get their own like multiple personal viewpoints of what they see in their own culture as well as the foreign one, like our U.S. culture, so I guess that added to it because of the number [of the Japanese students], it's more possible to learn various views.

Jake's comment above shows his awareness of and sensitivity to the other culture. He mentioned again how beneficial the actual intergroup interaction in class was for his learning experience.

I kind of already knew [the cultural differences] in the back of my head, but then I didn't really believe it until I actually heard it from the students themselves, because the best way to learn the culture is to hear it from someone from that culture. So that made me actually believe and understand why they see things that way. 


\section{Developing intercultural sensitivity.}

A few participants talked about their achievements through this course in terms of intercultural sensitivity development. Miyuki's new knowledge of cultural differences and self-discovery through the course fostered her intercultural communication skills.

I used to look at only behaviors, like Chinese people are sometimes cold to Japanese or Americans talk directly. I thought I understood their cultures, but it was very superficial. But after I took this course, I understood that the American directness comes from their individualism and they value the directness. So I got that it's okay for me to speak directly to Americans because it's valued. I thought I knew it before, but it was just imitation, like if they do so, I'll do so, but without understanding their value. Now I know it, so I can be direct but not rude.

Amy mentioned that her significant achievement in the course was being able to suspend her own cultural perspectives and to "improve the ability to build empathy to take on the perspective culture in order to facilitate communication and better understanding of another person." In other words, she gained the ability to see things through others' lenses and to understand their perspectives.

Cary's learning experience in this course helped her understand not only her bicultural background, namely her heritage and mainstream cultures, but also the other cultures, especially Japanese culture.

So before I just had contact with other cultures, but I was seeing them doing things differently from me. But I didn't understand why they did it. Like when I went to Japan for four or five days, it was really really different, and I was just wondering why they did some of the things in the way they did, like they were very quiet. Now I understand. So it (this course) helped me look back at my past experiences and understand why they did it. And now I can, instead of stereotyping or judging people before I get to know them, I can understand like why they do what they do. 
Cary was able to apply what she learned in class to her bicultural background and intercultural experiences in understanding each respective culture more deeply.

In sum, in terms of the first category, understanding basic cultural assumptions, half of the participants, two Japanese and two American participants, thought that understanding this core theory was fundamental in learning intercultural communication. The second category, developing cultural self-awareness, occurred mainly for Japanese participants through the intercultural learning experience. The third category, understanding through intergroup interaction, was the common highlight for American participants of their intercultural learning in this course. The last category, developing intercultural sensitivity, was reported by one Japanese and all four American participants. They perceived that they achieved great skills in intercultural communication by applying new knowledge to intercultural contexts in participants' actual lives.

\section{Kolb's Learning Dimensions and Intercultural Sensitivity Development}

After analyzing the sections of Kolb's four learning dimensions in the interview data and the reflection papers, three areas of intercultural competence emerged across the data. These areas are cultural self-awareness, cultural appreciation, and cultural inspiration. These three areas emerged from my analysis and can be indicators of intercultural sensitivity and competence. As Hammer (2009), M. J. Bennett (2004), and the other scholars have posited, cultural self-awareness refers to an ability to discover one's own culture and to cultivate cultural identity. Cultural appreciation refers to an ability to appreciate cultural diversity, including respect, politeness, patience, empathy, and curiosity toward other cultures. Cultural appreciation undergoes the process of "a 
major conceptual shift from reliance on absolute, dualistic principles of some sort to an acknowledgement of nonabsolute relativity" (Bennett, 1993, p. 25). In other words, it is a cognitive shift from dualism, indicating that one is good and the other is not, to pluralism or relativism, indicating that there is no absolute truth or that the truth depends on many different factors. This cognitive shift promotes an ability to suspend one's own judgment and to view things through another's lens. Cultural appreciation also covers a behavioral ability to apply intercultural knowledge to practice in order to adjust oneself to certain intercultural contexts. Cultural inspiration refers to an ability to transform one's worldview and to the intent to take action for better changes in intercultural contexts. The new intercultural learning experience inspires her/him to take action, based on a new worldview.

These three areas of intercultural competence seem to occur in the process of intercultural development. Cultural self-awareness is a fundamental process of understanding different cultures as well as one's own culture, as understanding one's own culture is a substantial element of intercultural competence (Byram, 1997; Deardorff, 2006; Okayama et al., 2001). Cultural appreciation is the next step that one undergoes in the process of the development of intercultural competence. This development process includes both cognitive and behavioral practices. And cultural inspiration is an advanced process that requires more complex understanding of intercultural sensitivity, including both cognitive and behavioral aspects. As Table 3 shows, different developments of intercultural sensitivity occurred across the four learning dimensions. 
Table 3. Three Areas of Intercultural Development by Kolb's Learning Dimensions

\begin{tabular}{|l|l|l|l|l|}
\hline & $\begin{array}{l}\text { Readings \& } \\
\text { Lectures: Abstract } \\
\text { Conceptualization } \\
\text { (AC) }\end{array}$ & $\begin{array}{l}\text { Tea Ceremony: } \\
\text { Concrete } \\
\text { Experience } \\
\text { (CE) }\end{array}$ & $\begin{array}{l}\text { Bicultural Guest } \\
\text { Talk: Reflective } \\
\text { Observation } \\
\text { (RO) }\end{array}$ & $\begin{array}{l}\text { Intergroup } \\
\text { Discussions: } \\
\text { Active } \\
\text { Experimentation } \\
\text { (AE) }\end{array}$ \\
\hline $\begin{array}{l}\text { Cultural Self- } \\
\text { Awareness }\end{array}$ & $\sqrt{ }$ & $\sqrt{ }$ & $\sqrt{ }$ & \multicolumn{2}{|}{$\sqrt{ }$} \\
\hline $\begin{array}{l}\text { Cultural } \\
\text { Appreciation }\end{array}$ & $\sqrt{ }$ & $\sqrt{ }$ & & $\sqrt{ }$ \\
\hline $\begin{array}{l}\text { Cultural } \\
\text { Inspiration }\end{array}$ & $\sqrt{ }$ & & & \\
\hline
\end{tabular}

\section{Theory-based materials as Abstract Conceptualization (AC).}

In the stage of Abstract Conceptualization (AC), learners logically analyze ideas in order to understand problems and situations. In this intentionally designed course, learning theories and concepts through readings and lectures cultivates students' knowledge base and provides them with the opportunity for cognitive understanding.

The reflection paper about the reading was the first writing assignment, which was given in the second week of the term. Students were assigned to read a certain chapter about the general intercultural theories, choose one concept from the chapter, demonstrate their understanding of the concept, and apply it to their own cultural experience, including their own cultural values as well as others'. Analyzing the participants' reflection papers, cultural self-awareness emerged as the main category of intercultural competence for both Japanese and American participants.

In the interview sessions, I asked the participants how the intercultural concept and theories they learned from the readings and the lectures helped them improve their 
intercultural sensitivity and competence. Three development patterns emerged, including cultural self-awareness, cultural appreciation, and cultural inspiration.

\section{Cultural self-awareness.}

In the reflection papers, participants explained some of the dichotomous cultural values in two cultures, such as collectivism and individualism, small and large power distances, or feminine and masculine gender roles. Understanding these dichotomous cultural values triggered Miyuki to realize her own values. She wrote, "It was interesting to find that my idea which I kept for a long time was actually from a broader cultural concept that my society shares, collectivism."

Three American participants realized the dichotomous cultural values existing in their lives, based on their background. Amy wrote that she had "experienced the shift between small and large power distances in familial situations" between her immediate family and her extended family in Mexico. Jake and Cary, the two Asian Americans, recognized the dichotomous cultural values of collectivism and individualism in their lives due to their bicultural backgrounds. Jake analyzed himself and wrote "I am in the middle of both."

For example, when pursuing a career and future for myself I choose the path I walk and ultimately all final decisions about my life and future lie with me. But in terms of education and my life in the present much of my decisions are influenced by my family. For example, the major reason I'm in college now is because my family insisted I go, they pretty much decided I was already going before I could make a decision. Though a little irritating for me I still went to college because I knew as well as my family that if I succeed, it would not only benefit my life but theirs as well.

Jake seems to have strong bicultural identity. He concluded: 
Although being in-between individualism and collectivism may not seem like a concrete classification for myself I still stand by my placement because I have two cultures that I live in as well as embrace; that is what makes me who I am.

During the interviews all four Japanese participants talked about learning and discovering their own culture through the readings and lectures. One American participant, Cary, mentioned that some self-assessment exercises done in class helped her discover her own cultural perspectives.

Miyuki said what she learned most from the readings was about Japan, which actually surprised her. She continued:

When I was immersed in my own culture, I was unaware of having this culture. When someone asked me about a Japanese concept, I couldn't answer immediately. Probably for all Japanese people, we understand the concepts but we can't explain them. When I was reading the explanations in words, I was surprised like that was it! It was particularly very interesting that a foreign scholar wrote about the Japanese tea ceremony from the outside lens. Everything is so new and foreign to her that she can explain every step of how to make tea with all the reasons behind it. It's impressive. I enjoyed reading about Japan!

Similar to Miyuki's comment, Aki thought it was very interesting that non-Japanese authors wrote about Japan. It was enjoyable for her to read the outsiders' viewpoints and to learn how unique Japanese culture could be.

Nao stated that she knew the Japanese cultural terminologies but did not know that there were cultural backgrounds or origins behind the terms until she read the articles about them. Masako also stated that the readings were very useful to her in learning the theories and concepts of intercultural understanding and Japanese culture. She mentioned that she had lived in the Japanese culture and known about it through experience and feelings, but she had never read about it. 


\section{Cultural appreciation.}

In her interview, Amy mentioned that she was able to learn the theories and concepts better in the combination of the readings and the lectures, because they reinforced her cultural appreciation toward the other culture.

I always enjoyed class lectures; I thought that often the lectures were reflecting and emphasizing what we were learning about the materials, which was very helpful. Often the things can be sort of dense and difficult to interpret when it's in the text or in the graph or something. But it was always very helpful and reinforcing and kind of clarifying things when it was presented in the lecture. And also the lectures were fun to attend because you know we talked about the various topics like the iceberg analysis and stuff like that, so I mean adding fun and also reinforcing things that we were learning were very helpful.

\section{Cultural inspiration.}

Cultural inspiration refers to an intercultural learning experience that inspires students to transform their worldviews. Learning theories can become a trigger for a learner's transformation of worldview as a part of intercultural sensitivity development. In her interview, Amy mentioned that two theories stuck in her mind. The first one is the Japanese in-group and out-group boundary theory, which she liked because of its presentation with a diagram. She ended up making the American boundary theory and comparing to the Japanese one with her Japanese discussion partner in class. She mentioned, "I definitely liked it, so we were able to comment on it and do comparison using the material." Second, Amy thought of the concept of relativism as a big concept that seems to say that things always fall along the spectrum, not on one or two poles.

All of these things fall in the spectrum and Japanese are not necessarily here and Americans are not necessarily over here, but someone is in the middle. I've just come to understand that it's not one or the other, but oftentimes comparison is up to things that are dissimilar but which have concepts between them. 
Relativism is indeed an important concept in understanding different cultures without stereotypes. It is interesting that it stuck in her mind, because although it was in a particular reading it was not greatly focused on in class.

\section{Tea ceremony as Concrete Experience (CE).}

In the stage of Concrete Experience (CE), students learn from specific experiences, relying more on their feelings rather than on a systematic approach to the situations (Kolb, 1984). The tea ceremony experience offered an authentic intercultural context where students could feel the unique atmosphere with people around them.

In the reflection papers about the tea ceremony experience, students were assigned to discuss what they observed at the tea ceremony using the cultural iceberg analysis and application of the concepts of a Japanese tea ceremony learned from the reading and the lectures. They were also directed to discuss how they felt toward the whole experience of the tea ceremony and how this experience helped them improve intercultural awareness and sensitivity. The reflection papers demonstrated the participants' intercultural learning experience by the feelings they experienced through the unique atmosphere. Miyuki summarized her learning experience from this dimension.

The process of preparing, calming oneself, sharing atmosphere, showing respect and feeling the nature is more important than the final objective, which is to drink tea. From this experience, I learned that experience is as important as learning in intercultural communication. We can learn and understand the concepts of distinctive culture much better if we experience and really feel how the concepts are integrated with the actual tradition.

Jake and Amy expressed appreciation of this firsthand experience. Jake stated, "In all of my life I have never experienced anything so methodical and yet serene at the same time." Amy wrote, "I am very grateful to have been able to visit the Japanese 
Garden and take part in a real traditional Tea Ceremony. I now have a greater awareness of how the basic assumptions and values of Japanese culture are manifest in traditional practices." These comments indicate the power of concrete experience. Further analysis of these papers revealed two areas that indicate the participants' intercultural sensitivity development: cultural self-awareness and cultural appreciation.

Three interview questions were asked about Concrete Experience (CE), including (1) what the experience of the tea ceremony was like for the participants, (2) how openminded and willing they were to learn from their feelings and the people sharing the experience, and (3) how the tea ceremony helped them improve intercultural sensitivity and competence. Two areas of development emerged, including cultural self-awareness and cultural appreciation.

\section{Cultural self-awareness.}

The tea ceremony seemed to prompt the Japanese participants to discover their own culture. In the interviews, three of them, Nao, Miyuki, and Masako, mentioned their cultural self-awareness through the tea ceremony experience.

Although Nao was familiar with the tea ceremony back in Japan, she had never studied the deep meanings of the ceremony. She stated that it was an eye-opening experience.

I learned that Japanese culture is condensed into the tea ceremony. Before this experience I thought the tea ceremony was just one of the Japanese traditions, and I didn't know it reflects on all aspects of Japanese culture, such as the harmony with nature, formality, silence that is full of meaning, and so on.

In her reflection paper, Nao focused on silence and space in the tea ceremony, which she was able to learn by feeling it. She wrote that the silence during the tea 
ceremony even with several people in the room is related to the small space of the tea room with a low ceiling and the natural surroundings of trees and bamboo. She added, "Another factor to make the Tea Ceremony silence is paying attention to the tools, which are made from nature, and paying attention to the act of a host." Through her feelings during the concrete experience, Nao discovered her identity. In her interview, she said:

What I felt the most during the tea ceremony was what my identity is. I strongly identified myself as Japanese. It is because the silence and the space, which are made of nature, was comfortable to me and the meaning of every movement during the Tea Ceremony was valuable to me.

Miyuki discovered her own culture to a great degree through this experience. She said:

Even though I took a lesson about the tea ceremony when I was a kid, I learned a lot about it through this experience. The tea instructor explained in detail during the ceremony. In Japan, it's cultural that you have to grasp the deep meanings without explanation. It is more so for the traditional practices, such as the tea ceremony. So I learned only the steps but didn't understand the meanings behind it. It's probably partly because I was too young to learn. Now I understand the basic assumptions. For example, it is very much Uncertainty Avoidance to wipe the tea bowl many times, assuring it is purely clean. I thought the basic assumptions were the concepts that had been established recently in order to compare and contrast with different cultures since we started to interact with other countries. So I doubted that the basic assumptions would fit in the Japanese traditional practice until going to the tea ceremony. But ta-da! everything in the ceremony fits the basic assumptions. I thought, wow, Japanese people haven't changed for a long time.

Miyuki also discovered how Japanese she is through the experience of the tea ceremony with American classmates. She stated:

I felt strange in having the tea ceremony in America. But through this experience, I felt even more Japanese. After the ceremony, I was talking with an American classmate, and he said "Why didn't they serve tea right away instead of taking every step of wiping the equipment and stuff? It's tedious to take all the steps in order to serve a single cup of tea, while you're kneeling formally with your legs numb. You can buy some tea for one dollar at the store." I was very shocked to 
hear his comment. It wasn't offensive because he didn't say it negatively and we agreed that it was about the process-oriented part of Japanese culture. But listening to his comment, I thought I would've had no clue that they were thinking about buying tea instead of waiting for a long time with their legs numb, while I was looking at the scroll and thinking how beautiful it was. I realized how Japanese I am.

Masako said it was greatly beneficial to know the core Japanese culture through her first-time observation of the whole process of the tea ceremony. She realized how deep the Japanese tradition was. For example, she was impressed that the scroll, the flowers, and all the other objects had meanings, which indicated that Japanese is a highcontext culture. She mentioned that she enjoyed feeling very much as if she had been in Japan, probably even more so than when she was in Japan.

In her paper, Masako emphasized the important connection with nature for Japanese people that she felt in the tea room for the entire time. And she realized how Japanese she was.

I was comfortable with the Japanese way of showing nature and silence. Also I somehow felt the meanings of each action and silence. It might be because I'm Japanese, and I can understand the cultural context naturally. Therefore, I recognized that I'm totally Japanese and the tea ceremony is a very Japanese cultural thing. The tea ceremony can remind us of our cultural identities as well as showing the relationship with nature.

In answer to how the tea ceremony experience helped her improve her intercultural sensitivity and competence, Masako stated that she discovered her own culture and has an ambition to introduce it to the rest of the world. She said:

First, I thought that I need to know Japan more, realizing that I know little about Japan as a Japanese person. Secondly, I thought that Japanese culture is great and mighty, I don't know if I feel this way because I'm Japanese. But it's special and different from other cultures. I hope I can introduce Japanese culture to other people. I want them to know it. 
Her comments show her cultural self-awareness as well as her willingness to learn more about her culture and to introduce it to others.

\section{Cultural appreciation.}

Interestingly, all four Japanese participants mentioned that they were curious about how their American classmates might have been thinking and feeling about this experience during the tea ceremony. Their comments indicate their willingness to see things though another's lens.

Nao wrote in her paper and said in the interview that she enjoyed thinking about what American students were thinking and feeling about the complete silence of the whole group, which could be very awkward in American culture. In her interview, Aki mentioned that she was also fascinated by how interested the American classmates seemed to be in this experience. She was wondering what they were thinking and feeling during the ceremony. Specifically, Aki enjoyed watching the two American classmates who had volunteered to be served tea. She mentioned "I sensed their tension in that unique space. It was interesting to see that not only Japanese but also Americans can enter that special space and feel this distinctive tension."

In her interview, Masako stated that during the tea ceremony she observed that her American classmates who volunteered to have the tea served in the tea house did not act naturally; for example, they bowed awkwardly, probably without noticing it. She was also wondering how the non-Japanese classmates felt about the silence. She thought that non-Japanese people might have felt awkward about the silence, while Japanese people felt comfortable with it. 
In her interview, Miyuki mentioned how enjoyable this experience was, which was different from learning in the classroom. She also enjoyed looking at the tea ceremony through an American lens.

It was a tranquil space where I was able to think a lot. It was very enjoyable to think of each element of the tea ceremony, appreciate it, and realize I'm Japanese. At the same time, I was also wondering how American classmates sitting next to me were thinking about the ceremony. While I was enjoying watching each step as the process-oriented part of Japanese practice, I guessed Americans were thinking like why they weren't drinking tea right away. It was fun to think about it from their point of view.

Mark volunteered to participate in the ceremony and was served tea. He mentioned that it was a good experience in the way that he got a closer view and tried to put himself in the position of a Japanese person and to imagine what the Japanese person might think of the situation.

I tried to keep in mind everything is more process-oriented and so they're going to value movements in a certain way, like turning the tea cup a half way or something like that. It's just drinking a bowl of tea, but what I've got from it helped to give an active example of how a series of high-context, process-oriented actions would be up to simple actions of drinking tea.

Using his full knowledge of intercultural communication and a positive attitude, Mark was able to learn from the experience by putting himself in the position of a Japanese person and trying to feel as if he were the Japanese person. Mark also wrote in his reflection paper that he gained insight through how he felt during this experience.

I feel as though I have gained a deeper insight into the nature of how one works.... The simple act of drinking tea is ritualized in Japanese culture, it is highly process oriented so that the person who consumes the tea may enjoy it to the fullest extent.

Cultural appreciation refers to an ability to appreciate cultural diversity. Through the tea ceremony experience in particular, the American participants, Amy, Jake, and 
Cary, reported in the interviews that they enjoyed being respectful to the other culture and enjoyed the peaceful and tranquil atmosphere. They seem to learn to appreciate the other culture through the authentic cultural experience.

Amy was another one of four volunteers who got to be served tea at the tea room.

She truly enjoyed the experience. She said:

I did not know at all what I was supposed to do, and so I was afraid of messing up, but more than that I was excited about the opportunity because I mean I figured I didn't know what I was doing and so it was great. It was enjoyable. I loved seeing everything, like the real thing, the work, the thought, the cleansing ritual, and all the things I was into. The ceremony itself I think was cool and interesting and admirable, but the experience itself I thought was great.

It is notable that Amy accepted all sorts of uncertainty with a positive attitude and was actually enjoying all the uncertainty. I asked if she was nervous when she was sitting up there with all the attention.

I was nervous, but I wasn't like embarrassed to be in front of everybody. More than anything I just wanted to be as respectful as possible to the woman who was making the tea and also the one who was explaining what was going on. Just wanted to convey that even though I was ignorant, that I was still, you know, wanting to be respectful as much as I could.

Amy wanted to be respectful more than anything. My following question was about the atmosphere. The very slow and quiet atmosphere is generally an unusual situation for Americans. She stated, "I really enjoyed it. That's what I liked the most. It was a cool atmosphere. I liked the calmness, tranquility, and symbolism of the various steps. I mean all of that was great. I liked it all.”

Amy remarked that her actual participation in the tea ceremony improved her intercultural sensitivity. She stated: 
I think my sensitivity increased by seeing the culture in action and more than just like the words, you know, that I wrote on my notebook, but like harmony and tranquility and harmony with nature and stuff, and it wasn't just that. It was like seeing it in action and so you come to have greater appreciation for the culture. I thought I was very sensitive at the time because I was wanting to do my best to immerse myself in it. I mean I wasn't just an observer, I actually got to take part in, so it was very much kind of, I was allowed to take part in the culture and kind of like ingratiate myself into it, which was very valuable.

Amy's reflection paper also indicates that she felt cultural appreciation through this concrete experience. She wrote:

I found the entire experience to be both enlightening and pleasant. Especially striking was the care taken to preserve the calm, reflective, meditative atmosphere. Upon entering the Tea House, I was immediately overcome with a sense of peace and quiet contentment. I came, also, to admire the hostess who was preparing the tea. Careful observation revealed the precision of her every movement and her obvious devotion to the tradition and significance of the ceremony. Experiencing the Tea Ceremony has given me a new perspective on Japanese values and tradition by allowing me to observe them in action. I have more respect for values which underlie the Ceremony because I see how they serve to enrich the Japanese culture.

The other two American participants also enjoyed this rare peaceful and tranquil

atmosphere. Jake mentioned that he had positive feelings about his whole new cultural experience. He said that he enjoyed the silent, relaxing, and tranquil atmosphere during the ceremony. He wrote in the reflection paper:

The ceremony was very interesting and I am sure that there were some other details and hidden meanings that I failed to observe which would give me a reason to go and experience it again. Although I wasn't participating directly in the tea ceremony I still felt a sense of calmness and relaxation just from watching it, though the next time I experience a tea ceremony I would rather not have a person explaining the process of the ceremony so that I can enjoy it to the fullest.

In her interview, Cary said that even though it felt a little too slow for her, she enjoyed learning a lot about Japanese culture, such as the fact that every single movement in every little thing symbolizes something. She mentioned that the ceremony was very 
peaceful and tranquil and it was nice to sit down and focus on something happening, in contrast to her busy daily life, when so many things are going on. She recalled that her life being very busy was probably why the ceremony had felt too slow. She said:

I've never seen the tea ceremony before, so it was something brand new. I've heard of that, I've read about it, I've seen pictures, but to experience it, it's so different to just sit there and see it. We don't really have anything like that in American culture. So it was nice to be able to just sit there and watch her pour the tea and mix everything together from scratch. When I make green tea it's just from tea bags, so it was interesting to see her put the powder and whisk it. It was a good experience. I really liked it.

Cary's comment shows her appreciation of the tea ceremony. And her further comment in her reflection paper indicates her appreciation for cultural differences.

It helped me improve my intercultural awareness by teaching me that I need to be more patient when observing rituals and customs of different cultures. Each culture moves at a different pace than another, but that does not make one culture superior or inferior to another.

Amy and Jake applied their intercultural knowledge to the tea ceremony in order to adjust themselves to this intercultural context. In the reflection papers, both of them wrote about their intention of cultural adjustment after the tea ceremony experience.

Amy stated, "I have also learned how to conduct myself appropriately during a ceremony of this type and so will be able to avoid being unintentionally rude should another similar occasion arise." Jake wrote:

After experiencing the tea ceremony I went home with more of a feeling of respect for Japanese culture mainly because traditional practices being hard to come by nowadays, especially here in America, so the tea ceremony was a nice departure from all the stresses and anxiety of the outside world. Now when I drink tea anywhere else I will put more thought into my process and actions instead of just downing the tea like I used to do. The Japanese tea ceremony has widened my perception on how one would go about doing things some might take for granted. I now have a better appreciation of the simple things I do in life. 
Jake intends to apply the new insight from the tea ceremony experience to his daily life, such as drinking tea at home.

\section{Bicultural guest talk as Reflective Observation (RO).}

In the stage of Reflective Observation (RO), learners watch and listen in order to understand ideas and situations from multiple viewpoints. They do not necessarily take any action, but rather rely on their own thoughts and feelings in forming opinions (Kolb, 1984). The third learning dimension is the bicultural guest talk as Reflective Observation. The guest speaker was a Japanese woman named Chai, who talked about her working experiences in Japan and America.

In the reflection papers, students were assigned to choose two stories of the guest speaker and analyze them with the cultural iceberg model and to discuss their reactions and feelings when they were listening to the guest talk, relating to how the talk helped them improve intercultural awareness and sensitivity. One area of intercultural development, cultural appreciation, emerged from the reflection paper analysis.

In the interviews, the participants were asked (1) whether and how the guest talk was helpful in developing intercultural sensitivity and (2) what they observed in the guest speaker and her talk in terms of cultural differences they had learned from the course. Interestingly, the Japanese and American participants perceived the guest talk differently. The Japanese perceived Chai's talk as very Americanized, energetic, clear, and engaging; while some of the American participants perceived her talk as formal, polite, and indirect. Thus, the Japanese and American participants learned differently through the dimension 
of Reflective Observation. Considering these differences, one development, cultural appreciation, emerged in the interviews.

\section{Cultural appreciation.}

By listening to Chai's intercultural work experiences, several participants applied their intercultural knowledge to intercultural business situations. Chai's experience in intercultural business situations was informative for Amy, Cary, Masako, Aki, and Miyuki since some of them want to do business internationally in the future.

Miyuki wrote in her reflection paper that she learned about the cultural gaps in a business situation and learned how to apply an intercultural communication theory to analyze the gaps.

From the guest talk I learned that there are cultural gaps between Japan and the U.S. in the workplace and many of those gaps can be analyzed by the cultural iceberg model. It was really interesting to listen to the guest talk because I could use the cultural iceberg model to analyze the problems that the guest had and it was a real story from what she experienced. It was good to know that I can apply the cultural iceberg model and the basic assumptions to real-life problems.

Jake said he learned the different communication styles between Japan and America in a business situation. He gave the example that in Japan subordinates seldom give their opinions directly to the highest ranked people due to the hierarchical system, and the example that people scarcely talk about private topics in the Japanese workplace due to formality. These two stories are relevant to the intercultural concepts of "vertical relationship" and "formality" that he learned in class. His comment indicates that he applied to Chai's stories his knowledge of the cultural basic assumptions.

Besides the content of the talk, the participants observed how Chai gave her talk and applied intercultural knowledge to it. According to the interviews, Masako, Aki, 
Miyuki, and Jake observed her talk as very Americanized and casual; while Cary and Mark perceived it as formal and indirect.

Aki observed how Americanized Chai had become. She said:

I thought a person can change so much when she comes to America. I mean, I don't know Chai's past, but I can tell she has changed a lot, like being Americanized. It may be because she was speaking English. She spoke in a very energetic way with confidence, like saying "Be yourself!" It is very different from a Japanese norm that values being like others. In America, there is no such norm, so I sensed that she was telling us like "you can be yourself in this country."

Jake stated that he also observed Chai's speech style to be surprisingly casual for a Japanese woman. Here is the conversation during the interview session:

Me: Do you think that Chai is Americanized, based on her casual speech style?

Jake: I think she's very good at blending or you know like incorporating or switching cultures. I think there was a term for it I learned in class, but I don't remember what it was.

Jake analyzed Chai's casual attitude from what he had learned in this course. The term Jake was talking about is "cultural code switchers," which are defined as those who can effectively switch values and attitudes across their multiple cultural identities, such as a Japanese self and an American self, in order to fit smoothly in the immediate cultural context (Campbell, 2000). Jake brought his knowledge that he had learned in class and nicely applied it to the case of the guest speaker rather than just labeling her as being Americanized.

On the contrary, Cary viewed Chai as very formal and polite, which is part of Japanese culture. Mark also observed that Chai spoke around the topics, which is a Japanese indirect and spiral way of speaking, so that it was sometimes hard for him to 
grasp her points. Both in the interview and the reflection paper, Mark mentioned that the guest talk was useful because it provided another example of a Japanese trait.

Chai's talk gave Japanese participants hope, inspiration, motivation, and encouragement to be a well-adjusted bicultural person. In other words, the talk had a great impact on the Japanese participants' plans for the future.

Miyuki reported that she observed the guest speaker and learned how to give an effective speech to an American audience.

I thought Chai spoke like an American, I mean she has been working with Americans and knows how to speak to them. I was impressed that at the beginning of her speech Chai reminded us that we can ask any question anytime during the speech and remarked that she was going to talk about her experience. It was very clear to follow. Every time she changed the topic, she asked us if we were following or had any questions. This way of speaking was very American, because Japanese speakers usually ask for questions at the end of speech.

Miyuki was also impressed by how well Chai understood the differences in

American and Japanese cultures. She said:

I was impressed that Chai knows intercultural communication very well. She knows what Americans don't know about Japanese ways of doing things. She explained thoroughly like "I'm Japanese and it's common to say no when compliments are made, but when I did this in America, people gave a weird look." Japanese people don't usually know that Americans don't know the Japanese common sense of modesty and wouldn't explain this part. But she pointed out this part first. That means she experienced it and learned from the experience. She explained every single element of the cultural differences that Americans probably don't know. She knows what Japanese do and what Americans do. It was very impressive. I learned how to give a speech to an American audience, like how to explain Japanese culture to Americans.

Miyuki's comment indicates that the guest speaker's way of speaking motivated Miyuki to be a good international speaker. 
In her interview, Nao mentioned that Chai became a role model of a Japanese person living and working in America. Although Nao had not thought about immigrating to America, she realized the possibility of doing so.

Chai was an example of how life would look if I would ever immigrate to a foreign country. I don't know about my future yet, but Chai's talk made me think about my future. If you were in Japan, an ordinary life would mean that you would graduate from college, find a job, get married, raise a child or children, and die someday. I've never thought about any alternative. Or if I had thought about an alternative, it would have been unrealistic for me. But since I came to the U.S. and saw lots of different ways of life, especially Chai's example, it all became real and made me think it might be possible for me to have an alternative life. It's exciting to think about it.

Her comment shows that watching and listening to the guest talk led Nao to whole new possibilities she could have in the future.

Masako stated that she observed Chai's demeanor and her way of speaking as culturally well-adjusted to American culture. Masako was impressed by the fact that it is possible to become so fluent in a second language and culture. She was encouraged and motivated to learn the language and the culture more in order to be like Chai.

In her reflection paper, Masako wrote that through listening to Chai's stories, she learned cultural differences in working styles and grasped a relativistic viewpoint that it is important to know the differences without making judgments and that ample experience would enable people to adjust to different working styles. In her reflection paper, Masako concluded:

The differences are significant; however, each way is related to their social values and beliefs. It might be difficult to adjust to the different working styles, but by knowing the differences and having lots of experiences, people can adjust to different ways of working.

Masako's comment indicates her appreciation of cultural diversity. 
In his reflection paper, Jake discussed the different concepts of politeness in the two cultures.

Chai's speech was really interesting in its own way because it helped me to learn something new. When she asked the class what we thought when we hear "politeness" I was stumped because I thought it was so obvious, but as Chai continued her speech I questioned my interpretation of "politeness" and came to the conclusion that being "polite" has different meanings in the U.S. and Japan. From my interpretations of Chai's speech and what I learned and know, it seemed to me that being "polite" in the U.S. means being kind and caring to others while in Japan "polite" means being respectful. This is because of their cultural basic assumptions and what they value like the need for hierarchy in society, the strong uncertainty avoidance, harmony with nature, collectivistic ideals, and formalities. All of these basic assumptions share the notion of respect above all.

This argument indicates that Jake appreciated that there are different meanings in a certain word across cultures and became enlightened by exploring those meanings.

Amy listened to Chai's talk with appreciation and empathy. Amy mentioned that it was "an encouraging and positive thing" to listen to a firsthand experience of working in two different countries and to see Chai being so bicultural and competent in navigating the two different cultures. Amy observed Chai in a mindful way, imagining the hardship she must have gone through. She said:

I suppose that there was friction or difficulty at first and she, I think, even said she didn't really know the language very well, so I observed resilience and I observed that she herself probably had to implement or undergo a lot of change, and you know we talked about the different levels of ethnorelativity. She probably had to go through some of those steps and I'm sure there are a lot of other things, but I'm not really sure.

Amy wrote her reflection paper from the same stance.

Over time, though, one can build confidence and competence in navigating the working world and even learn how to effectively shift between cultural perspectives as part of an international scope of employment. Our class's guest speaker was an excellent example of a person who accepted the challenge of 
succeeding in the business world not only in her native country of Japan but in the United States as well.

\section{Intergroup discussions as Active Experimentation (AE).}

The stage of Active Experimentation (AE) takes an active form, getting things done and influencing people and events through action. Learners take a practical approach rather than simply watching and listening. In this study, through actual interaction with classmates from different cultural backgrounds, students were able to experiment to see if what they had learned worked in the intercultural context and to see the results of the action.

The last learning dimension is intergroup discussions as Active Experimentation. This dimension took place in two settings in small-group and class discussions and culture-exchange group discussions that were assigned as outside-of-class activities. The lecture style in this course encouraged students to share their insights during and immediately after the lecture. The small-group discussion followed by the class discussion usually came sequentially after lectures. Soon after the lecture, the students had a chance to exchange different cultural perspectives with each other. This style allowed students to not only think but also participate in the class discussions during and after the lecture. In other words, students were thinking deeply to analyze the theories; at the same time, they were learning by listening to their classmates' comments and sharing their own perspectives.

In the reflection papers, students were asked to address two cultural differences they learned and observed during the culture-exchange discussions, to analyze each cultural difference with the cultural iceberg model, and to explain how they reacted to the 
different communication patterns. Document analysis of the reflection papers yielded one area of intercultural development: cultural appreciation.

The interview questions about the culture-exchange group discussions included:

- During the cultural exchange group discussions, with your intercultural knowledge from this course, how differently than before did you interact with your group members from different cultures? In other words, what did you keep in mind?

- During the culture-exchange group discussions, what did you observe in terms of cultural differences in your group members' communication patterns, values, and norms?

- How did you react to these differences?

- How did the culture-exchange group discussions help you improve intercultural sensitivity and competence?

It is noteworthy that three out of the four American participants mentioned that this dimension was most helpful for learning intercultural sensitivity. (The other American, Amy, said all four dimensions were equally helpful.) Cary remarked that she learned the most from the culture-exchange group discussions, describing it as "a real world experience." She stated that she liked the casual setting outside of the classroom as well as the small group size of three to five, in which especially the Japanese students could be comfortable enough to speak up.

The interview data are framed into two categories based on intercultural sensitivity development: cultural appreciation and cultural inspiration. 


\section{Cultural appreciation.}

Cultural appreciation is an ability to admire cultural differences, including respect for and curiosity about the other culture. In their interviews, Cary, Masako, Jake, and Amy claimed that the interactive lectures worked together with the readings very well. Cary stated that she found it beneficial to have lectures about the content of the readings, followed by the small group and class discussions, because she was able to learn different cultural perspectives from the other classmates.

Masako mentioned that the class discussions completed her understanding from the readings.

I was able to realize a lot of things from the classmates' comments. It was enjoyable to listen to the class discussions that were expanded from the content of the readings, because I learned various opinions and different perspectives about the topics. I read the articles and understood the content, and after discussing the topics with concrete examples I was able to understand them better or more deeply.

Jake mentioned that the course readings helped him structure his previous knowledge into the concepts and set guidelines on what he was going to learn. However, he considered the readings a supplementary part of his core learning experience through class discussions with his classmates from different cultures.

Looking at just readings and theories, it was kind of hard to take it for a fact because the authors could be different, could be American-based or Europeanbased, so I still think that the best way to learn the culture is from the person actually from the culture.

Amy stated that getting to talk to her classmates and hear firsthand student perspectives was her favorite activity. She said, "That was really cool, and I mean it's 
just another way to see how the culture would be apparent and be supported by their actual experiences, so I really did like that."

According to the interview, Miyuki observed a cultural difference in the type of class participation with curiosity, talking about her American classmates' active participation in class discussions.

American students' reaction during lectures is very different from Japanese. Japanese listen to it to the end and if we have a question, think about if it would be an appropriate question, then ask the question to the teacher. But Americans cut off the lecture and speak up like, "I don't think so." I thought, "wait a minute, the teacher is still talking! Is it acceptable?!" But I learned it's more valued in this culture to speak their opinions and show their disagreement.

Through her observation of American classmates, Miyuki found it interesting to know what part of Japanese culture struck them, which was unexpected to her. She said:

A few American students raised their hand at the same time in the lecture about Japanese culture. I got to see their real responses and learn what part of Japanese culture is intangible for them or different from American culture. I learned what Americans don't understand about Japanese culture.

At the same time, Miyuki found it beneficial to be able to ask American classmates about

American culture in class. In her interview, she continued:

If I didn't understand some American culture, I was able to ask American classmates right away. For example, I didn't understand the home schooling system because we don't have it in Japan. First, I was hesitant to ask about it because the implication of home schooling in Japan is negative, like it is only for children who can't go to school because they have problems or disabilities. So to me, home schooling was almost like a taboo and wasn't a topic that you could openly ask about. But American students explained it openly and pleasantly. I learned that it is okay and not rude to ask about their culture in class.

Miyuki continued her exploration of mutual understanding through intergroup interaction in class. She concluded: 
An American student asked Japanese students in class, like "I don't know about Japanese culture, so please teach me about..." I was happy that she got interested in Japanese culture and asked us about any small thing. Flipping the situation around, I learned that it's okay to ask them simple questions about American culture. I thought it would be annoying to ask such dumb questions, like common sense for them, but I learned it's okay if I explain that it might be easy for you but I don't know your culture and want to know about it. I think this kind of mutual understanding is the beginning of intercultural communication and I learned how to do it through the lectures and class discussions.

Miyuki's exploration of mutual understanding comes from cultural appreciation.

Regarding the outside-of-class activity, the culture-exchange group discussions, one benefit of the intergroup discussion activity for participants was to explore cultural differences at the individual level by listening to their own voice and exchanging their cultural perspectives with the group members. In their interviews, Nao, Masako, and Jake shared their learning experience. They appreciated that people are different even in the same cultural group.

Nao remarked that the actual interaction with American students was very beneficial to confirm the general knowledge that she gained from lectures and to realize differences among individuals as well as among cultures.

Masako also mentioned that it was beneficial to have an opportunity to talk with the American classmates. She learned about different values and beliefs among the American group members by conversing with them. She stated:

Through the conversation, I was able to hear their opinions and in return I was able to tell them about Japanese culture since they got interested in it. I learned a lot by exchanging our perspectives. It was interesting to learn multiple opinions based on their various backgrounds and experiences. 
Jake said the intergroup discussions reinforced his knowledge that he gained in the classroom, stating that "it was fun to learn what they experienced and about their life in Japan."

Besides appreciating diversity, cultural appreciation includes appreciative attitudes toward the other culture, including respect, politeness, patience, and curiosity. Jake and Cary mentioned patience as a key word for intercultural communication. Jake stated:

Because [the Japanese students] had their language barrier and were choosing their words carefully, you got to have patience to wait for them to finish explanations or have patience to take your time to try to understand and decode what they are saying or what they are trying to say. ...Patience is a big thing, especially in the cross-cultural communication, in my opinion.

Thus, Jake claimed that direct interaction with someone from a different culture is a better way to learn intercultural communication and to become more sensitive to the culture, because you start to develop your own skills to try to deal with the situation.

Cary remarked that overall she learned about patience through the cultureexchange group discussion assignments.

It taught me more about patience, and then taught me how to, I guess, put myself in their shoes and see how they're feeling, because they might be shy and things like that. So it really helped, yeah.

Based on their comments, patience comes from cultural appreciation. In other words, when you encounter a cultural difference, having cultural appreciation means admiring the gaps in values, norms, and communication patterns, and knowing where you need patience in the process of understanding and dealing with these gaps.

Amy observed the Japanese students to be good listeners. She said: 
Whenever I was speaking or someone else was speaking, they were always attentive and I think very good listeners. You know, like nodding and smiling, and so that was actually quite enjoyable to talk to someone like that because you're feeling encouraged to talk... they seemed so interested by me, maybe they weren't; I don't know.

Amy concluded in her reflection paper that she deepened her appreciation of Japanese culture through the intergroup discussions.

I have learned through these discussions that while we have many differences between us, we also have many similarities and those differences we do have only serve to make our interactions more interesting and educational. While the Japanese students come off as very reserved, I have learned that they are still quite eager to become friends, learn about others, engage in new experiences, and share their own experiences. It is a simple matter of respect and kindness to make others feel comfortable.

Besides the cognitive level of cultural appreciation, behavioral development, such as adjusting oneself to certain intercultural contexts, occurred through intergroup interaction. During the class discussions and the culture-exchange group discussions, participants first observed cultural differences in verbal or nonverbal communication styles, and then found a way of adjusting themselves to these cultural differences afterward. In other words, participants implemented active experimentation by applying their knowledge of intercultural communication to a real-world experience with a positive attitude.

During the class discussions, Aki and Nao observed cultural differences in class participation and communication styles, and tried to adjust themselves to the other culture. Aki said she was impressed by how actively American students participate in the class discussion. Nao tried to adapt to the new communication style. Nao mentioned that she learned not only the content from the lectures but also the different communication styles 
used in the classroom. More specifically, she learned that it is important to speak up in order to convey your opinions clearly in American classrooms, which indicates a lowcontext communication style. It was difficult for Nao, who is from a high-context culture, to speak up in class; however, she claimed that she had gotten motivated and made an effort to be more outspoken inside and outside the classroom and that she was at least able to talk more with her host family about this class and the intercultural topics. Her comment shows her positive attitude toward cultural adjustment. She was willing to apply what she learned and observed about different communication styles to her daily life in order to practice her intercultural communication skills.

In the interviews, all four Japanese participants shared their struggle with the differences in communication styles between the Japanese and Americans, namely highand-low context communication styles. And they reported that after trying to change their communication style in order to adjust themselves to the new culture they improved their intercultural communication skills and felt more comfortable interacting with their group members from different cultures.

Aki claimed that after she learned intercultural communication concepts, she tried to speak directly to her discussion group members in order to convey her messages precisely, and she thought it worked. She reminded herself not to take her colleagues' comments personally, because she learned that Americans speak more directly and do not mean to indicate anything other than what they say, unlike Japanese who speak indirectly and always imply something more than what is said. Aki also observed that during discussions American students were making constant eye contact that almost embarrassed 
her. She understood it was a cultural difference and became used to it, though she confessed that she still hesitates to make eye contact herself.

Similar to Aki's experience, Masako also talked about her effort to adjust herself to the other culture by trying to speak up. She mentioned that it was difficult to join the American group members' nonstop conversations with almost no pauses, which is opposite from the Japanese communication style that has a lot of silence. Her attempt to speak up worked sometimes and did not work other times. Eye contact is another difference between the two cultures. She stated that she felt like she was being looked at all the time. She tried to make eye contact and she thought she did pretty well.

Nao stated that at first she was very scared of communicating with someone in English; however, at the end of the series of discussion sessions she was able to communicate better without fear. For example, at first she could not say anything, but later she was able to ask a group member if she did not understand what s/he was saying.

Miyuki mentioned that at first she acted like a Japanese person in the cultureexchange group discussions and learned that didn't work well; then she changed the way she communicated to more of an American style and that worked better. She said:

At first, like the first couple of weeks, I was quiet during the discussion, because I thought it was a good thing to listen to the group members; you know I didn't know them very well, so that was a polite way for me. But as I studied about American culture, I realized that I was wrong! They must misunderstand me. I wanted to show friendliness by paying attention and listening carefully to their stories with interest. But after I learned about the American way of communication, I realized my attitude gave a negative impression and they must have been thinking I was not participating in the group discussion. Realizing that, I tried to share my opinions, ask questions if I didn't understand something, and say "I see" instead of staring at them in order to clearly show them that I was listening. And then, the communication with them seemed to get smoother. 
Miyuki said that through the intergroup discussions she gained confidence in communicating with American students.

During the culture-exchange group discussions, Miyuki also observed a cultural difference in her American group members' style of discussion. She mentioned that she first thought that her two American group members were fighting, but she realized that they were actually just arguing about a topic. Miyuki first worried that they were not getting along, and later she learned that it was a cultural difference in communication styles, as in Japan people do not usually directly oppose the other's opinion. Then, she dealt with such situations by pondering why they were arguing in order to understand their viewpoints better.

Mark also kept in mind the cultural differences in communication styles when interacting with his group members. Mark stated that he mainly kept the high-low context communication styles in mind when interacting with his Japanese group members. He experienced a few challenges in discussing things with the Japanese students due to the different communication styles and the language barrier. He remarked that he tried to be patient and rephrase what he said many times. In his reflection paper, Mark concluded:

One of the most important things I have learned is to try to be more sensitive to high-context situations (like when I offer to buy someone a drink). Japan is a society which maintains its harmony with others through sensitivity to others. In order to function well in Japanese society, I will have to learn how to communicate using a high-context style.

During the culture-exchange group discussion sessions, Jake tried to be polite and respectful, because he learned that being polite and respectful is a Japanese cultural norm 
in communication. He mentioned that he enjoyed his experience and experiment in keeping track of speaking slowly to his Japanese group members and to make sure they could keep up with what he said. He said, "I always pretty much watched how I talked and if I didn't say anything stupid to them or offend them in any way."

Jake also observed the different hand movements between his group members and himself during the intergroup discussions. He noticed that the Japanese students had little hand movement when speaking. This observation made him realize that he moved his hands a lot during a conversation. Thus, Jake discovered his nonverbal communication style through the observation of his cultural counterparts. Then, he tried to stop using his hands so much and tried to adapt to their communication style. He said:

They made me realize my hand movements or doing like this or something like pointing at the air trying to get it to kind of come across. I don't know why I do that, but I realized that I do that now, so I kind of try to not do so much movement. ...When I try to explain something, if my hands are moving, it might somehow get misinterpreted from their cultural view.

In his reflection paper, Jake also wrote:

[Our different communication patterns] got me to self-consciously be aware of my own communication patterns, there were multiple times where I found myself choosing the right words to say in my explanations and trying to restrict my hand gestures.

His comments indicate his effort to adjust himself to the other culture during the intergroup discussions.

In his reflection paper, Jake pondered his cultural observations and adjustment through the intergroup discussions. He concluded:

In these culture group interactions I learned that our cultural differences are present and unique in ways but in the end those differences are what make us all 
similar, down to how we deal with situations or how differently we may think we still come to a conclusion, though through different methods.

Amy wrote in her reflection paper about her cultural adjustment and showing her cultural appreciation.

Upon encountering the reserved nature of the Japanese students in conversation, I compensated by asking them questions and guiding the conversation the best that I could in a gentle way. I am happy to do this, as I respect their different communication style, enjoy their company, and am able to practice my own skills of relating to and communicating with others.

The intergroup discussion activity let Amy think about how hard but beneficial it was to put yourself in the place of another person in order to better understand people from different cultures. She said:

The real experience of interacting was very helpful. It's one thing to know about culture or intercultural communication. And it's another thing to practice it and it's a challenge, but it can put you in the place of another person. I mean, when you actually talk to someone and hear their perspective, you can better understand where it's coming from.

\section{Cultural inspiration.}

Cultural inspiration refers to an ability to transform one's worldview and to the intent to take action for better changes in intercultural communication contexts. The new intercultural learning experience inspires people to take action, based on the new worldview. The intergroup interaction inspired some participants to act in order to deal with intercultural issues and to mitigate the tension among the discussion groups. Two American participants, Amy and Cary, acted as facilitators bridging the cultural gaps when they observed that a fellow American group member was not adjusting to the other culture and had offended their cultural counterparts. 
Amy realized the intergroup discussions were a unique opportunity to interact with people in an open way about intercultural issues and the real world. She tried to utilize her intercultural communication skills as much as she could. She stated:

I tried to be open to [the opportunity] and I did my best to first of all to be respectful and to try to make them, the exchange students, feel more comfortable, I guess, by rephrasing things that I wasn't clear, doing my best to have clarity or if another American student said something, maybe rephrasing it or sort of trying to not be too probing or anything but in a way that was comfortable. It's not always easy because we don't know, we don't have the same sort of cultural references, so we had to take a step back about what you are saying and try to think about the perspective of other students, and so I was really careful about what I said.

Amy said her efforts were effective. Moreover, she felt like she was taking on the role of a facilitator and trying to ask questions and bridge things in conversation or communication between the group members from different cultural backgrounds. Knowing the different communication styles across the cultures, Amy sometimes felt uncomfortable seeing her American group member talking in an aggressive way. That is why she felt she had to jump in and take on the role of a facilitator. She said:

Sometimes I got worried that my fellow American partner in the group was a little bit too forward. One time that made me feel uncomfortable. I would be like, well maybe don't do that or maybe I would rephrase what they said.

Then, Amy adopted the Japanese way of communication in order to become a cultural bridge. She continued:

I, in some ways, felt myself mirroring [the Japanese students] also trying to do sort of back-channeling things because I think it's natural to imitate them. I also tried to make them feel more comfortable. I tried to do that and gave them plenty of time to talk and tried not to ask too many questions at one time; usually one thing at a time is best.

Cary observed that one of the great differences in communication styles between Americans and Japanese were that Americans were informal and talkative and Japanese 
were quiet and reserved. She observed the other American group member being overly informal during the discussion sessions, getting derailed from the assignment topics and making inside jokes that the Japanese group members did not understand. She felt uncomfortable and tried to include the Japanese group members. She said:

I kept in mind that their English isn't obviously their first language, so I tried to use words that maybe they would understand and I would speak a little bit slower to help them, and if sometimes I would repeat what I said like even more slow so they could understand, which is fine for me. But before this class, I didn't really do that. I didn't really understand or pay attention to what I was doing. But it made me more conscious when I'm talking to others like international students.

Cary observed the Japanese group members as well. If they did not seem to understand something or they did not give a reply, she tried to help them by using different words and talking more slowly. Her experience of studying Chinese seemed to help her understand the Japanese students' hardship of communicating in a foreign language. Cary mentioned that at first she felt frustrated about their quietness and later on she found it interesting to see them getting more comfortable with the people in her group and talking more. She showed her feeling of achievement about helping the Japanese group members get comfortable in her group.

\section{Application to Real Life}

Finally, the interview moved on to the application of what the participants learned in this course to their daily life. The participants answered the two questions below:

- How differently than before taking this course would you interact with people from different cultures? 
- How would you apply intercultural knowledge and skills you learned from this course to your real life, including your personal and academic life, and your career?

These questions attempted to investigate the outcomes of this course. The participants' answers revealed their standpoint as an interculturalist in terms of their daily life and their vision for the future as a compilation of what they had learned from this intentionally designed intercultural course. Based on participants' comments, two areas of intercultural development emerged: cultural appreciation and cultural inspiration.

\section{Cultural appreciation.}

All the participants showed their intention to utilize the knowledge and skills gained in this course for intercultural communication in daily life. They also showed their continuing efforts to adjust themselves to new cultural contexts. The participants learned to observe unfamiliar situations or people without judgment and to be willing to interact with people from different cultural backgrounds in order to get a better understanding of other cultures.

Aki reported that outside of the class she tries hard to adjust herself to American culture, by communicating more directly with her host family and friends. She said:

Right after I came to the country, when someone asked me what I wanted to do, I said like "it's up to you." But now I can be a little more direct and tell my opinions. For example, when I go to a party, I used to wonder when I should go home. In Japan, you can't just leave when you want to leave, you know. You have to observe the other people and if you think it's almost time to wrap up the gathering, you maybe clean up to send a cue. But here in the States, even when I start to clean up, they just don't care. So I learned that I can just say good-bye and leave. 
Nao stated that she was no longer scared of communicating with non-Japanese in English. She regards the other person as an individual, not as a non-Japanese person, and can communicate with her or him even though her English is not perfect. Not only that, she now enjoys talking with people from other cultures, because she is interested in their cultural background and experience. Nao acknowledged her vast change in attitude toward people from different cultures and her shift to an ethnorelative worldview after taking this course.

Masako stated that before taking this course she was judgmental about the frank and direct communication style of Americans, but through this course she learned that it was about cultural difference. Since the course has ended she has been making a continuing effort to speak her opinions in order to adjust to the culture. Her comment indicates her development of intercultural sensitivity in the process of gaining knowledge and practicing skills with a positive attitude.

Mark made a comment that he would want to keep in mind the different communication styles, which he thinks is a big one in intercultural communication. Amy remarked that she felt more willing to speak or interact with people from different cultures than before taking this course.

I feel like I'm somewhat equipped with some tools and ways of thinking and perspectives. I do need to be more competent in intercultural communication so I'll have greater confidence, and having some interactions makes me feel more likely to seek them out, and it's just less scary and less worried.

As his last remark, Jake again underscored having patience to try not to interrupt people's conversations and to just wait until they are done talking and then say something. He stated, "I have to be more polite. This course has made me nice." 
Cary underscored the importance of intercultural theories and concepts in order to deal with intercultural contexts. As to overall achievement through this course regarding intercultural sensitivity development, Cary mentioned that even though she had been interested in different cultures before, she now can understand the differences more systematically by utilizing the theories and concepts that she learned in this class. She said:

Before I was just kind of not as understanding why they do things as they do, but then I took this class it opened up all different learning styles, conflict styles and I just learned about how other people deal with everyday life in different cultures. It's just beneficial because now I have more understanding and again I'm more patient when interacting with people from other cultures.

Cary remarked that her favorite tool is the cultural iceberg analysis.

Before like when I went to Thailand or even Japan or China, it was just so different. And now I haven't really been overseas since the class, but I mean when I go there now I think I will be more conscious about the cultural differences and maybe I'll do the cultural iceberg analysis in my head, yeah. I do that from time to time. It's really stuck with me and I like it because it helps me understand more. ... And especially learning about the cultural basic assumptions and how we are so different from other cultures.

Miyuki also mentioned the cultural iceberg analysis and basic assumptions as an important utility for daily-life intercultural communication. Miyuki said she would apply the knowledge of cultural basic assumptions when encountering culturally different behaviors or communication patterns. She believes that this approach produces mutual understanding and builds more trustworthy friendships. Before, she didn't try hard to get to know people from different cultures because she was scared of uncertainty and hesitated to talk to them. However, now she is willing to be friends with them and learn the differences. 


\section{Cultural inspiration.}

In the end, all four Japanese participants and two American participants, Mark and Amy, talked about how much their learning experience in this course made an impact on their future planning and vision. They are ready and willing to encounter new intercultural experiences, to learn more through them, and to take action to improve intercultural relations.

Miyuki is eager to learn more about different cultures besides American culture. She said that she will continue to enjoy exploring new cultures and will deal with the differences very positively.

Aki mentioned that the knowledge and skills that she gained from the course had an impact on her future life. Aki wants to continue to explore her own and other cultures in the future. She is eager to go to other countries and experience more different cultures. More specifically, she is interested in moving to Thailand as a teacher at the Japanese school for Japanese children of relocated families. She wants to assist those children in adjusting to a new culture and understanding intercultural communication without losing their Japanese cultural identity. Yet she claimed that she wants to go back to Japan eventually.

Nao remarked that she changed not only her daily-life communication but also her plans for the future.

I have changed a lot since I took this course. My new perspective must affect my study abroad experience in America this year. I will have a totally different life when I go back to Japan than before. For example, I'd like to communicate with people from different countries when I go back to Japan. I kind of wanted to do that before, but couldn't act on it. This time I will definitely do that. About my career, when I was in Japan I thought I would graduate from college and work at a 
company for my whole life in Japan, but now I see other options, so I want to do whatever I want to do at each time in my life. I also want to know more about different cultures in the world.

Thus, Nao transformed her worldview through this course.

As her career, Masako wants to get involved professionally in international relations, analyzing different cultures with the cultural iceberg analysis and basic assumptions that she learned in this course and introducing different cultures in the globalized world. She concluded that this course greatly helped her learn new things as well as her own culture and guided her to the path of international relations as a career.

Mark thinks that what he learned in this course will become useful in his career, such as in the situation when he as a doctor sees patients from different cultures.

Amy became more open and willing to interact with people and to explore different cultures in her life.

That [intercultural knowledge and skills] is just something that would help anyone in life and especially in career and in school. I feel like probably more inclined to seek out meeting people or talking to people or initiating an interaction or friendship with the person who is from another culture more so than before. This course made me more comfortable with doing that. Also I do want to travel a great deal so this type of thing becomes invaluable for traveling.

\section{Necessity of Intercultural Learning for This Globalized World}

Cary mentioned the necessity of intercultural learning for all college students. In concluding the interview with Cary, she said bridging cultures and learning from each other are key in this globalized world.

I think it's beneficial to have contact with other people because maybe they have a different way of doing something that's more efficient and you can learn from them and we can both learn from each other. I think more people should be more open to other cultures and differences. It (this course) is very helpful. It should be one required course in every single major because I think you're going to have 
contact with someone from a different culture sometime in the future. It's inevitable in today's world, and it could be very beneficial to understand and be more open to change and see how they're doing.

Regarding the effectiveness of learning intercultural theories and concepts, Jake mentioned the benefit of having a nonmainstream instructor as a significant factor. He thinks that the lectures were effective because the instructor was from the target culture and spoke about her experience.

I think that [whether the lectures were helpful] is depending on the situation; in this case it worked because the lecture was from a professor, you, who were originally from that culture, so you have your own experience to draw from. So in my mind the lectures were effective. They worked well. ... An American instructor who lived in Japan for years could provide information, but I'll take it for granted still, because they won't be native to the country or something, so they could be still viewing it through an American lens, you never know.

\section{Conclusion}

The results of the pre- and postassessments using the Intercultural Development Inventory (IDI) show that all eight participants reached the stage of Minimization or higher on the post test. More specifically, seven participants out of eight increased their scores of intercultural sensitivity at the postassessment, and six of them moved up to more advanced stages. Three out of the four Japanese participants improved their intercultural sensitivity more than the American participants, and these three increased their scores remarkably.

The data of the interviews and the reflection papers indicated that the participants transformed their worldview by learning intercultural communication from Kolb's four different learning dimensions: theory-based materials in readings and lectures as Abstract Conceptualization (AC), an intercultural experience at the tea ceremony as Concrete 
Experience (CE), a bicultural guest talk as Reflective Observation (RO), and intergroup interaction during the class and small-group discussions and the culture-exchange group discussions as Active Experimentation (AE). Interestingly, the majority of the American students (three out of four) mentioned that the intergroup discussions were the most effective learning experiences, while this was not the case for the Japanese participants. Learning the theories from the readings and lectures and the tea ceremony experience were perceived as the two most effective learning dimensions for the Japanese participants. There is little connection between the most effective learning dimensions based on the participants' perceptions and their Kolb learning style preference results.

In examining how the participants developed their intercultural sensitivity in each learning dimension, three areas of intercultural competence emerged from the data of the interviews and the reflection papers: cultural self-awareness, cultural appreciation, and cultural inspiration. Different development areas occurred across the four learning dimensions, depending on the participants' cultural background and their level of intercultural competence. For example, most of the Japanese participants experienced cultural self-awareness through readings and lectures (Abstract Conceptualization) and the tea ceremony experience (Concrete Experience). Another example is that cultural inspiration, the more advanced development area, was mainly experienced by Amy, who got the highest assessment scores.

The next chapter discusses the significance of the findings in order to answer the following research questions: Is there a connection between an intentional intercultural course using Kolb's learning cycle and student intercultural sensitivity development? 
More specifically, (a) how are these connections or patterns the same or different for American students and Japanese exchange students? and (b) how are the aspects of the intentional course design more or less effective for developing students' intercultural sensitivity? 


\section{Chapter 5}

\section{DISCUSSION}

This chapter will discuss the significance of the findings by integrating all the data and examining how it reinforces or challenges existing research and applies to intercultural education. First, merging the findings with the literature review, the discussion will proceed with the three areas of intercultural development in mind: cultural self-awareness, cultural appreciation, and cultural inspiration. Second, the effectiveness of each of Kolb's four learning dimensions is discussed, followed by the other factors that come into play in an intercultural learning environment. Next, I provide recommendations for designing an intercultural course using Kolb's four learning dimensions, followed by the limitations of my research and the possibilities for future research. Finally, this section concludes with the implications of the study. Throughout the chapter, I answer the research question, "Is there a connection between an intentional intercultural course using Kolb's learning cycle and the development of students' intercultural sensitivity?" In other words, I scrutinize how effective the four pedagogical strategies associated with Kolb's learning cycle can be when designing an intercultural course that is meant to develop students' intercultural sensitivity.

\section{The Intercultural Development Inventory (IDI) Scores}

The results of the pre- and postassessments show that seven participants out of eight increased their scores of intercultural sensitivity and competence. Six of them moved up to a more advanced developmental stage, and all three participants who were at 
the Polarization stage increased their scores remarkably and moved up to the Minimization stage, indicating a change from ethnocentrism to ethnorelativism. This transformation of worldview is notable because the students used to view the world only from their own cultural perspective and can now recognize other cultures and their multiple perspectives. Overall, at the postassessment, all the participants were at the stage of Minimization or above, which demonstrates that all the participants were in progress toward or were fully in the ethnorelativistic stage. These findings show that the course designed with Kolb's four pedagogical strategies was effective for students in developing their intercultural sensitivity. The interviews and reflection papers explained in detail how the participants improved intercultural sensitivity by learning from Kolb's four learning dimensions.

\section{Anatomy of Intercultural Development: Japanese vs. American Participants}

This section will scrutinize the answer to subresearch question (a): "How are these connections or patterns the same or different for American students and Japanese exchange students?"

\section{Japanese Participants: The Development of Cultural Self-Awareness}

The findings reveal that a difference in intercultural development between Japanese and American participants occurred. More specifically, this section will explore why the Japanese students seem to have developed intercultural sensitivity more than the American students. In answering this question, the development of cultural selfawareness must be a crucial factor for the Japanese participants' development of intercultural sensitivity. 
As mentioned in Chapter 3, the development of cultural identity or cultural selfawareness is a substantial element of intercultural sensitivity and competence (Byram, 1997; Deardorff, 2006). In other words, discovering and understanding one's own cultural identity is crucial for understanding others (Okayama et al., 2001). Therefore, cultural self-awareness or self-discovery of one's own culture is one of the overall objectives in intercultural learning. The process of cultural identity development is a type of transformational learning in which people transform their way of framing personal identity. This process starts from one's experience of identity encounters (Knefelkamp, 2006). Encountering culturally unfamiliar contexts can become a trigger for realizing the existence of different cultural perspectives as well as one's own cultural values and beliefs.

The development of cultural self-awareness was observed among all the Japanese students. They mentioned that they discovered their own culture especially through the theory-based materials, such as readings and lectures, and through the tea ceremony, which together comprise the most effective perceived learning dimensions for them. They also claimed cultural self-awareness as a highlight and as an achievement in this course.

The Japanese participants' remarkable increase of their IDI scores supports the fact that cultural self-awareness is a substantial factor in the development of intercultural sensitivity. M. J. Bennett (1993b, 2004) argued that the recognition of one's own culture is the first step in the transformation from the ethnocentric to the ethnorelative stage of cultural sensitivity. More specifically, cultural self-awareness is addressed as the 
resolution to the Minimization phase on the intercultural development continuum by deepening the understanding of one's own culture, which leads to more "understanding of culture-general and specific frameworks for making sense (and more fully attending to) culture differences" (Hammer, 2009, pp. 208-209).

The Japanese students, who had just come to a new country, had intercultural experience daily outside class as well. They presumably encountered great cultural differences on a daily basis, which means that they had already started to experience their identity encounters outside class. However, identity encounters in an informal setting can be shocking and dangerous, because the person going through an identity encounter might be judgmental and claim that his or her culture is superior or inferior to the counterpart. This is why the second step of cultural identity development, academic input, is so important, and a space where people need to process their experiences and feelings and to scrutinize their own cultural perspectives as well as the other's by applying intercultural concepts (Bennett, 1993b). Thus, it is imperative for students to have an opportunity to explore their cultural identity in a formal setting in conjunction with informal settings.

Based on the findings, the Japanese students in this course appear to have found that the intercultural theories and concepts contributed valuably to their understanding of the issues they encountered every day. The tea ceremony experience was another opportunity for Japanese students to discover or learn more about their own culture. They realized that the tea ceremony reflects on all aspects of Japanese culture. Therefore, the intentional intercultural course reinforced the Japanese students' daily cultural 
encounters with the theoretical and structural instruction of intercultural concepts, which helped them undergo the process of development of cultural identity and intercultural sensitivity and competence. The combination of both informal and formal settings possibly explains why the Japanese participants progressed in their intercultural sensitivity more than the American participants.

\section{American Participants}

It is notable that the majority of the American participants (three out of four) mentioned that the intergroup discussions were the most effective type of learning experience. They also raised intergroup interaction as a highlight of this course. Because American students do not often experience such intercultural contexts outside the classroom, it is a crucial learning experience for domestic American students to interact with international students, who bring new cultural perspectives to the class throughout the term. Smith (1997) insisted that domestic students could obtain great benefits from culturally blended classrooms because they constitute the majority of the student body and have less contact with people from different cultural backgrounds than do international students.

Unlike the Japanese participants, the American participants had diverse cultural backgrounds that may have brought about the varying results in intercultural development. The findings from the interviews and the reflection papers support their orientations of intercultural sensitivity on Hammer's (2009) intercultural development continuum (IDC). 
Amy, who had the highest scores in both pre- and postassessments and who was the only one to reach the stage of Acceptance, showed her advanced level of intercultural sensitivity in the findings. She was also the only American participant who perceived that all the four learning dimensions were equally effective for her intercultural development. To prove her perception, her comments and statements reflected the development of cultural appreciation and cultural inspiration in all four dimensions. In particular, cultural inspiration was a significant area of development that occurred to Amy in two learning dimensions of Abstract Conceptualization (AC) and Active Experimentation (AE). Her development gap between the pre- and postassessment was not very large, and she had the fifth-largest score increase out of the eight participants. This is because she was already at the cusp of Acceptance in the pretest and she did not have as much room to develop compared to the other participants. Therefore, the findings of Amy's intercultural development from the interviews and the reflection papers support her orientation of intercultural sensitivity on Hammer's (2009) intercultural development continuum (IDC).

Mark, on the other hand, remarkably increased his assessment scores of intercultural sensitivity, perhaps because there was substantial room for change. His score increase was the fourth largest of all and the first largest among the American participants. Even though he progressed greatly, his posttest results placed him at the beginning of Minimization and the lowest of all the participants. The findings from the interview and the reflection papers showed that he experienced the development of cultural appreciation through the tea ceremony and intergroup discussions; however, he 
did not experience cultural self-awareness in any learning dimensions. In other words, he did not mention at all the discovery of his own culture or cultural identity and talked only about how to adjust himself to the other culture. The new intercultural knowledge, such

as cultural basic assumptions, seemed to become a strategy to deal only with intercultural communication without trying to deeply understand either the other culture or his own culture. His comments and statements were always limited and indicated that he realized the existence of the other culture but tried to manipulate intercultural situations.

Therefore, the findings of Mark's intercultural development from the interviews and the reflection papers support his orientation of intercultural sensitivity on Hammer's (2009) intercultural development continuum (IDC).

Mark's case also indicates that it is important to progress in each area of development in order for robust intercultural development to occur. In other words, people need to become aware of and analyze their own culture before being able to understand other cultures truly and deeply.

\section{Cultural marginalization.}

The assessment scores raised a question as to why Jake and Cary improved the least and stayed in the same stage, in the middle of Minimization. They seemed to have maintained the status quo. It is notable that they are (respectively) first- and secondgeneration Asian Americans who practice their heritage culture at home. They have a bicultural background where they switch culture codes between the mainstream culture and the heritage one on a daily basis. Hammer (2009) stated that since nonmainstream members are often aware of how mainstream members' privilege functions in the society, 
"Minimization therefore functions more as strategy for getting things done within a dominant cultural context" (p. 208), taking the form of "go along to get along," for example. Hammer (2012) added that a little increase or a slight decrease in scores may be expected for those who already have some intercultural experience or experience cultural differences daily such as people from immigrant families, because they tend to think about intercultural issues more complexly than their monocultural counterparts and a single series of cultural experience may not stimulate a change in their worldview.

In Jake and Cary's case, they may be dealing with issues related to their own cultural marginalization, where they "construe their identities at the margins of two or more cultures and central to none" (Hammer et al., 2003, p. 425). Encapsulated marginality is one of the two categories in cultural marginalization, and is a state in which "the separation from culture is experienced as alienation" (Hammer et al., p. 425). M. J. Bennett (2004) claimed that nonmainstream group members in this condition "may find themselves 'caught' between their own minority ethnic group and the majority ethnic group" (p. 72). As a result, "while people in this condition are quite interculturally sensitive, they lack the ability to implement that sensitivity in consistently competent ways" (p. 72).

Based on the interviews with Jake and Cary, they showed some acute understanding of intercultural communication, such as cultural appreciation, respect, patience, and curiosity. The stagnation of their intercultural sensitivity scores could mean that for Jake and Cary, as nonmainstream members, the intercultural experience through this course would not have been a major enough intercultural event to transform their 
worldview. However, even though the scores of the assessment do not necessarily show a great development in their intercultural sensitivity, the data of the interview and reflection papers indicate that the intentional intercultural course stimulated them to explore their multicultural identity and to understand the complexity of intercultural communication.

\section{Three Areas of Intercultural Development and Existing Models}

This section investigates whether the emergence of three development areas of intercultural competence is supported by the existing models of intercultural development. I examine two significant models: Deardorff's (2006) pyramid model of intercultural competence and Hammer's (2009) intercultural development continuum (IDC), which is modified from M. J. Bennett's (1986; 1993b) Developmental Model of Intercultural Sensitivity (DMIS).

\section{Three Areas of Intercultural Development and Deardorff's Pyramid Model}

The three development areas of intercultural competence that emerged from the interviews and the reflection papers support Deardorff's (2009) pyramid model of intercultural competence. Deardorff argues that the pyramid model moves from the individual level of attitudes and personal attributes to the comprehension of knowledge, to the internal outcome, and to the external outcome. 


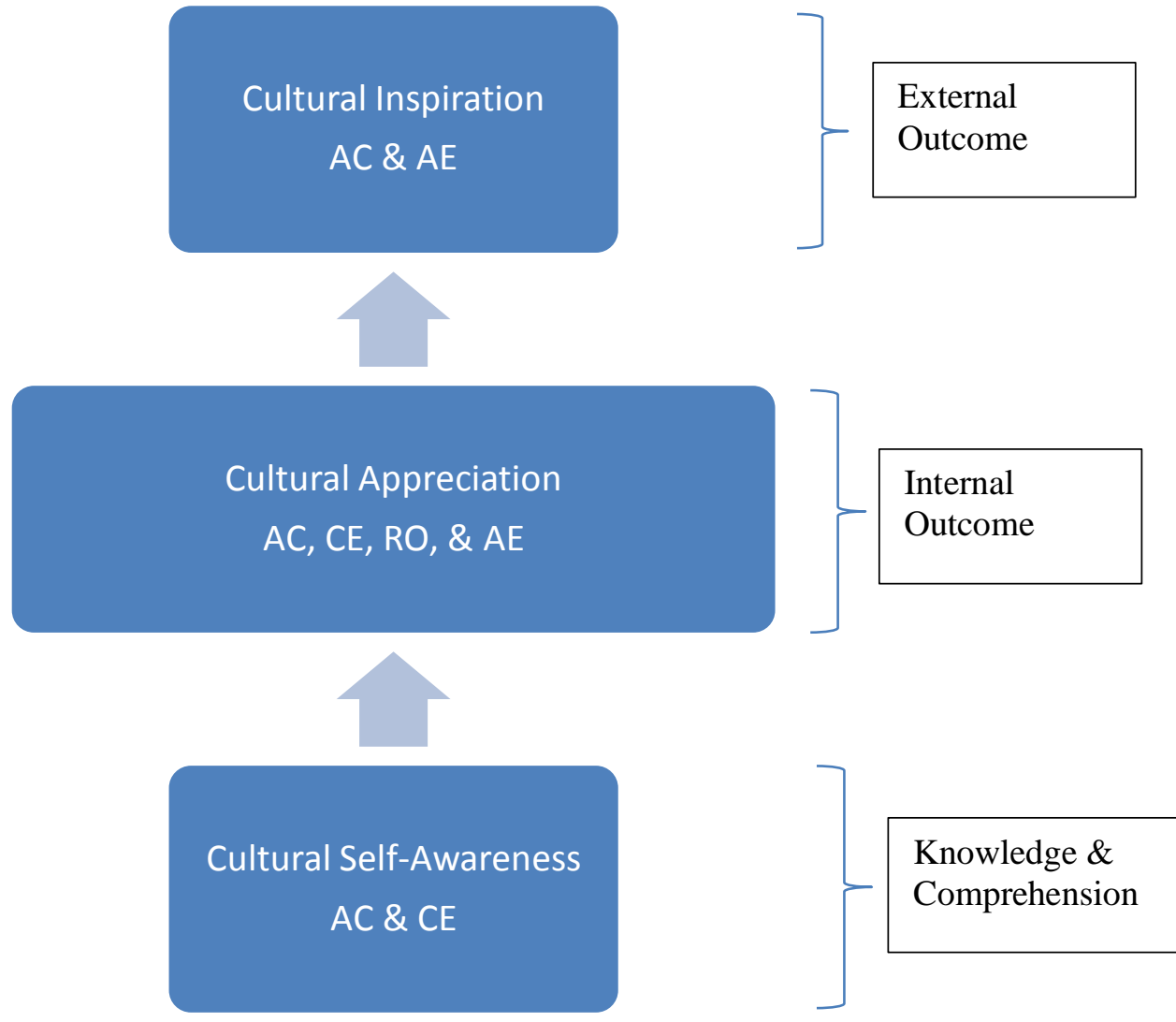

Figure 8. Diagram of the Three Development Areas of Intercultural Competence With Kolb's Learning Dimensions Combined With Deardorff's Pyramid Model

As the diagram in Figure 8 shows, the three areas of intercultural competence are equivalent to the components of knowledge and comprehension (cultural self-awareness), internal outcome (cultural appreciation) and the external outcome (cultural inspiration). Deardorff's (2006) definition of knowledge in this model, a deep understanding of other cultures as well as one's own culture, matches the concept of cultural self-awareness. The practice of the internal outcome, which includes adaptability to different communication styles and behaviors, adjustment to new cultural environments, cognitive flexibility, and an ethnorelative perspective, happened in the practice of cultural appreciation. Finally, the description of the external outcome - the appropriate and 
effective behaviors and communication in intercultural situations based on one's intercultural knowledge, skills, and attitudes - fits the concept of cultural inspiration, which involves active participation in intercultural relations through appropriate and effective communication.

\section{Three Areas of Intercultural Development and the Intercultural Development Continuum}

The triangulated data of this study, including the assessments, the interviews, and the reflection papers, support the connection between the three development areas of intercultural competence that emerged from the interviews, the reflection papers, and Hammer's (2009) intercultural development continuum (IDC). The development of cultural self-awareness can be placed in the stage of Minimization where the transformation from ethnocentric mindset to ethnorelativistic mindset starts to happen. Cultural appreciation seems to occur in the process of moving from Minimization to Acceptance, which involves more complex understanding of cultural differences with continuing efforts to adjust oneself to other cultures. Cultural inspiration seems to mainly happen in the stage of Acceptance, which includes bringing more active and skillful participation to intercultural relations with a deeper understanding of cultural differences.

\section{Kolb's Learning Dimensions and Intercultural Development}

This section will scrutinize the answer to subresearch question (b): "How are the aspects of the intentional course design more or less effective for developing students' intercultural sensitivity? In other words, this section will examine how effective each of Kolb's learning dimensions was for developing intercultural sensitivity. First, I discuss 
the disconnection between perceived and preferred learning styles. Next, I discuss the connection between Kolb's learning dimensions and the three areas of intercultural competence, examining if any learning dimension facilitated any specific area of intercultural development. Finally, I investigate the effectiveness of each respective learning dimension to see if the four learning dimensions are equally valued or effective for intercultural development.

\section{Perceived vs. Preferred Learning Styles}

The findings raised a question about why there is a gap between the perceived most effective learning styles and the preferred learning styles. The perceived learning styles were yielded from the interviews, based on the question, "Which dimension do you think would have been most helpful for your intercultural learning?" This question attempted to investigate which learning dimension worked best for each participant for learning intercultural sensitivity. The preferred learning styles came from Kolb's Learning Style Inventory that the participants did during the class. The inventory assessed the students' general preference of learning styles, not specific to the subject of intercultural learning. The finding of the gap indicates that participants do not necessarily follow their general preference for a learning style when learning about intercultural sensitivity. The process of intercultural learning involves multiple cultural factors, such as cultural backgrounds, cultural identities, intercultural experiences, different stages of intercultural competence, and so forth. Therefore, the disconnection between perceived and preferred learning styles can be explained to be culturally conditioned over personal preference. 


\section{Kolb's Learning Dimensions and the Three Areas of Intercultural Development}

The three areas of intercultural development were observed across all of Kolb's learning dimensions. This finding raised a question as to whether any learning dimension facilitated any specific area of intercultural development.

Table 4 shows the three areas of intercultural development and Kolb's learning dimensions with the number of Japanese and American participants added. All three development areas were observed in the dimension of Abstract Conceptualization (AC),

Table 4. The Three Areas of Intercultural Development in Detail by Kolb's Learning Dimensions

\begin{tabular}{|l|c|l|l|l|}
\hline & $\begin{array}{l}\text { Readings \& } \\
\text { Lectures: Abstract } \\
\text { Conceptualization } \\
\text { (AC) }\end{array}$ & $\begin{array}{l}\text { Tea Ceremony: } \\
\text { Concrete } \\
\text { Experience } \\
\text { (CE) }\end{array}$ & $\begin{array}{l}\text { Bicultural Guest } \\
\text { Talk: Reflective } \\
\text { Observation } \\
\text { (RO) }\end{array}$ & $\begin{array}{l}\text { Intergroup } \\
\text { Discussions: } \\
\text { Active } \\
\text { Experimentation } \\
\text { (AE) }\end{array}$ \\
\hline $\begin{array}{l}\text { Cultural Self- } \\
\text { Awareness }\end{array}$ & $\begin{array}{l}\text { 4 Js } \\
\text { 3 As }\end{array}$ & 3 Js & & All \\
\hline $\begin{array}{l}\text { Cultural } \\
\text { Appreciation }\end{array}$ & 1 A (Amy) & All & $\begin{array}{l}\text { 4 Js } \\
\text { 3 As }\end{array}$ & $\begin{array}{l}\text { 2 As } \\
\text { (Amy \& Cary) }\end{array}$ \\
\hline $\begin{array}{l}\text { Cultural } \\
\text { Inspiration }\end{array}$ & 1 A (Amy) & & & \multicolumn{2}{c}{} \\
\hline
\end{tabular}

*J = Japanese participants; $\mathrm{A}=$ American participants

the theory-based materials, such as readings and lectures. Two of the development areas were observed in two dimensions: Concrete Experience (CE) of the tea ceremony and Active Experimentation (AE) of intergroup discussions. One development area occurred in the Reflective Observation (RO) of the bicultural guest talk. These findings indicate that the dimension of Abstract Conceptualization (AC) promoted all three areas of intercultural development. However, looking at the data more closely, in the dimension of AC, cultural appreciation and cultural inspiration were experienced only by Amy, the culturally advanced participant. 
Examining the data by the development areas, cultural self-awareness, which is the fundamental type of development, occurred in two of the learning dimensions: the readings and lectures as Abstract Conceptualization (AC) for all four Japanese participants and three Americans, and the tea ceremony experience as Concrete Experience (CE) for three of the Japanese participants. The findings indicate that acquiring new knowledge about intercultural theories and concepts prompted both Japanese and American students to think about their own culture and cultural identity. The tea ceremony experience encouraged Japanese students to realize how Japanese they were because they were able to feel the very Japanese atmosphere there.

The development area of cultural appreciation was observed in all of the four learning dimensions. In the dimensions of $\mathrm{CE}$ (the tea ceremony) and $\mathrm{AE}$ (intergroup discussion), cultural appreciation was experienced by all the participants. In the dimension of RO (the bicultural guest talk), cultural appreciation was experienced by seven out of eight participants. As mentioned above, in the dimension of AC (readings and lectures), cultural appreciation was experienced by Amy. Cultural appreciation involves a lot of developmental factors, including a cognitive shift from a monocultural to an intercultural mindset and the behavioral development of cultural adjustment. The findings indicate that cultural appreciation happened actively in three of the learning dimensions: the Concrete Experience of the tea ceremony, the Reflective Observation of the bicultural guest talk, and the Active Experimentation of the intergroup discussions.

The most advanced development area, cultural inspiration, was experienced in Abstract Conceptualization by Amy and Active Experimentation by Amy and Cary. The 
findings indicate that the theory-based learning dimension stimulated an interculturally advanced student to develop more complex thinking and that the intergroup discussions encouraged some American students to take an active role in facilitating the easing of tense intercultural situations.

\section{Effectiveness of Respective Learning Dimension}

The data from the interviews and the reflection papers raise the question of whether Kolb's four learning dimensions are equally valuable or effective for intercultural development. This section will go over each of Kolb's learning dimensions and scrutinize this question by considering the existing theories. In analyzing the data, I found two patterns relating to the development of intercultural competence that each respective learning dimension can offer. One is the processes of intercultural development: cognitive, experiential, perceptional, and behavioral; and the other is the stages of intercultural competence, which are either fundamental or progressive. Table 5 shows that one of these two patterns emerged in each learning dimension.

Table 5. Two Patterns of Intercultural Competence by Kolb's Learning Dimensions

\begin{tabular}{|l|c|c|l|l|}
\hline & $\begin{array}{l}\text { Readings \& } \\
\text { Lectures: Abstract } \\
\text { Conceptualization } \\
\text { (AC) }\end{array}$ & $\begin{array}{l}\text { Tea Ceremony: } \\
\text { Concrete } \\
\text { Experience (CE) }\end{array}$ & $\begin{array}{l}\text { Bicultural Guest } \\
\text { Talk: Reflective } \\
\text { Observation } \\
(\mathrm{RO})\end{array}$ & $\begin{array}{l}\text { Intergroup } \\
\text { Discussions: } \\
\text { Active } \\
\text { Experimentation } \\
\text { (AE) }\end{array}$ \\
\hline $\begin{array}{l}\text { Components of } \\
\text { IC Competence }\end{array}$ & Cognitive & Experiential & Perceptional & Behavioral \\
\hline $\begin{array}{l}\text { Stages of IC } \\
\text { Competence }\end{array}$ & Fundamental & Fundamental & Progressive & Progressive \\
\hline
\end{tabular}




\section{Theory-based materials as Abstract Conceptualization (AC).}

The findings support the idea that the dimension of Abstract Conceptualization is effective, specifically for the fundamental development of understanding other cultures as well as one's own culture and for cognitive development. Knowledge or cognition of intercultural communication has to be the base of intercultural sensitivity and competence. Students need to learn and understand theories and concepts in order to apply them. In other words, knowledge and cognition will maximize the learning experiences in the other three dimensions. This first step of intercultural learning, cognitive development, is synchronized with the first learning dimension of theory-based materials, such as readings and lectures.

Regarding cognitive development, it is important to consider in what order the content of the course should be taught. This topic relates to the first dimension of Smith's (1997) core of scholarship: the curriculum—what we teach. Smith emphasized the course content that gives core knowledge acquisition. M. J. Bennett (1998) addressed a two-layer approach to introducing intercultural course content: culture-general and then culture-specific, as discussed in Chapter 2 of this dissertation. Weaver (1993) insisted that "the sequence of topics is very important" (p. 160), and that it should move from the culture-general to the culture-specific, because learners "are more likely to develop coping strategies and gain understanding rather than simply amassing questionable information" (pp. 160-161).

The course in this study introduced the cultural iceberg model with the 10 dichotomous basic assumptions as a core theory of cultural general knowledge at the 
beginning. When culture-specific topics were introduced later, students had constantly practiced analyzing aspects of the cultures with the cultural iceberg model throughout the course. This model strongly impacted the students' intercultural sensitivity development. Learning the core theory and how to analyze culture with the iceberg model helped students gain a deeper understanding of the other culture as well as their own culture. Moreover, after students practiced repeatedly and once they mastered the concepts and the skills to analyze any culture, the cultural iceberg analysis with the basic assumptions became an important utility for daily-life intercultural communication even after the course was over.

Thus, this core theory promoted the cognitive part of intercultural sensitivity development and expanded into practice as skill building. It was effective to apply the two-layer approach of intercultural content and to introduce the cultural iceberg model as a core theory at the beginning of the course. The findings support the first component of Smith's (1997) core scholarship, the curriculum—what we teach, and M. J. Bennett's (1998) two-layer approach as the fundamental component of intercultural competence. Therefore, the learning dimension of Abstract Conceptualization (AC) is crucial and effective for the cognitive component of intercultural development at the fundamental stage.

\section{Tea ceremony as Concrete Experience (CE).}

The findings support the effectiveness of the dimension of Concrete Experience, specifically for fundamental development of understanding other cultures as well as one's own culture with the experiential learning process. Kolb (1984) argued that learning 
should be experiential so that learners can directly be in touch with realities being studied and can strongly relate the classroom and the real world. In this sense, the dimension of Concrete Experience is specifically powerful because students can get involved with people in new experiences where they are open-minded and willing to learn from their feelings and the people around them.

The course in this study included a field trip to the Japanese Garden where students experienced the Japanese tea ceremony. This experience provided both Japanese and American students with an opportunity to learn in an authentic cultural context. Three Japanese participants experienced cultural self-awareness through the authentic context of their own culture. All American participants experienced cultural appreciation through the tea ceremony experience.

I insist that this dimension is strongly linked to the dimension of Abstract Conceptualization. More specifically, in the fundamental stage of intercultural development, the input of new knowledge reinforced the effectiveness of the learning dimension of Concrete Experience. In other words, the students would not have learned as much from the tea ceremony if they had just experienced it without the input of intercultural theories and concepts. The data of the interviews and reflection papers support this assumption. The Japanese participants commented that the tea ceremony was an eye-opening experience because they got to realize all aspects of Japanese culture, based on the knowledge about the cultural basic assumptions that they had just learned. The American participants claimed that they appreciated such a fascinating and authentic 
cultural experience and applied their new knowledge to this particular context for a deeper understanding of the other culture.

Therefore, in the fundamental stage of intercultural development, learning through an authentic cultural context is essential because students can connect what they learned in the classroom with the real world. The learning dimension of Concrete Experience (CE) is crucial and effective for the fundamental development of intercultural competence, in combination with Abstract Conceptualization (AC).

\section{Bicultural guest talk as Reflective Observation (RO).}

The findings support the effectiveness of the dimension of Reflective Observation, specifically for the progressive development of navigating intercultural situations with a deeper understanding of other cultures as well as one's own culture at the perceptional level. Kolb (1984) posited that the learning process involved perceiving, which means to learn by watching and listening and to view things from a variety of perspectives to look for the meaning of what one observes.

The course in this study invited a Japanese guest speaker to share her personal stories of bicultural perspectives and intercultural work experience. All four Japanese and three of the American participants experienced cultural appreciation by watching and listening to the guest speaker. This finding also supports Merriam and Caffarella's (1999) power of storytelling. They asserted storytelling as a powerful tool because it is someone's real voice, not something in lectures or readings. The participants remarked that they learned from both the content of the talk and the speaker's way of presenting. 
They applied their new knowledge and perspectives to what they saw and heard from the speaker.

Therefore, the learning dimension of Reflective Observation (RO) is a perceptional learning experience, which is crucial and effective for the progressive development of intercultural competence.

\section{Intergroup discussions as Active Experimentation (AE).}

The findings support the effectiveness of the dimension of Active Experimentation, specifically for the progressive development of navigating intercultural situations with a deeper understanding of other cultures as well as one's own culture at the behavioral level. Kolb (1984) argued that learners could apply the theories they learned by taking action and experimenting with influencing or changing situations to see and learn from the results of the action.

The course in this study provided students with plenty of opportunities for intergroup discussions inside and outside of class. As the main activity, the students were assigned culture-exchange group discussions outside of class so that they were able to exchange different cultural values and norms along with the topics and theories they learned. All participants experienced cultural appreciation in this learning dimension. Based on their new knowledge of intercultural communication, participants took action and tried to adjust themselves to the other culture. They reported that as a result they soothed tension in intercultural situations, achieved mutual understanding, and built productive relationships with their group members. Two of the Americans experienced cultural inspiration by playing the role of a cultural bridge in order to narrow the 
intercultural gaps. Thus, this dimension expands opportunities for learners to improve their intercultural competence at the behavioral level.

The findings support Otten's (2003) argument that the important thing is the theoretical and structural instruction of intercultural concepts along with intergroup interaction. With academic input, students could try to apply what they learned in the course to facilitate the interactions with each other. The intergroup discussions were also a hands-on learning opportunity to learn about multiple individual viewpoints even within the same culture group.

The findings also support Allport's (1954) intergroup contact theory. He posited that intergroup contact would reduce prejudice and foster mutual understanding if the contact situation was associated with four positive features: (a) equal status between the groups, (b) common goals, (c) intergroup cooperation, and (d) the support of authorities, law, or custom. The intentionally designed intercultural course in this study met these features, because the domestic American students and Japanese exchange students had the same status in the sense that they were all students who were taking the course, sharing the common goals of learning the same subject and completing the course. The American and Japanese students both experienced intergroup cooperation through the group discussions in class and the assigned intergroup discussions outside of class by working together and relying on each other to achieve their shared goals. Pettigrew and Tropp (2005) emphasized that common goals are likely to be attained with an interdependent effort based on cooperation rather than competition. This cooperative learning environment reinforces students' understanding because they can learn about 
each other's ways of thinking and problem-solving (Duster, 1995). Regarding the support of authorities, I, as the teacher, played the role of authority figure by creating guidelines and a safe learning environment in the classroom and by providing proper topics for productive discussions.

The learning dimension of Active Experimentation (AE) is a behavioral learning experience, which is crucial and effective for progressive development of intercultural competence.

In sum, it is hard to determine that one dimension is more effective than the others. Rather, each learning dimension provides students with an opportunity to develop different components of intercultural competence, such as cognitive, experiential, perceptional, and behavioral, and different stages of intercultural competence, such as fundamental and progressive.

\section{Recommendations}

In this section I offer some recommendations for designing an effective intercultural course in order to develop students' intercultural competence, based on the findings of this study. The recommendations given are for culturally hybrid classrooms, which I believe are the type of classrooms that will become most typical at colleges. The recommendations start with Kolb's four learning dimensions, followed by three other factors for intercultural learning, including the benefit of nonmainstream instructors, the benefit of a culturally hybrid classroom, and the necessity of intercultural courses.

The findings of this study suggest that the order of Kolb's learning dimensions to be introduced is important. More specifically, the course should start with Abstract 
Conceptualization (AC) in order to provide students with the fundamental knowledge of intercultural learning, followed by Concrete Experience (CE) and Reflective Observation (RO). Active Experimentation (AE) can start early and continue throughout the term so that students can have enough time to experiment with intergroup interaction and improve their intercultural communication skills.

\section{Theory-Based Materials as Abstract Conceptualization (AC)}

It cannot be overstated that learning from theory-based materials such as readings and lectures is crucial for building the base of all the other learning dimensions. To maximize the effectiveness of this learning dimension, the course reader should include a variety of resources about relevant topics in order to provide multiple perspectives. It is important to consider the different levels of reading skills in the culturally hybrid class. For example, international students may struggle to read the materials, which are not written in their first language. To accommodate the international students, the course reader can include different reading levels of materials or the instructor can give the American students extra readings.

Lectures can reinforce the contents of the readings and provide additional information. An instructor can share her/his personal stories and intercultural experiences, because storytelling is a powerful tool for helping learners understand complex theories and concepts. Lectures should take the non-native students' level of English into consideration. The instructor should make sure to speak clearly and slowly enough for non-native students to understand and be sure to avoid using slang or cultural expressions. S/he can remind American students to speak in the same way when they 
speak up. But s/he can also sometimes summarize or paraphrase what students say in order to help non-native speakers understand it.

\section{Intercultural Experience as Concrete Experience (CE)}

In this study, the class went to the Japanese Garden and experienced the tea ceremony, where Japanese participants felt the authentic and unique Japanese atmosphere and enhanced their cultural self-awareness, while American students enjoyed learning in an authentic cultural context by experiencing the unfamiliar atmosphere. As Kolb (1984) recommended, experience-based education is crucial for intercultural learning.

For future implementation, depending on what cultures are represented in the classroom, multiple opportunities for authentic cultural experiences that represent each culture can be scheduled if time allows. For example, the class can go to foreign gardens, a cultural place or event, such as a cultural fair, a refugee center, or be assigned historic preservation service learning.

\section{Bicultural Guest Talk as Reflective Observation (RO)}

It is ideal to have two bicultural guest speakers: one from the mainstream culture and the other from a nonmainstream culture. In this case, students can learn two different perspectives by watching and listening to the two different types of presentations.

\section{Intergroup Interaction as Active Experimentation (AE)}

It is important to provide students with a lot of opportunities for intergroup discussions inside and outside of class. For example, every time that a new theory or concept is introduced, a chance to have a small-group or pair discussion should be 
provided. The instructor should match up students from different cultural backgrounds so that they can exchange different cultural perspectives.

The class can be divided into culturally mixed groups of three to five students for outside-of-class discussion assignments. The small group size is better because nonnative speakers or students from nonmainstream cultures may be more comfortable speaking in a small-group setting. It is best to assign a few discussion sessions with the same group members throughout the term so that students can get to know each other better, get more comfortable sharing their stories and opinions, and build intercultural friendships.

\section{Benefit of Nonmainstream Instructors}

According to one American participant, learning from a nonmainstream instructor is beneficial because s/he speaks through her/his experiences from a nonmainstream cultural perspective that an American instructor cannot provide. Another benefit of nonmainstream or non-native instructors is that they can automatically create an intercultural context in the classroom. In other words, students have to listen to nonnative English, which requires more effort to understand, and communicate with a nonnative instructor, who may not share the same perspective with them. Therefore, students have to deal with intercultural issues constantly when navigating the course, which is already an intercultural learning experience.

\section{Benefit of the Culturally Hybrid Classroom}

All participants mentioned that the culturally hybrid class was beneficial for their intercultural learning. The culturally hybrid classroom creates an intercultural context. 
In this setting, students can interact with their classmates from different cultural backgrounds inside and outside of the classroom, exchanging different values, beliefs, and norms.

\section{Necessity of Intercultural Courses}

One American participant remarked that she strongly believes that intercultural courses should become a requirement for college students, because bridging cultures and learning from each other are key in this globalized world. I agree with her because every college student needs to develop intercultural sensitivity in order to work and live as a

global citizen. To do so, students need to learn intercultural knowledge and interact with people from different cultures in the academic setting.

\section{Limitations of the Study}

The findings of this research study must be tentative because the size of the research sample was small. For future research, larger samples will be necessary. My research is limited to only one case, which is a college course. This study investigated one course, which had a unique hybrid setting with American students and Japanese exchange students, and therefore it is difficult to generalize the findings to other populations. This unique student population is a limitation because the two student groups were from different cultural and social backgrounds and were in such a different learning context regardless of the intentionally designed course they took together. When considering why the Japanese participants improved their IDI scores greatly, we do not know how much is because of the intentional intercultural course and how much is because of living in the host culture. There are other possible factors that affected the 
research data besides the course design. In terms of the applicability to other intercultural courses designed with Kolb's four pedagogical strategies, further research studies would be necessary to examine a variety of intentional courses and different student populations from different cultural backgrounds.

Another limitation is that I taught the course in which the research study was conducted. Therefore, the students might have felt forced to participate in the research study, even though the grade criteria were articulated on the syllabus and the research results did not affect grades. This issue might have affected the data as well. As discussed in the interview section, the researcher-respondent relationship could also have been the teacher-student relationship, even though the students were assured that the course was over and the grades were already submitted so that the interview had nothing to do with the respondents' academic performance in the course. The fact that the respondents had already reviewed their grades might have skewed the interview data. For example, if a respondent received a low grade, s/he might have had a negative impression of this course and thought s/he did not learn much from the course. If a respondent received a good grade, s/he might have felt satisfied with the learning experience in the course and tended to voice positive things about the course. Since the written materials for document analysis were students' papers, which were a part of the course work, the data might have been skewed if participants had connected the research study to the course grading, even though it was emphasized that the grade criteria were articulated on the syllabus and that the research results did not affect the grades. Further research 
studies will be necessary with courses that are taught by someone who is not the researcher.

My position and biases were another limitation. Even though I kept this issue in mind and made sure that I shifted in my role from a teacher to a researcher, I was aware of the biases that I might have brought especially for the qualitative research methods.

Regarding the quantitative inventory, the interval between the pretest and the posttest might not have been long enough to show significant differences in terms of students' intercultural development. The instrument was conducted in the beginning and at the end of the course, an interval of 10 weeks, with 40 hours of course instruction during those 10 weeks. It usually takes at least 40 hours for learners to process what they learn and make a major cognitive and behavioral transformation (Hammer, 2009). Thus, the number of course-required hours reached the point where the students might show a developmental outcome on intercultural sensitivity and competence with the IDI; however, significant changes might not have occurred in such a short time. Further research studies with a longer interval between IDI pre- and posttests, such as six months or longer, will be needed in order to obtain more significant results.

The domestic participants were two males and two females; on the other hand, all four Japanese participants were female. Therefore, the sex of the participants is unbalanced. If there were two female and two male Japanese participants, the sex would be more balanced and the data would have been more consistent. Therefore, it is uncertain how much sex might have influenced the development of intercultural sensitivity. 
Regarding the learning dimension of Concrete Experience (CE), in addition to the field trip to the Japanese Garden, the class could have gone to a place or an event that represents authentic American culture, such as a rodeo or a historic center. In this case, American students could have experienced cultural self-awareness, while Japanese students could have felt the unfamiliar atmosphere, learned in an authentic cultural context, and developed intercultural sensitivity more.

The bicultural guest talk as Reflective Observation (RO) was only from a Japanese perspective. If we had had an American bicultural speaker to speak from an American point of view, the Japanese and American participants' reactions might have been different. More particularly, the American students might have had cultural inspiration, which might have helped them transform their worldview. Therefore, not having an American bicultural guest speaker may have limited the American students in learning and developing their intercultural sensitivity.

Regarding the learning dimension of Active Experimentation (AE), Japanese students had limited language abilities in the intergroup discussions. They had to utilize their second language in order to make themselves understood and make conversation with their American classmates. Therefore, it is uncertain how much the Japanese participants understood the contents of the discussions and how accurately they were able to convey their cultural perspectives to their classmates.

Regarding the document analysis of the reflection papers, it is notable that the Japanese participants wrote the papers in their second language. Specifically, it was the very first school term in America for them, which means that their papers may not 
perfectly reflect their thoughts and opinions, especially the first two papers that were written in the first half of the term when they were still learning how to write academic papers in English. Therefore, the data of the reflection papers may be skewed between the American participants and the Japanese participants.

\section{Implications of the Study}

This study implied that the four pedagogical strategies associated with Kolb's learning cycle were effective and crucial when designing an intercultural course in order to develop college students' intercultural competence. Each dimension provides learners with an opportunity to develop different components, such as cognitive, experiential, perceptional, and behavioral, and to improve different stages of intercultural sensitivity. Regarding the different components of intercultural competence, Abstract Conceptualization (AC) is more likely to promote the cognitive component, Concrete Experience (CE) the experiential, Reflective Observation (RO) the perceptional, and Active Experimentation (AE) the behavioral. Regarding different stages of intercultural sensitivity, Abstract Conceptualization (AC) and Concrete Experience (CE) are more likely to promote the fundamental knowledge and skills of intercultural competence; Reflective Observation (RO) and Active Experimentation (AE), on the other hand, are more likely to promote progressive components of intercultural competence.

This study revealed a gap in intercultural development through the intentional intercultural course between American students and Japanese exchange students due to their vastly different intercultural experiences. More specifically, the Japanese participants' intercultural sensitivity developed more than the American participants', 
because the Japanese exchange students were exposed to intensive intercultural experiences on a daily basis outside the classroom, and this course reinforced their intercultural understanding with academic input. The intentionally designed intercultural course provided American students with great opportunities to learn and experience intercultural communication and to improve their intercultural sensitivity at their own pace, depending on their cultural backgrounds. I would like to emphasize the importance and necessity of well-designed effective intercultural courses for domestic American students, because the majority of them stay on their home campus with limited exposure to intercultural experience. It is imperative that they become interculturally competent in order to live and work in this globalized world.

\section{Conclusion}

Responding to the rapid change toward globalization, higher education has a crucial mission to prepare students to be responsible global citizens and successful professionals in multicultural workplaces (Parsons, 2010). American higher education institutions have invested a great amount of effort, money, and staff time in internationalization, focusing on the following three elements: increasing participation in study abroad programs, enrolling more international students, and internationalizing the curriculum (Parsons, 2010). Yet, Parsons stated that there was little solid research evidence of the effectiveness of the various aspects of internationalization or the student learning outcomes expected as a result of internationalization. Research studies on student learning outcomes in the internationalized curriculum in particular are far fewer than those on learning experiences and outcomes from study abroad and international 
student programs, even though the majority of U.S. students stay and study on a U.S. campus. This study helped to fill in the gap in research, addressing the four pedagogical strategies for intercultural learning and investigating college students' intercultural learning experiences and developmental processes through a course designed with the systematic strategies. More specifically, this study was to examine whether and how Kolb's four pedagogical strategies work for domestic and exchange students' intercultural sensitivity development. The findings helped me improve the pedagogical strategies with a more effective course design associated with Kolb's learning cycle to use in future courses of this nature.

Internationalization at home (IaH) stresses the fact that it must start at home, in each institution, involving everybody (Teekens, 2007). This concept is based on the fundamental mission of higher education to create a better world "by helping students to study, live and work in the cultural, ethnic and social diversity that is a basic feature of society in the $21^{\text {st }}$ century" (Teekens, p. 11). It is important to acknowledge that "there are many components of internationalization; that successful IaH is always a work in progress, not an end state; and that it is a holistic process" (Paige, 2003, p. 61). It is hoped that this research study will potentially identify pedagogical approaches that facilitate college students' intercultural competence. 


\section{References}

Agar, M. (1994). Language shock: Understanding the culture of conversation. New York: William Morrow.

Allport, G. W. (1954/1979). The nature of prejudice. Reading, MA: Addison-Wesley.

Astin, A. W. (1993). What matters in college?: Four critical years revised. San Francisco: Jossey-Bass.

Bennett, M. J. (1986). A developmental approach to training for intercultural sensitivity. International Journal for Intercultural Relations, 10, 179-195.

Bennett, M. J. (1993a). Cultural marginality: Identity issues in intercultural training. In R. M. Paige (Ed.), Education for the intercultural experience ( $2^{\text {nd }}$ ed.) (pp. 109-136). Yarmouth, ME: Intercultural Press.

Bennett, M. J. (1993b). Towards ethnorelativism: A developmental model of intercultural sensitivity. In R. M. Paige (Ed.), Education for the intercultural experience $\left(2^{\text {nd }}\right.$ ed.) (pp. 21-71). Yarmouth, ME: Intercultural Press.

Bennett, M. J. (1998). Intercultural communication: A current perspective. In M. J. Bennett (Ed.), Basic concepts of intercultural communication (pp. 1-34). Yarmouth, ME: Intercultural Press.

Bennett, M. J. (2004). Becoming interculturally competent. In J. S. Wurzel (Ed.), Towards multiculturalism: A reader in multicultural education ( $2^{\text {nd }}$ ed.) (pp. 6277). Newton, MA: Intercultural Resource Corporation.

Bennett, J. M., \& Bennett, M. J. (2004). Developing intercultural sensitivity: An integrative approach to global and domestic diversity. In D. Landis, J. M. Bennett, 
\& M. J. Bennett (Eds.), Handbook of intercultural training $\left(3^{\text {rd }}\right.$ ed.) (pp. 147-165). Thousand Oaks, CA: Sage.

Bogdan, R. C., \& Biklen, S. K. (2007). Qualitative research for education: An introduction to theories and methods ( $5^{\text {th }}$ ed.). Boston, MA: Pearson Education.

Bostrom, C. A. (2010). Diffusion of internationalization in Turkish higher education. Journal of Studies in International Education, 14 (2), 143-160.

Brandeis University. (2011). Mission/diversity statements. Retrieved from http://www.brandeis.edu/about/mission.html

Brewer, M. B. (1996). When contact is not enough: Social identity and intergroup cooperation. International Journal of Intercultural Relations, 20, 291-303.

Butler, C., \& Zander, L. (2008). The business of teaching and learning through multicultural teams. Journal of Teaching in International Business, 19 (2), $192-$ 218.

Byram, M. (1997). Teaching and assessing intercultural communicative competence. Clevedon, UK: Multilingual Matters.

Camarota, S.A. (2010). Immigration and economic stagnation: An examination of trends 2000 to 2010. Retrieved from Center for Immigration Studies website: http://www.cis.org/highest-decade

Campbell, A. (2000). Cultural identity as a social construct. Intercultural Education, 11 (1), 31-39.

Chavez, A. F., \& Guido-DiBrito, F. (1999). Racial and ethnic identity and development. New Directions for Adult and Continuing Education, 84, 39-48. 
Clarke, I., Flaherty, T. B., Wright, N. D., \& McMillen, R. M. (2009). Student intercultural proficiency from study abroad programs. Journal of Marketing Education, 31 (2), 173-181.

Clinchy, B. M. (2000). Toward a more connected vision of higher education. New Directions for Teaching and Learning, 82, 27-35.

Creswell, J. (2005). Educational research: Planning, conducting, and evaluating quantitative and qualitative research. Upper Saddle River, NJ: Pearson Education.

Crowther, P., Joris, M., Otten, M., Nilsson, B., Teekens, H., \& Wächter, B. (2000). Internationalisation at Home: A position paper. Amsterdam: European Association for International Education.

Deardorff, D. K. (2006). The identification and assessment of intercultural competence as a student outcome of internationalization. Journal of Studies in International Education, 10 (3), 241-266.

Dunstan, P. (2003). Cultural diversity for life: A case study from Australia. Journal of Studies in International Education, 7 (1), 64-76.

Duster, T. (1995). They're taking over! and other myths about race on campus. In M. Bérubé, \& C. Nelson (Eds.), Higher education under fire: Politics, economics, and the crisis of the humanities (pp. 276-283). New York: Routledge.

Fantini, A. E. (2000). A central concern: Developing intercultural competence. In A. E. Fantini (Ed.), SIT occasional papers series: Addressing intercultural education, training \& service (pp. 25-33). Brattleboro, VT: School of International Training.

Fenwick, T. J. (2000). Expanding conceptions of experiential learning: A review of the 
five contemporary perspectives on cognition. Adult Education Quarterly, 50 (4), 243-272.

Freire, P. (2000). Pedagogy of the oppressed. New York: Continuum.

Gaertner, S. L., Dovidio, J. F., \& Bachman, B. A. (1996). Revisiting the contact hypothesis: The induction of a common ingroup identity. International Journal of Intercultural Relations, 20, 271-290.

Greenholtz, J. (2000). Assessing cross-cultural competence in transnational education: The Intercultural Development Inventory. Higher Education in Europe, 25 (3), 411-416.

Hammer, M. R. (1999). A measure of intercultural sensitivity: The Intercultural Development Inventory. In S. M. Fowler \& M. G. Mumford (Eds.), Intercultural sourcebook: Cross-cultural training methods vol. 2. (pp. 61-72). Yarmouth, ME: Intercultural Press.

Hammer, M. R. (2007). The Intercultural Development Inventory (IDI) manual. Ocean Pines, MD: IDI, LLC.

Hammer, M. R. (2009). The Intercultural Development Inventory (IDI): An approach for assessing and building intercultural competence. In M. A. Moodian (Ed.), Contemporary leadership and intercultural competence: Exploring the crosscultural dynamics within organizations (pp. 203-217). Thousand Oaks, CA: Sage.

Hammer, M. R. (2011). Additional cross-cultural validity testing of the Intercultural Development Inventory. International Journal of Intercultural Relations, 35, 474487. 
Hammer, M. R. (2012, June). The Intercultural Development Inventory (IDI) qualifying seminar.Seminar conducted at the meeting of IDI, LLC, Minneapolis, MN.

Hammer, M. R., Bennett, M. J., \& Wiseman, R. (2003). Measuring intercultural sensitivity: The intercultural development inventory. International Journal of Intercultural Relations, 27, 421-443.

Hopkinson, G. C., \& Hogg, M. K. (2004). Teaching and learning about qualitative research in the social sciences: An experiential learning approach amongst marketing students. Journal of Further and Higher Education, 28 (3). 307-320.

Institute of International Education. (2010). Open doors 2010 fast facts. Retrieved from http://www.iie.org/opendoors

Jackson, J. (2009). Intercultural learning on short-term sojourns. Intercultural Education, 20, 59-71.

Jon, J. (2009). 'Interculturality' in higher education as student intercultural learning and development: A case study in South Korea. Intercultural Education, 20 (5), 439449.

Joy, S., \& Kolb, D. A. (2009). Are there cultural differences in learning style? International Journal of Intercultural Relations, 33 (1). 69-85.

Kempner, K. (1992). Wolves in sheep's clothing: Positivists masquerading as phenomenologists. Educational Foundations, 6 (1), 67-80.

Klak, T., \& Martin, P. (2003). Do university-sponsored international cultural events help students to appreciate "difference"? International Journal of Intercultural Relations, 27, 445-465. 
Knefelkamp, L. (2006). Development of the multicultural self. Beaverton, OR: Intercultural Communication Institute.

Kolb, D. A. (1984). Experiential learning: Experience as the source of learning and development. Englewood Cliffs, NJ: Prentice-Hall.

Kramsch, C. (2003). Teaching language along the cultural frontline. In D. L. Lange, \& R. M. Paige (Eds.), Culture as the core: Perspectives on culture in second language learning (pp. 19-35). Greenwich, CT: Information Age.

Leask, B. (2007). Diversity on campus-An institutional approach: A case study from Australia. In H. Teekens (Ed.), Internationalisation at Home: Ideas and ideals (pp. 33-39). Amsterdam: European Association for International Education.

Merriam, S. B. (1998). Qualitative research and case study applications in education. SanFrancisco: Jossey-Bass.

Merriam, S. B., \& Caffarella, R. S. (1999). Learning in adulthood: A comprehensive guide ( $2^{\text {nd }}$ ed.). San Francisco: Jossey-Bass.

Mestenhauser, J. A. (1998). Introduction. In J. A. Mestenhauser, \& B.J. Ellingboe (Eds.), Reforming the higher education curriculum: Internationalizing the campus (pp. xvii-xxvii). Phoenix, AZ: Oryx Press.

Mestenhauser, J. A. (2007). Internationalisation at Home: A brilliant idea awaiting implementation. In H. Teekens (Ed.), Internationalisation at Home: Ideas and ideals (pp. 13-21). Amsterdam: European Association for International Education. Milem, J. F., Chang, M. J., \& Antonio, A. L. (2005). Making diversity work on campus: A research-based perspective. Association of American Colleges and Universities. 
Mishler, E. G. (1986). Research interviewing: Context and narrative. Cambridge, MA: Harvard University Press.

Mitsis, A., \& Foley, P. W. (2009). Do business students' culturally anchored values shape student-driven or teacher-driven learning style preferences? Journal of Marketing Education, 31 (3), 240-252.

Montgomery, C. (2009). A decade of internationalisation: Has it influenced students' views of cross-cultural group work at university? Journal of Studies in International Education, 13 (2), 256-270.

Mushi, S. (2004). Multicultural competencies in teaching: A typology of classroom activities. Intercultural Education, 15 (2), 179-194.

National Center for Education Statistics. (2010). The condition of education 2010. Retrieved from http://nces.ed.gov/pubs2010/2010028.pdf

Okayama, C. M., Furuto, S. B., \& Edmondson, J. (2001). Components of cultural competence: Attitudes, knowledge, and skills. In R. Fong \& S. B. Furuto (Eds.), Culturally competent practice: Skills, interventions, and evaluations (pp. 89-100). Boston: Allyn \& Bacon.

Otten, M. (2000). Impacts of cultural diversity at home. In P. Crowther, M. Joris, M. Otten, B. Nilsson, H. Teekens, \& B. Wächter (Eds.), Internationalisation at Home: A position paper (pp. 15-20). Amsterdam: European Association for International Education.

Otten, M. (2003). Intercultural learning and diversity in higher education. Journal of Studies in International Education, 7 (1), 12-26. 
Paige, R. M. (1993). On the nature of intercultural experiences and intercultural education. In R. M. Paige (Ed.), Education for the intercultural experience $\left(2^{\text {nd }}\right.$ ed.) (pp. 1-19). Yarmouth, ME: Intercultural Press.

Paige, R. M. (2003). The American case: The university of Minnesota. Journal of Studies in International Education, 7 (1), 52-63.

Paige, R. M., Jacobs-Cassuto, M., Yershova, Y. A., \& DeJaeghere, J. (2003). Assessing intercultural sensitivity: An empirical analysis of the Hammer and Bennett Intercultural Development Inventory. International Journal of Intercultural Relations, 27, 467-486.

Pappano, L. (2007, November 4). Why study abroad costs so much, what to do about it [Online editorial]. Retrieved from http://www.nytimes.com/2007/11/04/education/edlife/studyabroad-1.html

Parsons, R. L. (2010). The effects of an internationalized university experience on domestic students in the United States and Australia. Journal of Studies in International Education, 14 (4), 313-334.

Patton, M. Q. (2002). Qualitative research \& evaluation methods (3rd ed.). Thousand Oaks, CA: Sage.

Pedersen, P. J. (2010). Assessing intercultural effectiveness outcomes in a year-long study abroad program. International Journal of Intercultural Relations, 34, 70-80.

Pettigrew, T. F., \& Tropp, L. R. (2005). Allport's intergroup contact hypothesis: Its history and influence. In J. F. Dovidio, P. Glick, \& L.A. Rudman (Eds.), On the nature of prejudice: Fifty years after Allport (pp. 262-277). Malden, MA: 
Blakwell.

Phinney, J. S. (1996). Understanding ethnic diversity: The role of ethnic identity. American Behavioral Scientist, 40 (2), 143-152.

Portland State University. (2011). Our mission. Retrieved from http://www.pdx.edu/mission.html

Sakurauchi, Y. H. (2012). INTL 324U: Japan and U.S. cultures in contact. Syllabus. Portland State University.

Sercu, L. (2004). Assessing intercultural competence: A framework for systematic test development in foreign language education and beyond. Intercultural Education, $15(1), 73-89$.

Smith, D. G. (1997). Diversity works: The emerging picture of how students benefit. Washington, DC: AAC\&U.

Tatum, B. D. (1992). Talking about race, learning about racism: the application of racial identity development theory in the classroom. Harvard Educational Review, 62 (1), 1-23.

Taylor, K., Marienau, C., \& Fiddler, M. (2000). Developing adult learners. San Francisco: Jossey-Bass.

Teekens, H. (2007). Internationalisation at Home: An introduction. In H. Teekens (Ed.), Internationalisation at Home: Ideas and ideals (pp. 3-11). Amsterdam: European Association for International Education.

U.S. Census Bureau. (2011). U.S. POPClock Projection. Retrieved from http://www.census.gov/population/www/popclockus.html 
Wächter, B. (2003). An introduction: Internationalisation at home in context. Journal of Studies in International Education, 7 (1), 5-11.

Weaver, G. R. (1993). Understanding and coping with cross-cultural adjustment stress. In R. M. Paige (Ed.), Education for the intercultural experience $\left(2^{\text {nd }}\right.$ ed.) (pp. 137167). Yarmouth, ME: Intercultural Press.

Weaver, G. R. (1993). Understanding and coping with cross-cultural adjustment stress. In R. M. Paige (Ed.), Education for the intercultural experience $\left(2^{\text {nd }}\right.$ ed.) (pp. 137167). Yarmouth, ME: Intercultural Press.

Weaver, G. R. (1998). Contrasting and comparing cultures. In G. R. Weaver (Ed.), Culture communication and conflict (pp. 72-77). Needham Heights, MA: Simon and Schuster.

Yamazaki, Y., \& Kayes, D. C. (2004). An experiential approach to cross-cultural learning: A review and integration of competencies for successful expatriate adaptation. Academy of Management Learning \& Education, 3 (4), 362-379.

Zlatic, L. (2009, July 16). Study abroad 101: How much does it cost? [Online forum]. Retrieved from http://www.examiner.com/student-travel-in-washington-dc/study-abroad101-how-much-does-it-cost 


\section{Appendix A: Introductory Script}

(During the first class)

I am speaking on behalf of Yoko Sakurauchi, a doctoral student in the Graduate School of Education at Portland State University. She will conduct a research study on this course for her dissertation research. You are invited to participate in this study. With your help, she expects to understand the effectiveness of this intercultural course for college students to develop their intercultural sensitivity and understanding. If you are above 18 years old, you are eligible to participate in this study.

Participation is truly voluntary, and participation decision will not affect your grade of this course. You may withdraw from this study at any time without affecting your grade and your relationship with Sakurauchi.

If you agree to participate, you will take an online questionnaire in the first week of the course and during the week after the class is over. This assessment includes a 50-item multiple-choice questionnaire and four open-ended questions about your own intercultural experience. Your written materials for the course, such as daily reports, reflection papers, and a final paper, will also be collected and used for the study. After the class is over, selected participants will be asked to have an individual interview with Sakurauchi about the participants' learning experience and intercultural sensitivity development through the course.

A benefit for you as a participant is that you will be able to learn about your intercultural sensitivity and competence. This study will give you the chance for self-reflection and encourage you to discover your cultural identity and transform your worldview. Your participation may help the course improvement.

Your data will not affect your grade of the course because the grade criteria are articulated on syllabus.

Your name will be kept confidential and will not be mentioned anywhere in the publication or presentation of this research. All the collected data will be kept in a safe location where only Sakurauchi can reach.

If you are interested in participating, please read and sign two copies of the informed consent form.

Thank you very much for your consideration. 


\section{Appendix B: Informed Consent Letter}

You are invited to participate in a research study conducted by Yoko H. Sakurauchi, a doctoral student in the Graduate School of Education at Portland State University. This is a research study for her dissertation. With the help of this study, the researcher expects to understand the effectiveness of an intercultural course for college students to develop their intercultural sensitivity and understanding. Data collection will be conducted on a course in the spring term at Portland State University: INTL324U "Japan and U.S. Cultures in Contact" between April 2 and June 14, 2012. You are being selected as a participant in this study because you are enrolled in this course. If you are under 18 years old, you are not eligible to participate in this study.

Participation is truly voluntary, and participation decision will not affect your grade. You may withdraw from this study at any time without affecting your grade and your relationship with the researcher.

If you agree to participate, you will take an online questionnaire in the first week of the course and during the week after the class is over. This assessment includes a 50-item multiple-choice questionnaire and four open-ended questions about your own intercultural experience. Your written materials for the course, such as daily reports, reflection papers, and a final paper, will also be collected and used for the study. After the class is over, selected participants will be asked to have an individual interview with Sakurauchi about the participants' learning experience and intercultural sensitivity development through the course.

A benefit for you as a participant is that you will be able to learn your intercultural sensitivity and competence. This study will give you the chance for self-reflection and encourage you to discover your cultural identity and transform your worldview.

Your name will be kept confidential and will not be mentioned anywhere in the publication or presentation of this research. Information that is obtained in connection with this study and that can be linked to you or your identity will be kept confidential. To maintain confidentiality, the collected data and signed informed consent letters will be stored in a safe place, where only the researcher can reach.

If you have concerns or problems related to your participation in this study or your rights as a research participant, please contact the Human Subjects Research Review Committee, Office of Research and Sponsored Projects, Portland State University, PO Box 751, Portland, OR 97207, 503-725-3423. If you have questions about the study, please contact the researcher, Yoko H. Sakurauchi, Graduate School of Education, Portland State University, PO Box 751, Portland, OR 97207, 503-804-6385.

Your signature indicates that you have read and understood the above information and you agree to take part in this study. Please understand that you may withdraw your 
consent at any time without penalty, and that, by signing, you are not waiving any legal claims, rights, or remedies.

After signing on both copies, please keep one for your record and submit the other.

I agree to take part in this study.

Signature

Date

Name Printed 


\title{
Appendix C: Interview Protocol
}

Participant's Name:

Interview Date \& Time:

\author{
Introduction
}

- Provide a participant with refreshments.

- Restate appreciation to participate in my research.

- Research purpose and confidentiality

"The purpose of this interview session is for better understanding of your learning experience and intercultural sensitivity development through the course of "Japan and U.S. Cultures in Contact."

"I would like to assure that this interview is nothing to do with your academic performance in the course and that I am interested in your insights and perspectives regarding intercultural learning experience as a researcher, not as a teacher." "Your name will be kept confidential and will not be mentioned anywhere in the publication or presentation of this research. All the collected data will be kept in a safe location where only the researcher can reach."

- Get permission for audio taping.

- What's the participant's learning style?

- Any questions before we start?

\section{Part One \\ Participants' Backgrounds}

- What is your cultural background?

- What is your intercultural experience, if any, such as taking foreign language courses, traveling or studying abroad, or hosting international students?

Part Two

Overall Learning Experience of the Course

- What was the highlight of your learning experience in this course?

- What are your significant achievements of taking this course?

- How do you think this course helped you improve your intercultural sensitivity? 


\section{Part three \\ Kolb's Four Pedagogical Strategies}

Explain Kolb's four pedagogical strategies before talking about each dimension.

(1) Impact of Theory-Based Materials by Lectures and Readings (Abstract

Conceptualization)

- How did the intercultural concepts and theories you learned from the readings help you improve your intercultural sensitivity and competence?

- How did the intercultural concepts and theories you learned from the lectures help you improve your intercultural sensitivity and competence?

(2) Impact of the Tea Ceremony Experience at the Japanese Garden (Concrete Experience)

- What was the experience of the tea ceremony like for you?

- Did you enjoy learning from your feelings and people sharing the experience (of the tea ceremony) with you? What made you do so?

- How did the tea ceremony help you improve your intercultural sensitivity and competence?

(3) Impact of Guest Talk (Reflective Observation)

- Was the guest talk of Chie Furukawa helpful in developing intercultural sensitivity? If so, how?

- With your intercultural knowledge from this course, what did you observe the guest speaker and her speech?

(4) Impact of Intergroup Discussions (Active Experimentation)

- During the culture-exchange group discussions, with your intercultural knowledge from this course, how differently than before taking this course did you interact with your group members from different cultures? In other words, what did you keep in mind?

- During the culture-exchange group discussions, what did you observe in terms of cultural differences in your group members' communication patterns, values, and norms? Please give some examples.

- How did you react to these differences? 
- How did the culture-exchange group discussions help you improve your intercultural sensitivity and competence?

\title{
(5) Overall
}

- Which dimension do you think would have been most helpful for your intercultural learning?

\author{
Part Four \\ Influence on Participants' Real Life
}

- How differently than before taking this course would you interact with people from different cultures?

- How would you apply intercultural knowledge and skills you learned from this course to your real life, including your personal and academic life, and your career?

\section{Closure}

- If the participant hasn't finished the Learning Style Inventory, ask her/him to do so and send the result later.

- Get permission for a follow-up interview.

Post-Interview Notes 


\section{Appendix D: Interview Protocol in Japanese (日本語)}

Participant's Name:

Interview Date \& Time:

Introduction

- Provide a participant with refreshments.

- Restate appreciation to participate in my research.

- Research purpose and confidentiality

"The purpose of this interview session is for better understanding of your learning experience and intercultural sensitivity development through the course of "Japan and U.S. Cultures in Contact."

"I would like to assure that this interview is nothing to do with your academic performance in the course and that I am interested in your insights and perspectives regarding intercultural learning experience as a researcher, not as a teacher." "Your name will be kept confidential and will not be mentioned anywhere in the publication or presentation of this research. All the collected data will be kept in a safe location where only the researcher can reach."

- Get permission for audio taping.

- What's the participant's learning style?

- Any questions before we start?

\section{Part One \\ Participants' Backgrounds}

- What is your cultural background? あなたの文化背景は何ですか。

- What is your intercultural experience, if any, such as taking foreign language courses, traveling or studying abroad, or hosting international students? 今まで の異文化経験を教えてください。例えば外国語を取ったとか、海外旅行を したとか、留学生のホストファミリーになったなど。

Part Two

Overall Learning Experience of the Course 
- What was the highlight of your learning experience in this course? この授業で 一番印象的だったことは何ですか。

- What are your significant achievements of taking this course? この授業で一番 学んだこと/為になったことは何ですか。

- How do you think this course helped you improve your intercultural sensitivity?

この授業が、自分の異文化理解や異文化コミュニケーション能力の向上に どのように役に立ったと思いますか。

Part three

Kolb's Four Pedagogical Strategies

Explain Kolb's four pedagogical strategies before talking about each dimension in Japanese.

(1) Impact of Theory-Based Materials by Lectures and Readings (Abstract Conceptualization)

- How did the intercultural concepts and theories you learned from the readings help you improve your intercultural sensitivity and competence? リーディング から学んだ異文化概念や理論が、自分の異文化理解や異文化コミュニケー ション能力の向上にどのように役に立ったと思いますか。

- How did the intercultural concepts and theories you learned from the lectures help you improve your intercultural sensitivity and competence? 講義から学んだ異 文化概念や理論が、自分の異文化理解や異文化コミュニケーション能力の 向上にどのように役に立ったと思いますか。

(2) Impact of the Tea Ceremony Experience at the Japanese Garden (Concrete Experience)

- What was the experience of the tea ceremony like for you? 日本庭園でのお茶 の経験はあなたにとってどのようなものでしたか。

- Did you enjoy learning from your feelings and people sharing the experience (of the tea ceremony) with you? What made you do so？お茶の空間を共にした 
人々やその時の自分の気持ちからいろいろ学ぶことは楽しい経験でしたか。 その経験をどのように楽しみましたか。

- How did the tea ceremony help you improve your intercultural sensitivity and competence? お茶の経験が、自分の異文化理解や異文化コミュニケーシ ヨン能力の向上にどのように役に立ったと思いますか。

(3) Impact of Guest Talk (Reflective Observation)

- Was the guest talk of Chie Furukawa helpful in developing intercultural sensitivity? If so, how? 古川智恵さんのゲストスピーチは、自分の異文化 理解の向上にどのように役に立ったと思いますか。

- With your intercultural knowledge from this course, what did you observe the guest speaker and her speech? この授業で学んだ異文化知識を元に、古川 さんのスピーチの仕方や内容について気づいた点はありますか。

(4) Impact of Intergroup Discussions (Active Experimentation)

- During the culture-exchange group discussions, with your intercultural knowledge from this course, how differently than before taking this course did you interact with your group members from different cultures? In other words, what did you keep in mind? Culture-exchange group discussion で異文化のグループメン バーと接する時に、この授業で学んだ異文化知識を元に、何かこの授業を 受ける以前と違う接し方をしましたか。何に気をつけて／何を念頭におい てコミュニケーションしましたか。

- During the culture-exchange group discussions, what did you observe in terms of cultural differences in your group members' communication patterns, values, and norms? Please give some examples. 異文化のグループメンバーと接する時 に、何かコミュニケーションの仕方や価值観などの違いに気づきましたか。 例を挙げてください。

- How did you react to these differences? その違いにどのように対応しました か。 
- How did the culture-exchange group discussions help you improve your intercultural sensitivity and competence? Culture-exchange group discussion が 自分の異文化理解や異文化コミュニケーション能力の向上にどのように役 に立ったと思いますか。

(5) Overall

- Which dimension do you think would have been most helpful for your intercultural learning? 以上の 4 つの学ぶ側面の中で、どれが一番為になつ たと思いますか。

\section{Part Four \\ Influence on Participants' Real Life}

- How differently than before taking this course would you interact with people from different cultures? この授業を受ける以前と比べて、異文化の人々と の接し方がどのように変わりましたか。

- How would you apply intercultural knowledge and skills you learned from this course to your real life, including your personal and academic life, and your career? この授業で学んだ異文化知識や能力を実生活、例えばこれから のパーソナルライフや学歴や経歴の中で、どのように生かしたいですか。

\section{Closure}

- If the participant hasn't finished the Learning Style Inventory, ask her/him to do so and send the result later.

- Get permission for a follow-up interview.

Post-Interview Notes 


\section{Appendix E: Instruction of Reflection Papers}

\section{Reflection Paper \#1}

Reflect in writing on your learning experience from the assigned reading in the reading packet:

Ting-Toomey \& Chung (2005). What are the essential cultural value patterns?

- Choose one concept from the reading, such as individualism-collectivism, smalllarge power distance, weak-strong uncertainty avoidance, feminine-masculine gender roles, or other value orientations.

- Define the concept and demonstrate your understanding of the concept.

- Apply it to your own cultural experience, including your own cultural values as well as others. Demonstrate your reactions, thoughts, and feelings.

- In conclusion, sum up what you have learned from the reading, regarding your intercultural awareness and sensitivity.

\section{Reflection Paper \#2}

Reflect in writing on your learning experience from the two Culture-Exchange Group Discussion sessions.

- Address two cultural differences that you have learned/observed during the discussions:

(1) a cultural topic (discussion contents)

(2) a verbal or nonverbal communication pattern (observation)

- Analyze each cultural difference with the Cultural Iceberg Model.

- Explain how you have (re)acted to the difference of the communication pattern.

- In conclusion, sum up what you have learned through the culture-exchange intergroup discussions, regarding your intercultural awareness and sensitivity.

3. Reflection Paper \#3

Reflect in writing on your learning experience from the Tea Ceremony experience.

- Demonstrate your understanding of the key concepts of the Tea Ceremony "WaKei-Sei-Jaku" from the reading (Anderson, 1991) and the lectures.

- Discuss what you observed at the Tea Ceremony, conducting the cultural iceberg analysis and applying the key concepts.

- Discuss how you felt toward the whole experience of the Tea Ceremony and how this experience helped you improve your intercultural awareness and sensitivity. 


\section{Reflection Paper \#4}

Reflect in writing on your learning experience from the guest speaker. Listening to the bicultural guest speaker's stories is a great opportunity to apply what you have learned (specifically the cultural differences between Japan and the U.S.) to authentic contexts in order to deepen your understanding.

- Choose two stories of the guest speaker and analyze them with the cultural iceberg analysis. Make sure you discuss all the three levels (objective culture, values and beliefs, and Basic Assumptions).

- Discuss your reactions and feelings when you were listening to the guest talk. Any surprise or a-ha moment? Also, discuss how the guest talk helped you improve your intercultural awareness and sensitivity. 